Prof. Dr. Ahmad Mohammed Saad AL Hussein \& Dr. Noora Abdullah Hamad Al-Rasheed

Volume (4) No. (1) 2021

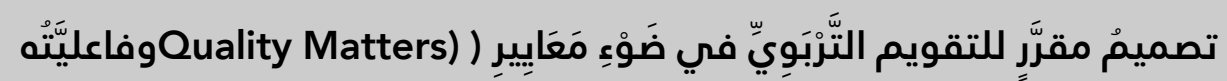

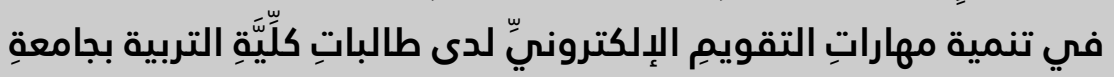
الملك سُعُودٍ إلِ

أ. أحمد بن محمد الحسين \& د. نوره بنت عبد الله الراشد 


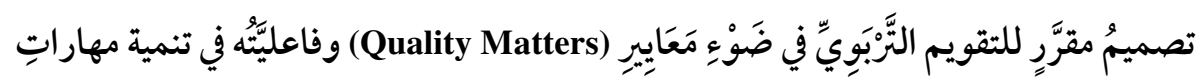
التقويمِ الإلكترونيّ لدى طالباتِ كلِّيَّة التربية بجامعِِ الملك سُعُوٍِ

$$
\text { أ. أحمد بن محمد الحسين }
$$

أستاذ المناهج وطرق التدريس، كلية التربية، جامعة الإمام محمد بن سعود الإسلامية، السعودية amhussein@imamu.edu.sa

$$
\text { د. نورهبت عبد الله الراشد }
$$

دكتوراة في المناهج وطرق التدريس، كلية التربية، جامعة الإمـام محمد بن سعود الإسلامية، السعودية Noora_a_r@hotmail.com

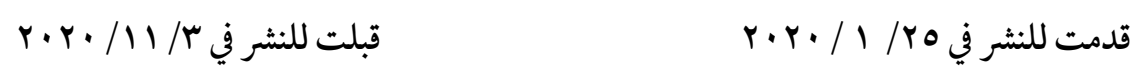

هدفت هذه الدراسة إلى تصميم مقرَّرٍ إلكترونيٍ للتقويم التربويِّ في ضوء معاييرِ كواليتي ماترز

Quality Matters وقياس فاعليَّنه في تنمية مهاراتِ التقويم الإلكترونيّ لدىن ( ( ع ) طالبة من طالباتِ كليّيَّة التربية بجامعةِ الملك سُعودٍٍ وهي مجموعة الدراسة التجريبية، طُبِقَ عليهن: (الاختبار المعرفي لمهارات التقويم الإلكتروني لمقرر التقويم التربوي، وثلاث بطاقات لملاحظة الجو انبَ المهاريَّةَ لمهارات التقويم الإلكترونيّ). وبعد إجراء المعالجات الإحصائية أظهرت نتائج الدراسة إلى: وجود فرق دال إحصائيًا عند مستوى (2 1 ( • , • ) بين متوسطي درجات عيّنة الدّراسة في التطبيقين القبلي والبعدي للاختبار التحصيليّ للجانب المعرفيّ لمهارات التقويم الإلكترونيّ لمقرر التقويم التربوي لدني طالباتِ كليّيَّة التربية بجامعِة الملك سُعودٍ، وذلك لصالح متوسط درجات التطبيق البعدي. ووجود فرق دال

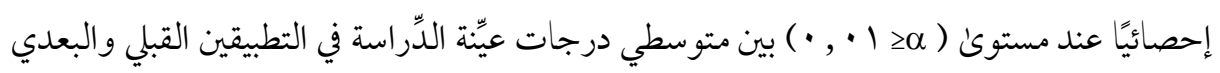
لجميع المهارات الرئيسة والدرجة الكلية لبطاقات ملاحظة الجانب الأدائيّ (الاختبارات الإلكترونية، الاستبانة الإلكترونية، ملف الانجاز الإلكتروني) لمهارات التقويم الإلكترونيّ لمقرر التقويم التربوي

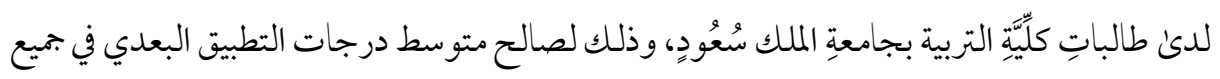

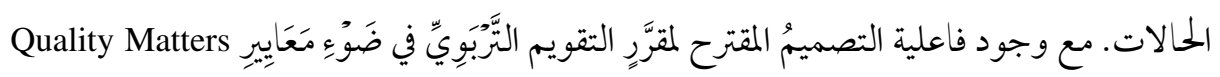
في تنمية مهارات التقويم الإلكتروني لدنا طالبات كلية التربية بجامعة الملك سعود. وقد أوصت 
الدراسة بها يلي: تصميم مقررات كلية التربية في ضوء معايير Quality Matters. وتدريب أعضاء هيئة التدريس علن تصميم مقررات إلكترونية في ضوء معايير Quality Matters. والاهتحام بتنمية مهارات التقويم الإلكتروني لدى الطالبات المعلمات في جميع كليات التربية. والاستفادة من المقرر في تدريب المعلمات أثناء الخدمة علئ مهار ات التقويم الإلكتروني. وقدمت الدراسة بجموعة مقترحات منها: دراسة اتجاهات أعضاء هيئة التدريس والطلاب حول المقرر المقترح ومعوقات تطبيقه. وتصميم بيئة تعليمية في ضوء معايي Quality Matters لتنمية مهارات التقويم الإلكتروني لدئ معلمات المرحلة الثانوية. الكلمات الدلالية: كوالتي ماترز، التقويم الإلكتروني. 


\title{
Design of Curriculum for Educational Evaluation in The Light of (Quality Matters) Standards and Its Efficiency in Develop Electronic Evaluation Skills for Students Females at Education in King Saud University
}

\author{
Prof. Dr. Ahmad Mohammed Saad AL Hussein
}

Professor of Curricula and Teaching Methods, College of Education, Imam

Muhammad bin Saud Islamic University, Saudi Arabia

amhussein@imamu.edu.sa

Dr. Noora Abdullah Hamad Al-Rasheed

$\mathrm{PhD}$ in Curriculum and Teaching Methods, College of Education, Imam Muhammad bin Saud Islamic University, Saudi Arabia

Noora_a_r@hotmail.com

Abstract: This study aimed to design of electronic curriculum for educational evaluation in the light of Quality Matters standards and measuring effectiveness in develop electronic evaluation skills for (42) students' female from students of education college in King Saud University and it's an experimental study group apply to them :(Cognitive test for electronic evaluation skills for educational evaluation curriculum and three card for notice skills sides for electronic evaluation skills). After proceed the statistical treatments, the study results showed the following: (a) There is a statistically function difference at the level $(\alpha \geq 0.01)$ between the average scores of the study sample in after and before application for the collective test for cognitive side foe electronic evaluation skills for educational evaluation curriculum for education college students in King Saud University for the benefit of before application scores average. (b) There is a statistically function difference at the level $(\alpha \geq 0.01)$ between the average scores of the study sample in after and before application for all main skills and total score for performance side notice cards (Electronic tests, Electronic questionnaire, Electronic achievement file) for electronic evaluation skills for educational evaluation 
curriculum for education college students in King Saud University for the benefit of before application scores average. (c) Suggested design efficiency for educational evaluation curriculum in the light of Quality Matters standards for education college students in King Saud University in electronic evaluation skills development. The study presents many recommendations as: Design education college curriculum in the light of Quality Matters standards, Training faculty members on design electronic curriculums in the light of Quality Matters standards, Interesting in electronic evaluation skills development for students' teachers in all education colleges. And Benefit from the curriculum to training teachers during the service on electronic evaluation skills. Also Some Suggestions presented as Study the attitudes of faculty members and students about the suggested curriculum and barrier of its application. And Design an educational environment in the light of Quality Matters standards to develop electronic evaluation skills for secondary school level teachers.

Key Word: Quality Matte, electronic evaluation 


\section{Summary}

\section{Introduction:}

The educational evaluation occupies a great place in the educational system in all its dimensions and aspects, due to its importance in determining the amount of what is achieved from the desired educational goals, which are expected to be positively reflected on the student and the educational process, both.

And for the importance of educational evaluation, we find that it is one of the basic courses that are indispensable in the colleges of education; to qualify the teachers and prepare them to engage in the teaching profession, as it provides them with methods and skills for designing appropriate evaluation tools for the educational situation, which the student must have the teacher and give attention to Teacher preparation programs (Al-Ruwaily, 2016, p. 372).

With the accelerating developments in the educational process, the educational calendar has evolved, and recent trends, fundamental changes, and a qualitative shift in its methods, tools, techniques, and field practices, which have directly reflected on the educational system, have emerged as an alternative to the traditional calendar that is an alternative to the traditional evaluation that It is measured by limited types of theoretical questions, most of which depend on the paper and the pen, and make the achievement of them at their lowest levels a goal and goal (Hashem and Khalifa, 2017 CE, p. 203).

The Fifth Annual Arab Scientific Conference (2010 AD) recommended the necessity of reviewing the methods of evaluating students, and paying attention to the learner-centered calendar in order to achieve educational and educational reform in institutions of higher education (Safr and Hebron, 2010 AD, p. 134), and many studies recommended that The transition from traditional evaluation methods to advanced modern methods, such as the Hassan study (2011) and the Nimri study (2013 AD), which recommended replacing advanced modern methods with traditional methods of evaluation.

With the advent of technological innovations in the recent period - such as: the Internet, multimedia, virtual reality, and e-learning - there is an urgent need to reconsider the teacher preparation programs in colleges of education to keep pace with 
these changes in the field of technology, which reflected on the educational process and affected it, and became The student's mastery of her skills is a basic requirement of teacher preparation and training programs (Zinedine 2011, p. 24).

From this standpoint, the electronic calendar received a lot of attention, and its multiple names such as computer-assisted evaluation, computerized evaluation, computer-based testing, and online evaluation, which aim to estimate students' performance of knowledge, skills, and directions in a particular course using electronic evaluation tools such as: objective tests, Forums, tasks, projects, achievement file, monitor their grades, analyze their responses, and write reports on their performance (Abu Step, 2013 AD, p. 180).

A number of scientific studies have recommended the importance of electronic evaluation, such as the Abbasi study (2011), which recommended that courses include the skills of designing and producing electronic evaluation tools, and that they be specific and available at any time, any place, and the study of Hala Doghmash (2014) that recommended the need to train student teachers in How to design and produce an electronic achievement file, and work to provide computer laboratories in colleges of education that meet the needs of students, and prepare them for training in the production of electronic evaluation tools.

The Kingdom of Saudi Arabia pays great attention to educational technology and uses it in the educational process. The current directions of the Ministry of Education are moving towards achieving the goals of the Kingdom's vision (2030) towards digital transformation through designing electronic courses and presenting them on the World Wide Web, which is one of the most recent uses of the Internet in education. This is causing a major transformation in the patterns of teaching and learning in the twenty-first century.

The results of a number of scientific studies resulted in the importance of the electronic course in the educational process, such as the study Yousry Youssef and Hayam Salem (2011) whose most prominent results were the effectiveness of the electronic course in developing cognitive achievement related to skills, and the study 
of Hanan Al-Jaramawi (2011) which recommended increasing the awareness of those in charge of colleges of education The importance of e-courses.

The second international conference on e-learning, which was held in Riyadh (2011), issued recommendations, including: making use of theories and research that were conducted in the field of designing electronic courses, and developing and designing curricula for the various academic stages under the supervision of a group of educational specialists, so that they are in line with the requirements of the era Knowledge and electronic course design according to internationally approved standards such as: SCORM and IMS.

More recently, attention has increased to the quality of design and production standards for e-courses, which pose a challenge to those interested in them, because lack of attention to them will lead to unrecognized electronic decisions and lack effectiveness and efficiency. Therefore, standards and quality should be taken into account when designing, and in light of this emerged many scientific studies that were concerned with the need for quality electronic courses such as Hala Ahmed and Saeed (2014) and Abu Khatwa (2011).

Quality Matters standards are among the global standards in the quality of designing e-courses approved by the University of Maryland in the United States of America, an international organization that represents joint cooperation between academic and governmental institutions to be the organizing basis for the quality of ecourses, and contribute to ensuring the quality, development and design of e-courses Based on faculty and peer review, based on the latest findings of scientific research and practical experiences in this field (Shattuck, 2012, p3).

Hoffmani (2012, p159) defined Qualty Matters as: “An internationally recognized organization that focuses on the peer review process to ensure the quality of electronic and integrated courses, and that it consists of eight basic criteria: an overview of the course, educational goals, assessment and measurement, and sources Educational materials, learner motivation, technology used in the course, learner support, and accessibility. 
The results and recommendations of a number of scientific studies resulted in the importance of Quality Matters standards in the process of designing decisions in the light of it, and in its effectiveness in achieving students; as a study ((Greenberg, 2010) presented to the twenty-sixth annual conference in tele-teaching, and (Ward, 2012) and (Al-Shehri) study, 2012 CE), and Blundell Study (2015).

\section{The study problem:}

The study problem appeared from the importance of the academic and educational preparation programs for the teacher and improving his performance level, and the importance of this real preparation for education and attention to its quality, and this is in line with the vision (2030) that aimed to prepare the teacher and his professional development in line with the requirements of the twenty-first century, and what he needs to develop his skills to keep pace with cognitive and technological developments. To achieve this vision, the Ministry of Education has endeavored to develop curricula and courses at all different stages of education.

In view of the association of the educational evaluation course with the professional practices of female students necessary to prepare them and prepare them for the teaching process, it was necessary for this course to evolve to suit the course of education and help achieve appropriate learning outcomes in the future.

Through the work of the researcher in supervising the requests of practical education, I noticed the low level of female students in educational evaluation skills, and the researcher attributes this to focusing the content of the educational evaluation course on the theoretical side, and neglecting the practical side that helps her to design appropriate evaluation tools, so that the student student is allowed to practice What I learned in the educational field, and qualify it for that, and this is proven by some studies, such as (Al-Saadawi, 2016) study that aimed to analyze the content of educational evaluation courses in some Saudi universities including King Saud University, and its results resulted in poor content of the evaluation My interest in teacher preparation programs, and its failure to cover the contemporary requirements of the calendar, and recommended the need to develop its content and teaching methods to allow combining theoretical aspects they receive from learning the subject, the 
applied aspects that they are trained to practice in the field, and Al-Ruwaili study (2016 $\mathrm{AD}$ ) that demonstrated the low level of student knowledge with the skills of evaluation and measurement, despite the developments that occurred in the educational evaluation, and the emergence of recent trends in it, the educational evaluation course in the College of Education aims to develop the skills of the student in the traditional assessment tools, which may not be compatible with the goals of education in the future: development Rapid data in education, and the emergence of electronic courses, and the adoption of more schools in education programs on the electronic calendar and follow-up to her students. Pays to encourage the student student to learn new skills to evaluate her students in the future in proportion to these developments.

The International Calendar Education Conference (2018 AD) recommended linking the general and university learning outcomes with the skills necessary for success in life, responding to the requirements of professions, future jobs, and digital transformation (p. 36).

And for the importance of electronic evaluation in teacher preparation programs: The eleventh scientific conference of the Egyptian Association for Education Technology for e-learning (2008 AD) recommended that students of the College of Education should be trained in designing and producing electronic evaluation tool, according to their cognitive style, as I recommend the first international conference on measurement and evaluation in the Kingdom of Saudi Arabia in (2012 AD) the necessity of using technological technology in applying the tests, and the 14th scientific conference of the Egyptian Association for Education Technology (2014 AD) recommended developing colleges of education programs in the light of the requirements of e-learning and training Several studies were also conducted with the aim of providing teachers with e-evaluation skills.

One of these studies is the "Abu Ste" (2013 AD) study, which recommended setting policies that adopt e-evaluation in higher education, because of its many advantages to the educational process, and training faculty to employ its patterns. And the Bassiouni study (2016 AD) that recommended the necessity of spreading the culture of electronic calendar as a modern trend in the calendar, and providing the requirements 
for its circulation to all educational institutions, and the Faraj Allah study (2017 AD) which recommended that mastery of electronic evaluation skills be an integral part of the expected outputs from colleges Education.

In the light of the foregoing, the researcher sees that it is necessary to re-design a course for the educational calendar, to include the most recent trends in the evaluation calendar, which is the electronic calendar, so that there is compatibility between rapid developments and digital transform and between the educational assessment course to become a teacher preparation for all skills before service and practice the profession more from training on it during the service, and to bridge the gap between the outputs of higher education and the labor market, the course will be designed in light of the Quality Matters standards that have proven effective in many studies, such as AlQahtani and Al-Bishi (2017), as studies have demonstrated the satisfaction of students and members Teaching for QM-based courses:

Vobornik Handbook (2012, Vobornik), Simpson Study (2012, Simpson), And Blundel Study (Blund el1, 2015) Study questions: The main question of this study is: What is the proposed design for the educational evaluation course in light of the Quality Matters criteria? What is its effectiveness in developing e-evaluation skills for students of the College of Education at King Saud University? It divides into the following subquestions.

1. What is the proposed design for the educational evaluation course in light of the quality standards (Quality Matters)?

2. What is the effectiveness of the proposed educational evaluation course in the development of college students Education Cognitive Aspects Skills Eevaluation at King Saud University?

3. What is the effectiveness of the proposed educational evaluation course in developing female college students Education, The skill aspects of eevaluation skills at King Saud University?

\section{Objectives:}

This study aimed to design of electronic curriculum for educational evaluation in the light of Quality Matters standards and measuring effectiveness in develop 
electronic evaluation skills for (42) student's female from students of education college in King Saud University.

\section{Study methodology:}

To achieve the aims of the study and answer its questions, the researcher used two types of research methods, namely:

1. The descriptive approach: which relies on the study of the phenomenon as it exists in reality, and is interested as an accurate description, and is expressed in a qualitative or quantitative expression (Obeidat, Adas and Abdel-Haq, 2005 AD, p. 191).

It was used in the current study to collect the information and data required to build the proposed course, to define the quality standards of Quality Matters, to define electronic evaluation skills, to write the theoretical framework, and to review previous studies related to study variables, as well as when building study tools.

2. The experimental approach (semi-experimental design): This approach was used to measure the effectiveness of the proposed educational evaluation course in light of the Quality Matters criteria (the independent variable) in the development of students of the College of Education at King Saud University in the skills of electronic evaluation (the dependent variable), following the known experimental design in the name of (pre / post design) of the same group, according to the following form:

Study community: The study community consists of all students of the bachelor's stage registered in the educational evaluation course at the College of Education, with its various departments (Islamic studies, Quranic studies, art education, kindergarten, psychology, English language, and computer) at King Saud University in the semester The second of the academic year (1439-1440 AH), whose number is (154) students spread over six divisions, as reported by the Supervision Office of the College of Education in the Department of Female Students at King Saud University.

Study Sample: The study sample consisted of a random sample of undergraduate students who are registered in the educational evaluation course at the College of Education in its various departments, for the second semester of the academic year 
(1439-1440 AH), it was estimated that (42) students were chosen from the study community in a simple random way., Whereby the people assigned to female students registered with this course were identified and restricted, and then one of them was randomly chosen and assigned one division to which the study experience and tools were applied.

First: Procedures to answer the question: What is the proposed design for the eeducational evaluation courses in light of the Quality Matters criteria?

The researcher used the descriptive approach to track the available literature in the field of designing electronic courses in general, and the Quality Matters criteria (QM) in particular, and in the field of electronic evaluation. The process of answering the first question went through several stages, which can be summarized in the following:

1. Course design basics.

2. Course design sources.

3. The foundations and theory in the course design: The researcher relied in its design on the content of the proposed educational evaluation course on the applied principles of structural theory, which the researcher considers to be compatible with (QM) standards and does not contradict them.

The proposed course design model: After reviewing the design models presented in the second semester, the researcher adopts the Saleh model (2005) because of its flexibility, and because this proposed model includes among its steps the quality standards that are compatible with this study. Second: The procedures necessary to answer the second question:

What is the effectiveness of the proposed educational evaluation course in developing female students of the College of Education in the cognitive aspects of e-evaluation skills at King Saud University?

To measure the effectiveness of the course in the development of cognitive aspects among students of the College of Education - the study sample - at King Saud 
University; a semi-experimental curriculum with a (tribal / dimensional) design was used for one group, according to the following steps:

First: Defining the most important aspects of knowledge of the electronic calendar: The most important aspects of knowledge of the electronic calendar were defined in the stage of designing the content of the course, and presented it to the specialists in the field of curricula and teaching methods, the field of evaluation and measurement to take their opinion and observations about them, until a list of the most important knowledge skills of the electronic calendar emerged.

Second: Building the test: After determining the cognitive aspects, the researcher built a test that agreed on the following steps: (Determining the goal of the test, preparing the specifications table, formulating the vocabulary of the test, formulating the vocabulary of the test, building a key to correct the test, test instructions, validating the test: internal honesty Phenotypic, pilot exploratory testing).

Third: The necessary procedures to answer the second question: What is the effectiveness of the proposed educational evaluation course in developing female students of the College of Education in the skillful aspects of electronic evaluation skills at King Saud University?

The process of answering this question went through several stages, which can be summarized as follows:

First: Defining the list of skill skills: The researcher identified the most important aspects of the electronic evaluation in the course design stage, as it contained (12) basic skills, and (110) sub-skills, distributed on three note cards.

Second: Building the note card: After building the list of skill skills, the researcher built three note cards to measure the level of performance of students of the College of Education - the study sample - for the skills of electronic evaluation, according to the following steps: (Determining the goal of the card, the content of the note card, setting a grade assessment Card, note card instructions, note card settings, note validation, note card stability). 


\section{Recommendations:}

- Design education college curriculum in the light of Quality Matters standards.

- Training faculty members on design electronic curriculums in the light of Quality Matters standards.

- Interesting in electronic evaluation skills development for students' teachers in all education colleges.

- Benefit from the curriculum to training teachers during the service on electronic evaluation skills.

\section{Suggestions:}

- Study the attitudes of faculty members and students about the suggested curriculum and barrier of it's application.

- Design an educational environment in the light of Quality Matters standards to develop electronic evaluation skills for secondary school level teachers. 


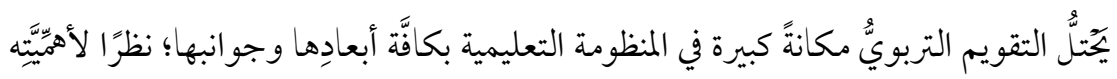
في تحديد مقدار مـا يتحقَّقُ من الأهداف التعليمية المنشودة، التي يُتوقَُّو منها أن تَنعكِسَ إيجابيَّا على الطالب و العملية التعليمية، سو اءُ بسواءٍ.

ولأهمِّة التقويم التربويٌٍ؛ نجد أنه مقَّرَّ من المقرَّرات الأساسية التي لا غنى عنها في كليَّات

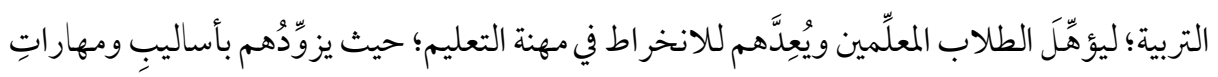
تصميمِ أدواتِ التقويم المناسِبة للموقف التعليميِّ، التي ينبغي أن يمتلكها الطالب المعلِّم، وتُعطى

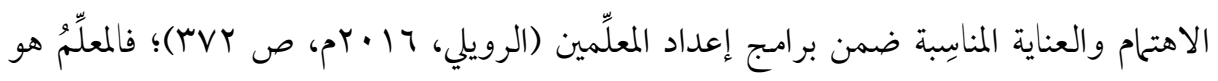
المسؤول عن إعداد أدوات التقويم الملائمةِ لتقويم أداء طلابه في الجهوانب المعرفية والمهارية والوِجدانية، التي يسعى لتَنمِيتها، وهو المسؤول عن تشخيص أدائهم، ومعالجِِِ جوانزب الضعف، وتعزيزِ جوانبِ القوَّةِ، من خلال تصميمَ بر امسجَ إثر ائيةٍ وعلاجية، و تنفيذِها. ومع التطوُّرات المتسارِعة في العملية التعليمية التربوية، تطوَّر التقويم التربويٌّ، وظهرت فيه

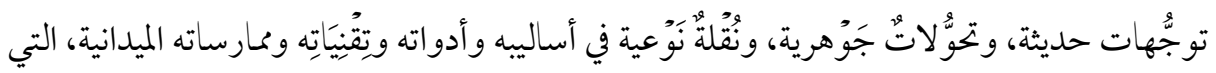
انعكست - بشكل مباشر - على النظام التعليميّ؛ لتكون بدياًا عن التقويم التقليدي الذي يركّز على جوانبَ معرفيةٍ بسيطة، تُقاس بأنواع محدودة من الأسئلة النظرية التي تعتمد في معظمها على الورقة والقلم، وتجعل من قياسها للتحصيل في أدنى مستوياته هدفًا وغاية (هاشم وخليفة، IV +r ام، ص ص r. (r)

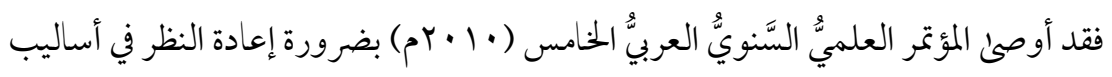
تقويم الطلاب، والاهتحام بالتقويم المتمَرُكِزِ حول المتعلِّم؛ من أجل تحقيق الإصلاح التربويِّ والتعليميِّ في مؤسَّسات التعليم العالي (بصفر وخليل، · ( • بم، ص ع با )، كما أوصت العديدُ من الدراسات بضرورة الانتقال من أساليب التقويم التقليدية، إلى أساليبَ حديثةٍ متطوِّرة؛ كدراسة حسن (1 ( • rم)

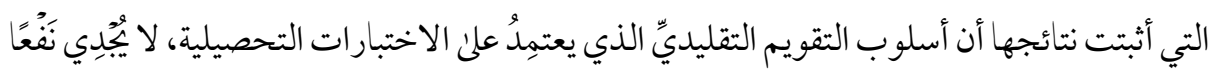


Prof. Dr. Ahmad Mohammed Saad AL Hussein \& Dr. Noora Abdullah Hamad Al-Rasheed Volume (4) No. (1) 2021

في ظلّّ التطوُّر الحاصل في بجال التقويم، وأوصت بحَصُرِ الأسلوب القائم علن الاختبارات التحصيلية

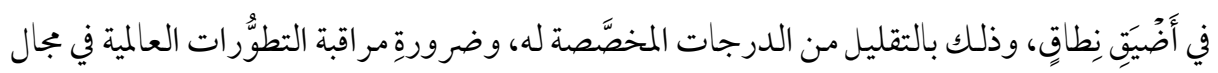

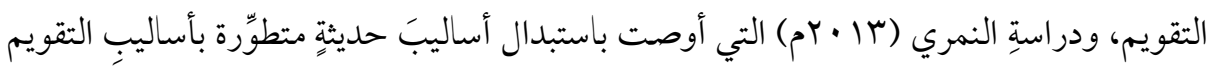
التقليدية.

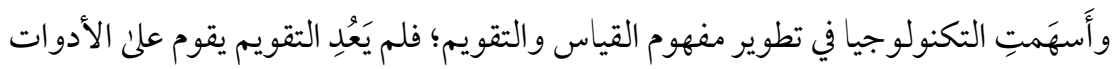

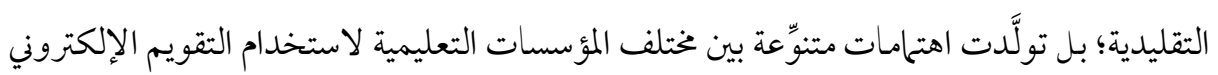

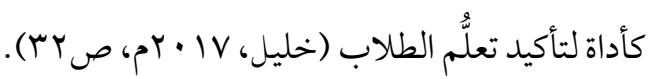

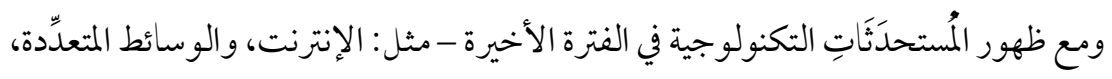

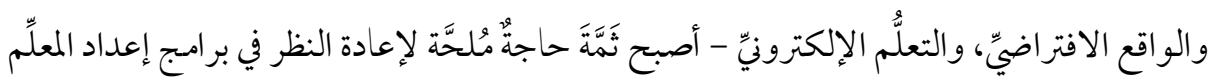

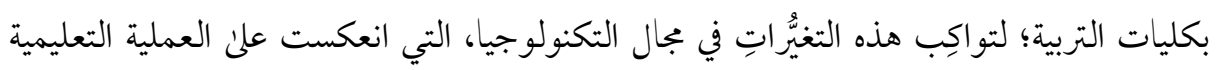

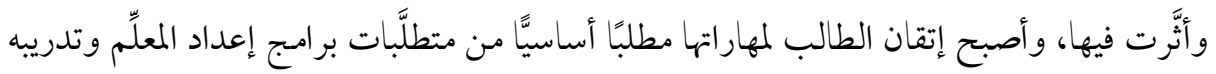

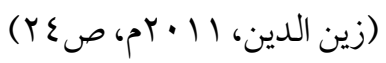
ومن هذا المنطلق، نال التقويم الإلكترونيُّ اهتمامًا كبيرًا، وتعدَّدت مسمَّمَاتُه؛ كالتقويم بمساعدة

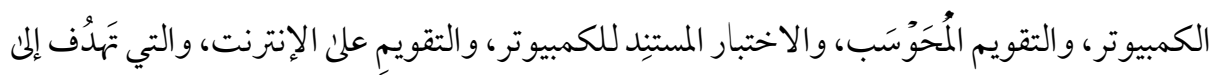

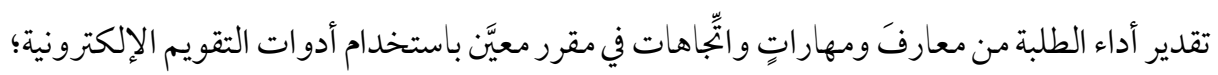

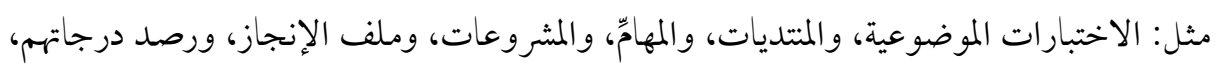

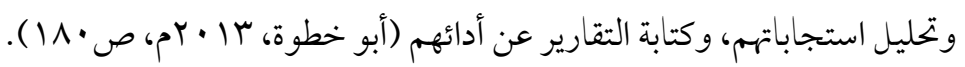

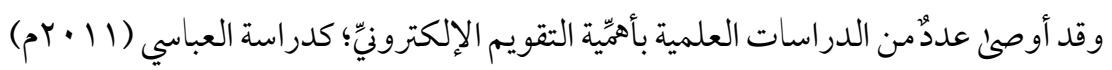

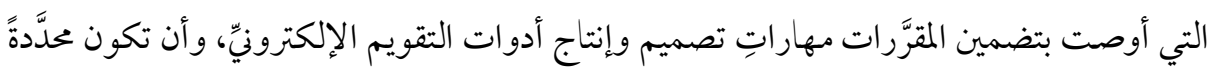

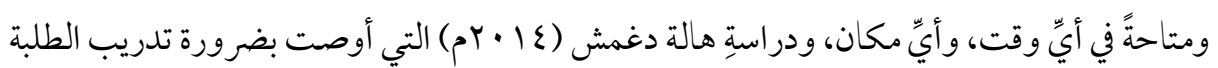

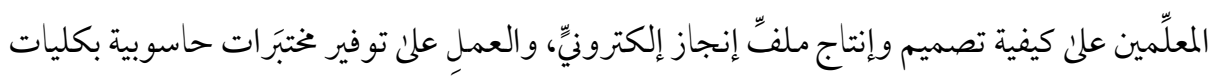
التربية، تَفِي بحاجات الطلبة، وإعدادِهم من أجل التدريب علن إنتاج أدوات التقويم الإلكترونيّ. 
وإن المملكة العربية السعودية لَتُولِي اهتمامًا كبيرًا بتكنولوجيا التعليم، وتوظيفها في العملية

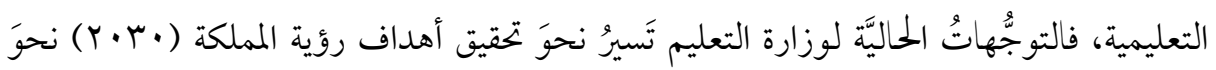

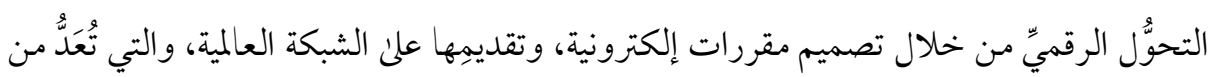

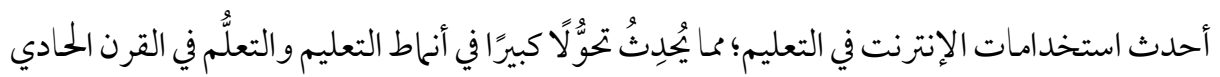

$$
\text { والعشرين. }
$$

وأسفرت نتائجُ عددٍ من الدراسات العلمية عن أهمية المقرَّر الإلكترونيّ في العملية التعليمية؛

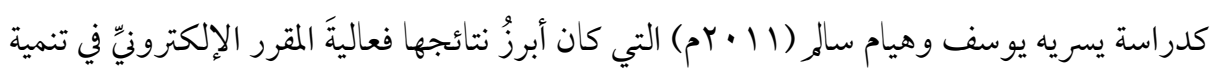

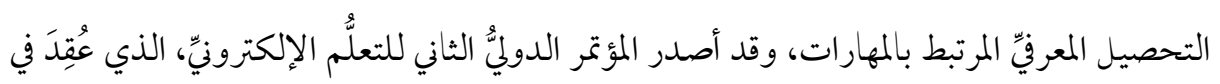

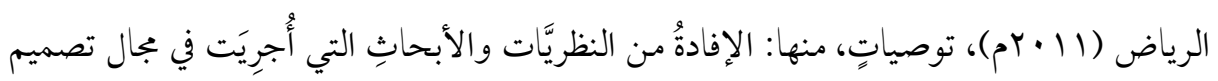

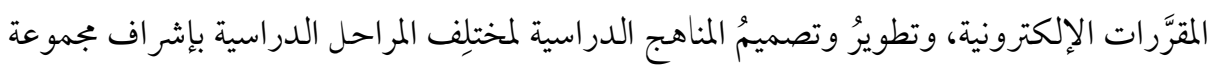

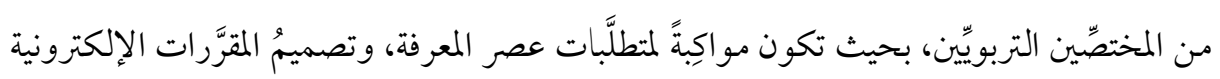

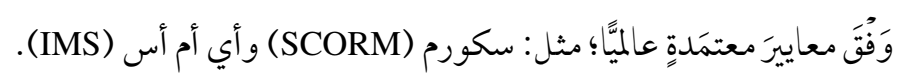
وفي الآونة الأخيرة ازداد الاهتمام بمعايير جودة تصميم وإنتاج المقررات الإلكترونية، التي

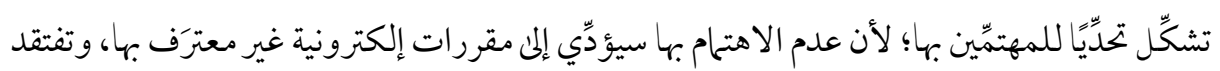

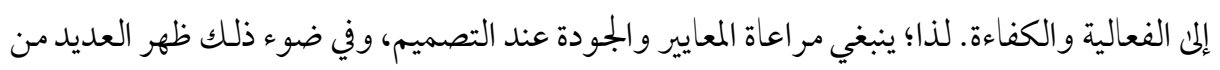
الدراسات العلمية التي عُنيَت بضرورة جودة المقررات الإلكترونية؛ كدراسة هالة أحمد وسعيد

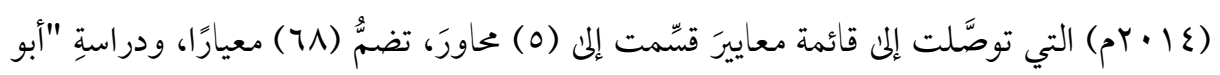
خطوة" (11 • إم) التي هدفت إلى تحديد معايير ضمان الجمودة في تصميم المقررات الإلكترونية، وتوصَّلت إلى قائمة تضمَّنت (11) معيارًا، و (1 • (1) مؤشِّر. ومعاييرُ كوالتي ماترز (Quality Matters) من المعاييرِ العالمية في جَوُدةِ تصميمِ المقَّرَات

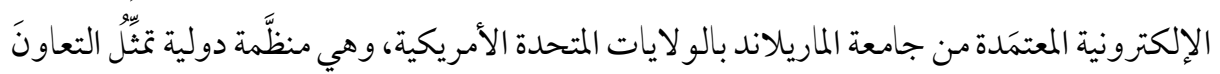

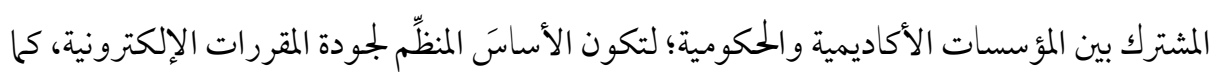


Prof. Dr. Ahmad Mohammed Saad AL Hussein \& Dr. Noora Abdullah Hamad Al-Rasheed Volume (4) No. (1) 2021

تُسهم في ضمان جودة وتطوير وتصميمِ المقررات الإلكترونية المرتكِّة علنم أعضاء هيئة التدريس، ومر اجعةٍ النظراء؛ بناءً علن آخِر ما توصَّلت إليه الأبحاث العلمية والتجارب العملية في هذا المجال

.(Shattuck,2012,p3)

وعرَّف هوفمان (Soffmani,2012,p159) كو الني ماترز بأنها:" منظمة معترف بها دولياً

ترتكز علن عملية مراجعة النظراء؛ لتأكد من جودة المقررات الإلكترونية والمدجة، وتتكون من ثمانية

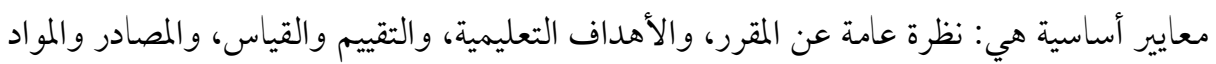

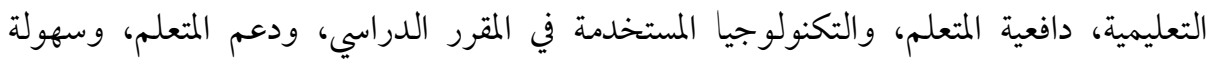

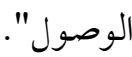

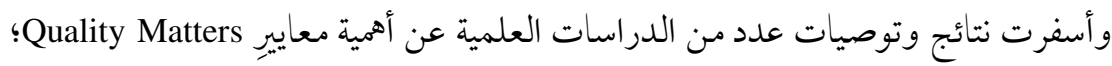

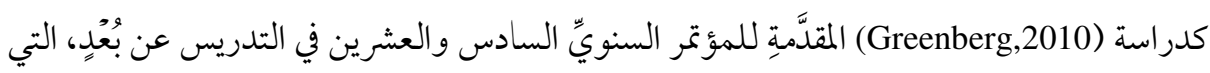
كان أبرزُ نتائجها أن الأعضاءً الذين يصمِّمون المقرَّراتِ - سواء في الكلية، أو المصمِّمين التعليميِّن،

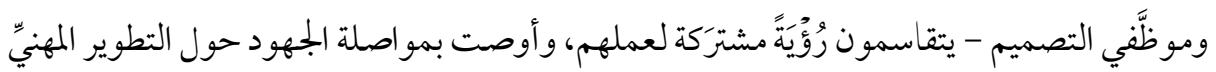

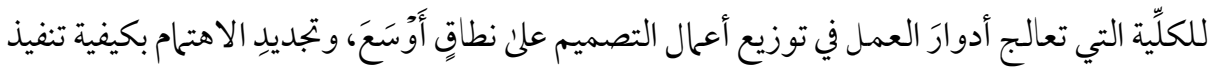

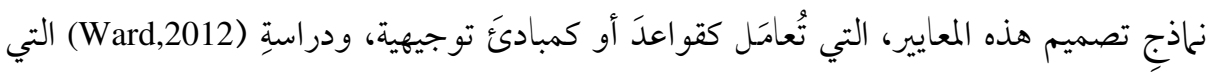

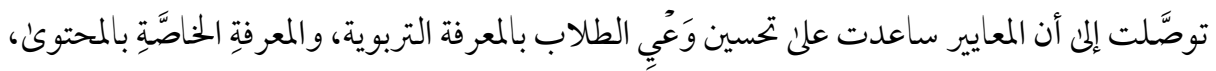

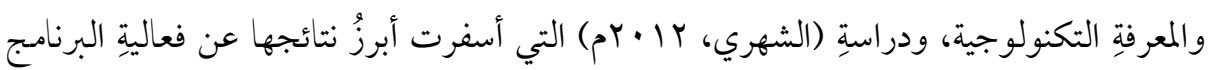

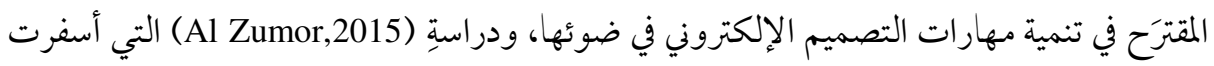

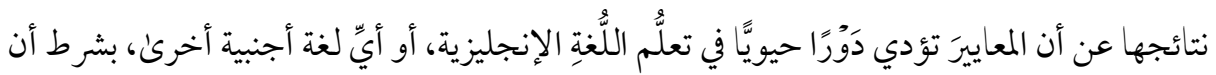

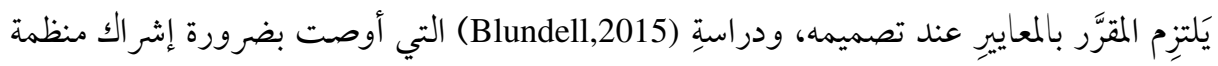

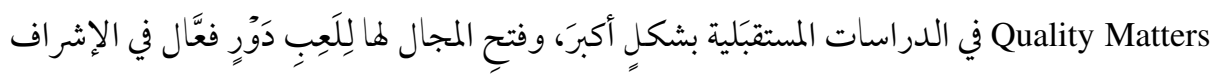
علن تصميم المقَّرات.

http://dx.doi.org/10.29009/ijres.4.1.9 
وفي ضوء نتائج الدراسات السابقة؛ ترى الباحثُة ضرورةً إعادةِ تصميمِ مقرَّر التقويم التربويٍ متضمِّنًا أدواتِ التقويم الإلكتروني، وَفققَ معاييرِ (Quality Matters)، التي أثبتت الدراسات فعاليتَها في تنمية المهارات المعرفية والمهارية.

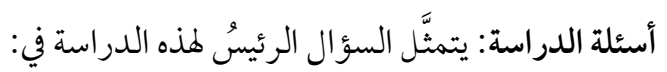
ما التصميمُ المقترَحُ لمقَّر التقويم التربويِّ في ضوء معايير كوالتي ماترز (Quality Matters)؟ وما

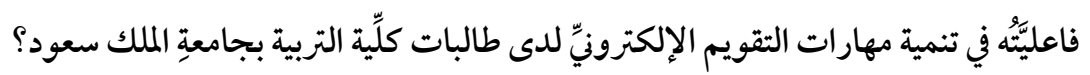
ويتفرَّع عنه التساؤلاتُ الفرعية التالية:

ا. ـ ما التصميمُ المقترَحُ لمقَّرَ التقويم التربويِّ في ضوء معايير كو التي ماترز (Quality Matters)؟ r. ما فاعلية مقرَّرِ التقويم التربوي المقترح في تنمية طالبات كلية التربية الجوانبَ المعرفيةَ لمهارات التقويم الإلكترونيّ بجامعة الملك سعود؟ r. ما فاعلية مقرَّرِ التقويم التربوي المقترح في تنمية طالبات كلية التربية الجوانبَ المهارية لمهارات التقويم الإلكترونيّ بجامعة الملك سعود؟

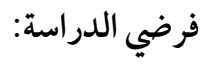

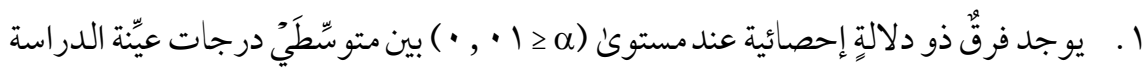

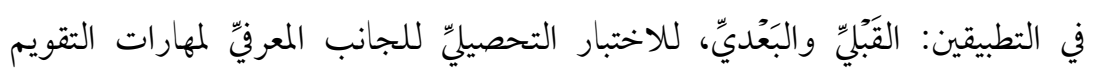
الإلكترونيّ لصالح التطبيق البعدي.

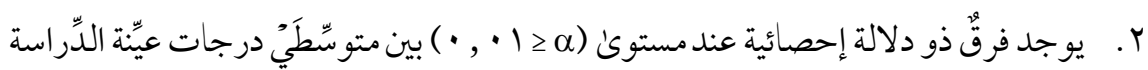
في التطبيقينِ: القَبَلِّ والبَعَديّي، لبطاقة الملاحظة للجانب الأدائيّ لمهارات التقويم الإلكترونيّ لصالح التطبيق البعدي. أهدافُ الدراسة: هَدَفت هذه الدراسةٌ بوجٍِ عامِّ إلى تصميم مقرٍَّ للتقويم التربويِّ في ضوء معايير كو التي ماترز (Quality Matters)، ويتفرَّعُ منه الأهدافُ التالية: 1. تحديدُ مهارات التقويم الإلكترونيّ اللازمِِ لطالبات كلية التربية بجامعة الملك سعود. 
Prof. Dr. Ahmad Mohammed Saad AL Hussein \& Dr. Noora Abdullah Hamad Al-Rasheed Volume (4) No. (1) 2021

r. تصميمٌ مقَّرِ للتقويم التربويِّ في ضوء معايير كو التي ماترز Quality Matters) لطالبات كلية التربية بجامعة الملك سعود. r. معرفةُ فاعلية المقرَّر المصمَّم في تنمية مهارات التقويم الإلكترونيّ (المعرفية- والمهارية) لدىن طالبات كلية التربية بجامعة الملك سعود. أهميّة الدراسة: تتَّضِح أهميّة الدراسة في جانبين، هما:

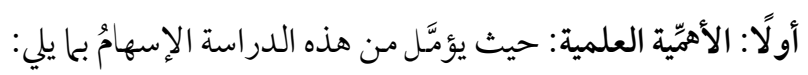
ا. تدعيم عملية تطوير التعليم باستخدام البرامج الإلكترونية المرتبطة بتصميم وإنتاج المقررات الإلكترونية.

r. إثراء المكتبات ومصادر المعلومات العربية، من خلال تقديم إطار مفاهيميِّ مُتَّرجَمِ للعربية لمعايير كو التي مـاترز (Quality Matters) الخاصَّة بتصميم وتقويم المقَّرَات الإلكترونية. r. ششر ثقافة المعايير، وضرورة الارتكاز عليها في تصميم وتطوير المقرَّرات الإلكترونية، في كافَّة المؤسَّسات التعليمية علن اختلاف مر احلها، وتنوُّع مرجعيَّاتها. ع. تقديم مقرٍِ مقترَح للتقويم التربوي كإضافة علمية في هذا المجال.

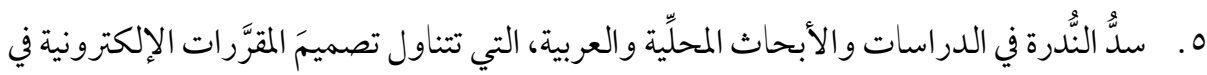
ضوء معاييرِ كوالتي ماترز (Quality) Matters). ثانيًا: الأهمية العملية: يؤمَّل من هذه الدراسة الإسهامُ بها يلي: 1. تقديم قائمةٍ بمهارات التقويم الإلكترونيّ اللازمِِ لطالبات كلية التربية بجامعة الملك سعود. r. تقديم مقَّرٍِ إلكترونيّ للتقويم التربويِّ، يمكِنُ أن تستفِيدَ منه طالباتُ كلية التربية بجامعة الملك

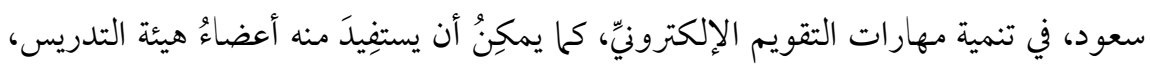
والجامعاتُ التي تَطرَح هذا المقرَّرَ ضِمْنَ خُطَّة بَرَنامجها.

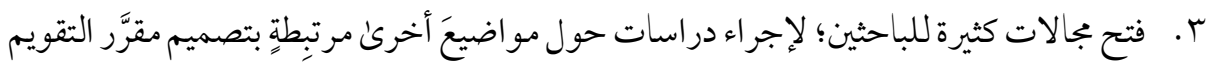
التربويِّ بمعايير كو التي ماترز (Quality Matters)، متناولة متغيِّات أخرىن، وفي بيئات مختِلفة. 
حدود الدراسة: تتحدَّد الدراسة بالحدود الموضوعية والمكانية والزمانية التالية:

أولًا: الحدود الموضوعية: اقتصرت الدراسة على الحدود الموضوعية التالية: ا. ـ معايرُ كو التي ماترز (Quality Matters) الخاصَّةُ بمعايير تصميم المقرَّرات الإلكترونية في التعليم

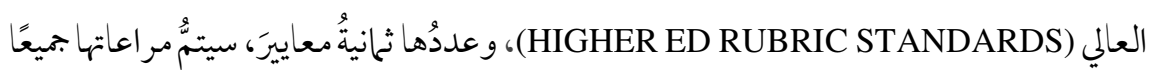
عند تصميم المقرر، وقد تَمَّ اختيارُ هذه المعاييرِ للأسباب التالية: - معايير كو التي ماترز (Quality Matters) معترَفُ بها عالميَّا في تصميم وقياس جَوَدَّة المقَّرَات الإلكترونية. - تجارِبُ الجامعات العالمية و العربية في تصميم مقَّرَاتها الإلكترونية وتقويمِها في ضوئها. - فعالية المقَّرَات الإلكترونية المصمَّمة في ضوء المعايير كما أثبتتها الدراسات العلمية. r. مهاراتُ التقويم الإلكترونيّ، حيث تُعَدُّ من أحدث الاتِّاهات الحديثة في التقويم التربويِّ،

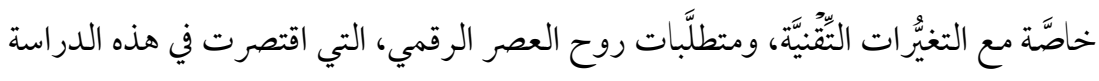

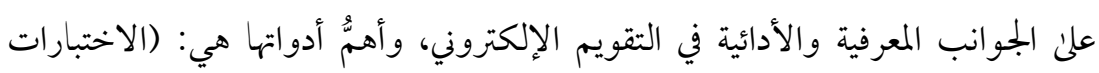
الإلكترونية، وملف الإنجاز الإلكتروني، والاستبانة الإلكترونية).

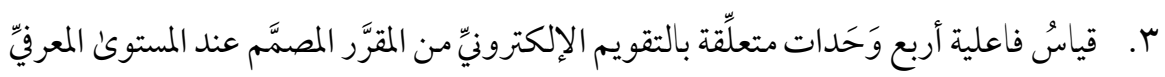
والأدائيِ.

ثانيًا: الحدودُ المكانية: تمثَّت بكلية التربية بجامعة الملك سعود في مدينة الرياض في المملكة العربية السعودية.

ثالثًا: الحدود الزمانية: تَمَّ تطبيق تجربة الدراسة في الفصل الدراسيّ الثاني من العام الدراسيّ وبـع ا - 
Prof. Dr. Ahmad Mohammed Saad AL Hussein \& Dr. Noora Abdullah Hamad Al-Rasheed Volume (4) No. (1) 2021

$$
\text { مصطلحات الدراسة: تتمثَّل أهمٌّم مصطلحات الدراسة فيا يلي: }
$$

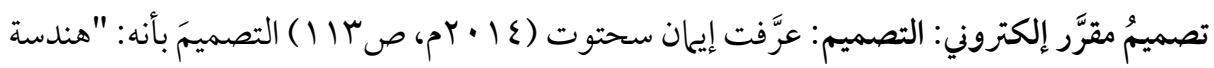

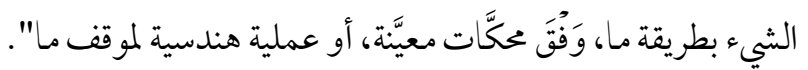

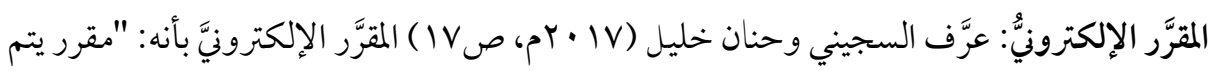
نشره علن الانترنت، ويتفاعل فيه الطلاب مع بعضهم البعض ومع المعلم باستخدام أدوات التفاعل عبر الانترنت، حيث يستطيع الطلاب دراسة المقرر في أي وقت خلال اليوم، وفي أي مكان بصورة تتناسب مع احتياجاتهم ".

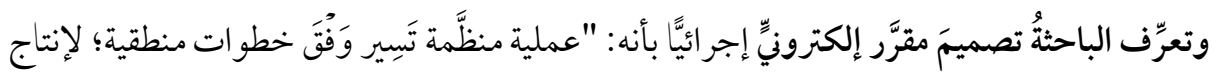
وتنفيذ مقَّر للتقويم التربويِّ في صورة رقمية عبر نظام إدارة التعلم البلاكك بورد، وَفقُ معايير كوالتي ماترز Quality Matters"، والمقدم لطالبات كلية التربية بجامعة الملك سعود.

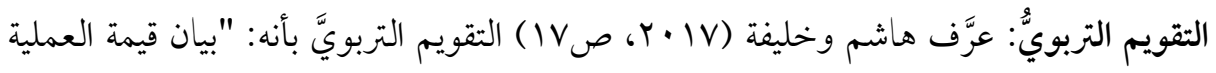
التعليمية، وكشفُ جو انب الضعف فيها، وتعديلُ مسارها، بـا يجقِّق الأهدافَ المنشودة".

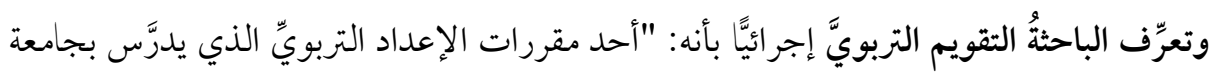

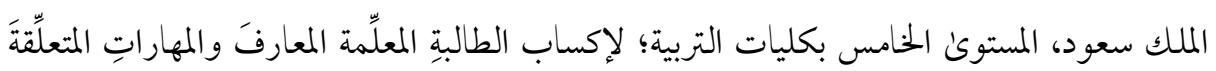

$$
\text { بتقويم تحصيل الطالبات وَفقَُ التوجُهات الحديثة". }
$$

معايير كو التي ماترز (Quality Matters): عرَّف بوزيك (Budzick,2014,p11) معايير كو التي ماترز بأها: "بجموعة من ثمانية معايير لتو جيه وتصميم وتطوير المقر رات الإلكترونية و المدبجة، وتستخدم كأداة تقييم لعملية مر اجعة النظر اء؛ للتحسين المستمر". وتعرّف الباحثةٌ معايير كوالتي ماترز Quality Matters إجر ائيّا بأنها: "معايير جودة تصميمِ المقررات الإلكترونية، التي في ضوئها تَمَّ تصميمٌ مقَّرّ التقويم التربويّّ لطالبات كلية التربية بجامعة الملك سعود". 


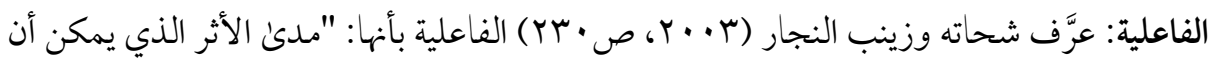
تحدثه المعالجات التجريبية، باعتبارها متغيرًا مستقلًا في أحد المتغيرات التابعة، كما يعرف بأنه مدئ أثر عامل أو بعض العو امل المستقلة على عامل أو بعض العوامل التابعة".

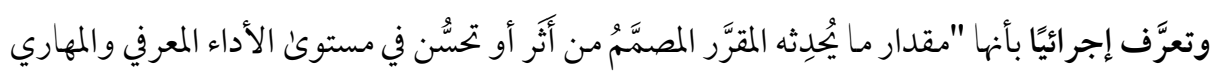
لمهارات التقويم الإلكتروني، لدى طالبات كلية التربية بجامعة الملك سعود".

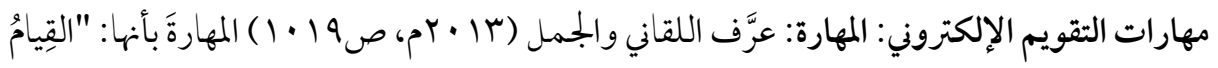

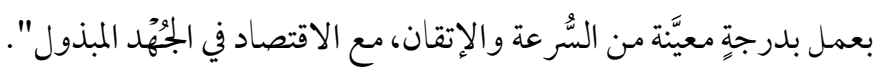

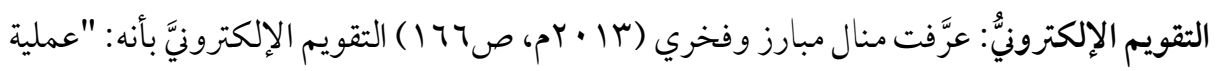
توظيفِ شبكات المعلومات، وتجهيزات الكمبيوتر، والبرجيَّات التعليمية، والمادَّة التعليمية المتعلِّدة المصادر، باستخدام وسائلِ التقييم؛ لتجميع وتحليل استجابات الطلاب بها يُساعد عضوَ هيئة التدريس

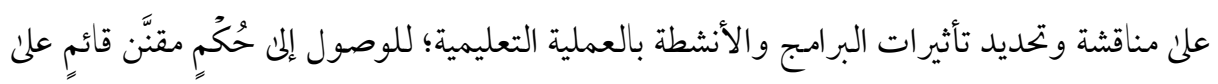
بيانات كَميةٍ وكيفية متعلِّة بالتحصيل الدراسيِّ"

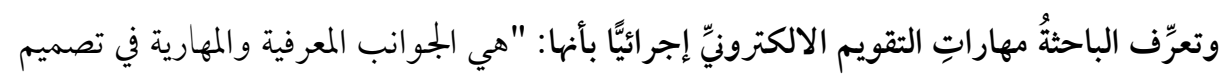
وإنتاج الاختبار الإلكترونيّ، وملفِّ الإنجاز الإلكترونيّّ، والاستبانة الإلكترونية، التي ينبغي أن تتمكَّن

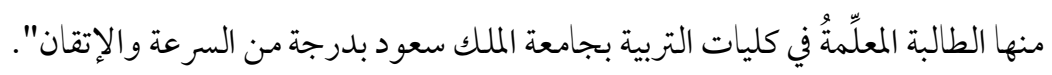

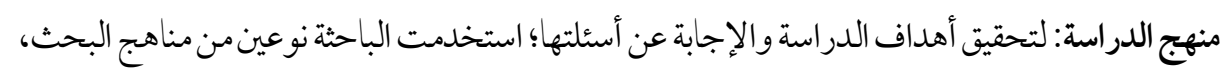
هما:

ا. المنهج الوصفيُ: يعد المنهج الوصفي أحد أساليب البحث العلمي الذي يعتمد علن دراسة الظاهرة كما توجد في الواقع، ويهتم بوصفها وصفًا دقيقًا، ويعبر عنها تعبيرًا كيفيًا أو تعبيرًا كميًا، فالتعبير الكيفي يصف لنا الظاهرة، ويوضح خصائصها، أمـا التعبير الكمي، فيعطي وصفًا رقميًا يوضح مقدار هذه الظاهرة أو حجمها، ودرجات ارتباطها مع الظواهر المختلفة الأخرى؛

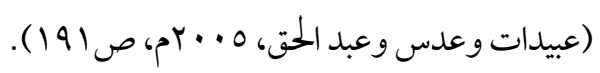


Prof. Dr. Ahmad Mohammed Saad AL Hussein \& Dr. Noora Abdullah Hamad Al-Rasheed Volume (4) No. (1) 2021

واستُخدم في الدراسة الحالية لجمع المعلومات والبيانات المطلوبة لبناء المقرر المقترح، ولتحديد معايير كو التي ماترز Quality Matters، وتحديد مهارات التقويم الإلكتروني، ولكتابة الإطار النظري، ومر اجعة الدراسات السابقة المتعلِّقة بمتغيِّرات الدراسة، وكذلك عند بناء أدوات الدراسة. r. المنهج التجريبيٌ (التصميمُ شِبْهُ التجريبيّ): استُخدم هذا المنهج لقياس فاعلية مقرر التقويم التربوي المقترح في ضوءمعايير كو التي ماترز Quality Matters (المتغيِّر المستقل) في تنمية طالبات كلية التربية بجامعة الملك سعود في مهارات التقويم الإلكتروني (المتغير التابع)، باتِّباع التصميم

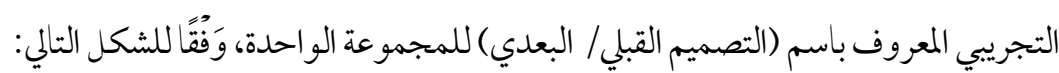
بجتمَع الدراسة: يتكوَّن بجتمع الدراسة من جميع طالبات مرحلة البكالوريوس المسجَّلات بمقرر التقويم التربوي بكلية التربية، بأقسامها المختلفة من (الدراسات الإسلامية، والدراسات القرآنية، والتربية الفنية، ورياض الأطفال، وعلم النفس، واللغة الإنجليزية، والحاسب الآلي)، بجامعة الملك سعود في الفصل

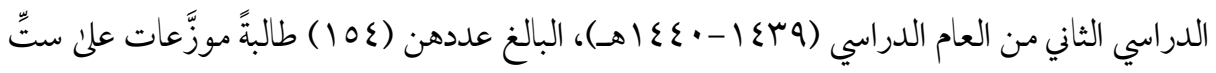
شُعب؛ حسبل أفاد به مكتب إشر اف كلية التربية بقسم الطالبات بجامعة الملك سعود. عيّنة الدِراسة: تمثَّت عيِّة الدراسة من عينة عشوائية من طالبات مرحلة البكالوريوس المسجَّلات بمقرر

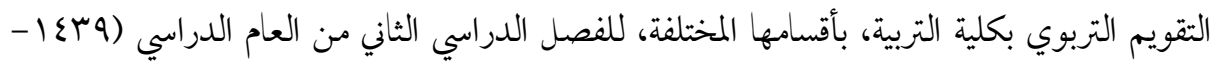

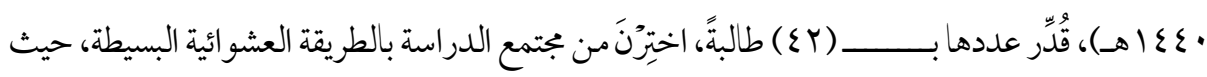

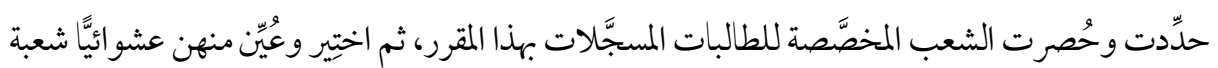
واحدة طبّّ عليها تجربة الدراسة وأدواتها. الإطار النظريٌّ والدراسات السابقة معايير كوالتي ماترز Quality Matters: تسعن الجامعات والمؤسسات التعليمية للحصول علئ الجودة في مقرراتها الإلكترونية

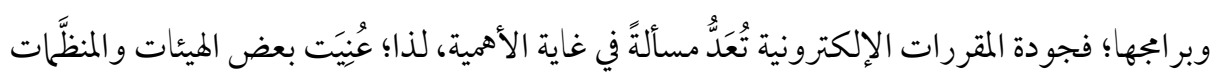
المهنية غير الرّبحية بتجويد المؤسسات والبرامج والمقررات الإلكترونية، ومنها منظمة كوالتي ماترز 
التي تعمل علن تحسين التعليم، والتحسين المستمرِّ للمقرَّر، مع التقليل في التكلفة؛ لضمان جودة QM

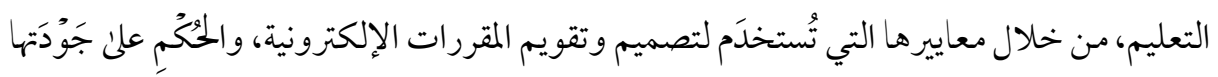
وصلاحيتها التعليمية؛ لحصول الطلبة على خِدمات تعليمية متميّزة، كما يضمن تحقيق الأهداف

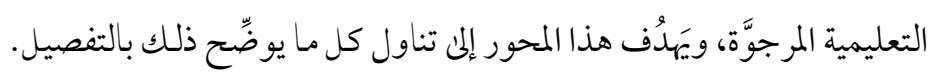

نشأة معاييرِ كوالتي ماترز Quality Matters:

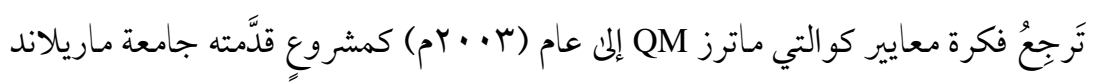

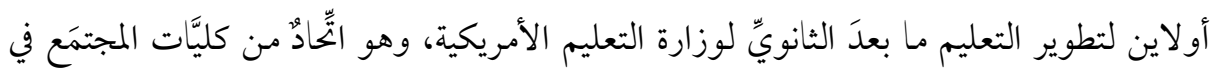

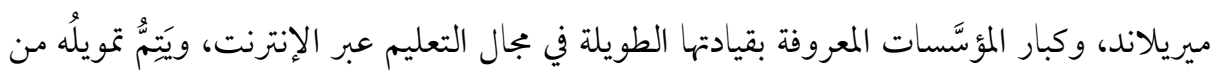

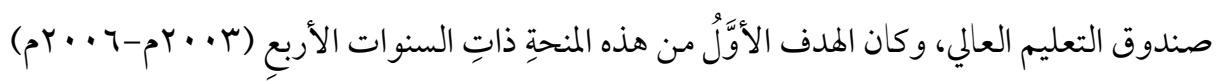

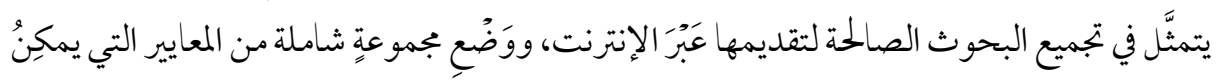
اتِّباعُها من قِبَلِ الكليَّات الإعدادية، ومؤسَّسات التعليم العالي، في تصميم مقرَّراتها علن الإنترنت.

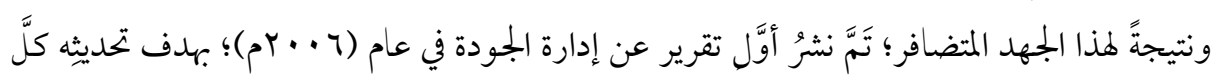

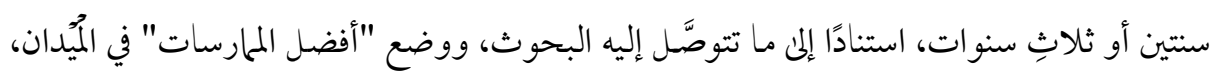

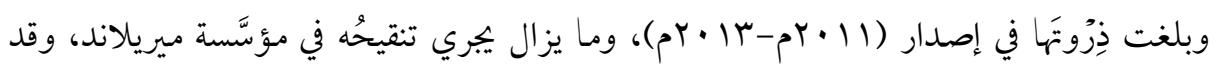

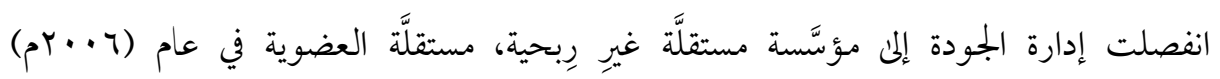
(Zimmerman, Adair, Shattuck,2014.p3)

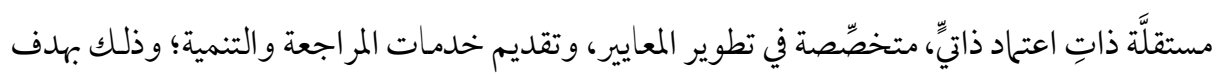

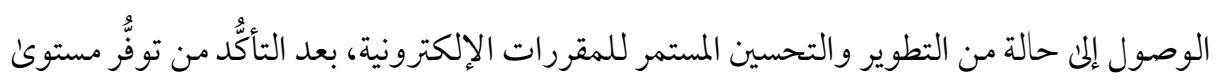
الجودة الأساسي لهذه المقررات، وذلك بمنهجية تعاونية ميَسَّرة.

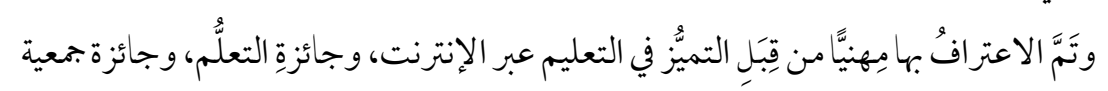
الو لايات المتحدة الأمريكية للتعلُّم عن بُعٍِّ (Adair,2011,p4). 
Prof. Dr. Ahmad Mohammed Saad AL Hussein \& Dr. Noora Abdullah Hamad Al-Rasheed Volume (4) No. (1) 2021

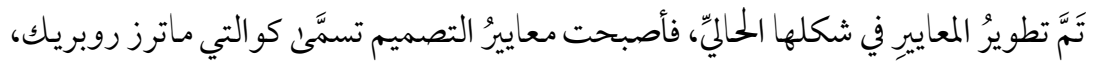
والهدف من ذلك هو أن نظام الروبريك سوف يقدّمّ تعريفًا عمليًّا وأداة عملية لتحديد مستوئ الجودة في تصميم المقرَّرات علن شبكة الإنترنت، وقد بُنيَ نظامُ روبريك علن أفضل الممارسات، والبحوثِ التعليمية عن بُعِدِ، ومبادئ التصميم التعليميِ.

مفهوم معاييرِ كوالتي ماترز Quality Matters: في السنوات الأخيرة بدأت منظَّمة QM بالانتشار والتوشُّع، فقي عام (ع ا ب rم) امتلكت ما يقارب سَبْعِمِئِة عضوِ مشترِك من الولايات المتحدة، ومن جميع أنحاء العاله، بها في ذلك الناشرون، وكليات المجتمَع، والجحامعات، وحتىل مدارس الثانويِّ (Loafman, g Altman,2014,p23)، وفي عام

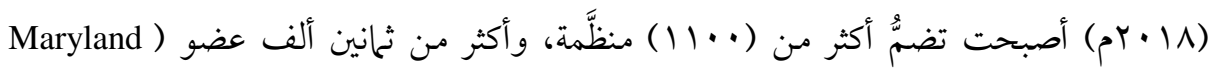

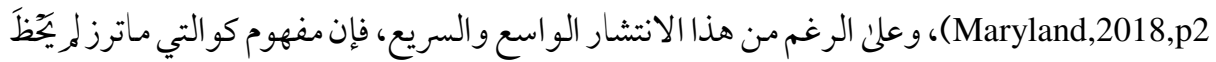

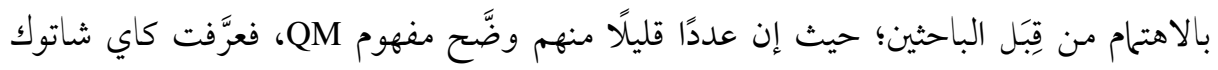
(Shattuck,2012,p37)

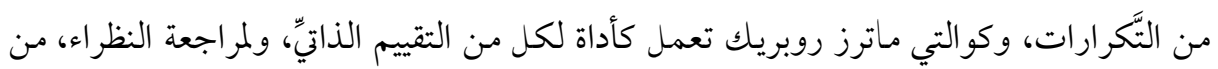

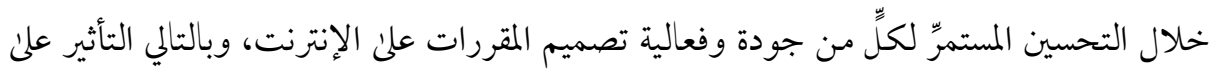
فعالية التعليم بالنسبة للطالب". ويرىن هوفمان (Hoffmani,2012,p164) أن معايير كوالتي ماترز روبريك (QMR) هي "معاييرُ عالميةٌ في تصميم مقرَّر علن شبكة الإنترنت، وهي الجهة الوحيدةُ التي تَقِيسُ معاييرَ تصميم

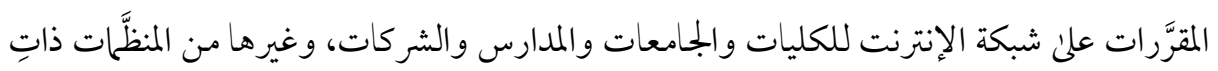

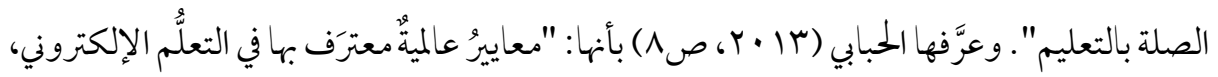
وتصميم المقررات الإلكترونية".

أما نانسي كروسن (Krusen,2015,p69) فتعرِّها بأنها: "عملية تركّز على البحوث

و التحسين المستمرِّ لجمودة التعلم عبر الإنترنت".

http://dx.doi.org/10.29009/ijres.4.1.9 
وتستند معايير QM على ثلاث مكوّنات أساسية، هي:

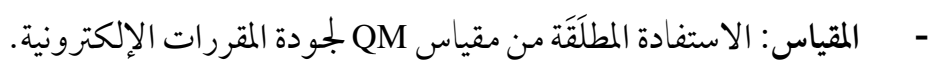
- المراجعة: الاستفادة من المراجعة العالمية للمقررات، وإعدادمر اجعين داخليين.

ويؤكّد بلونديل (Blundell,2015, p95) أنه لا توجد منظَّمة أو هيئة تحظى بالوصول والظهور و القياس والاعتحاد مثل التي تتمتَّع بها كوالتي ماترز QM في بجال تصميم ومراجعة المقررات التعليمية

$$
\text { علن الإنترنت، سواءُوفي الولايات المتحدة، أو في خارجها. }
$$

وترئ الباحثة أن معايير كو التي ماترز تميَّزت عن غيرها من الهيئات بتحديثها المستمرِّ للمعايير

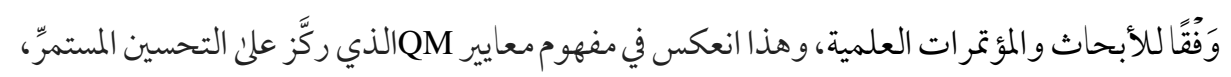

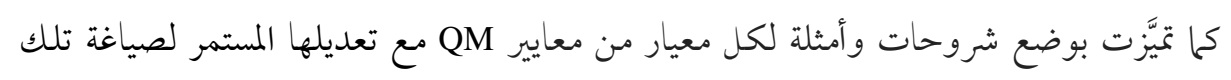
الشروحات.

المبادئ الأساسية لمعايير كوالتي ماترز Quality Matters:

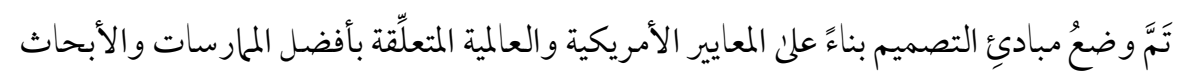
العلمية، ومباديئ التصـميم التعليمي (Shattuck,2007,p3)، ومن أهمّ المبادئ الأسـاسية للمعايير كما ذكرها ليجون (Legon,2006,p3):

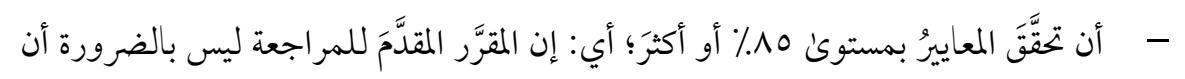

$$
\text { يكون مثاليًّا؛ لكن أكثر من جيّّد. }
$$$$
\text { - عملية تحسين مستمبَّة لجودة المقرَّرات الإلكترونية. }
$$

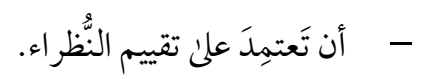

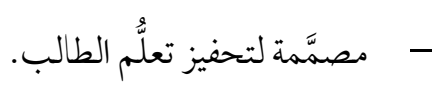

- مصمَّمة للتأكُّد من تلبية جميع المقَّرَرات المراجَعة لمعايير الجودة. - ليست عملية تقييم؛ بل عملية مر اجعة ودِّية بين النظر اء للمقرَّرات. 
Prof. Dr. Ahmad Mohammed Saad AL Hussein \& Dr. Noora Abdullah Hamad Al-Rasheed

Volume (4) No. (1) 2021

$$
\text { - - - مريق المراجعة يجب أن يضمَّ عضوًا من خارج المؤسَّة. }
$$

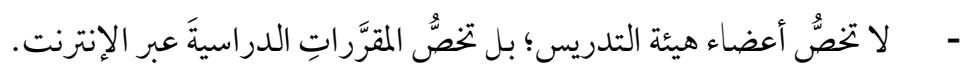

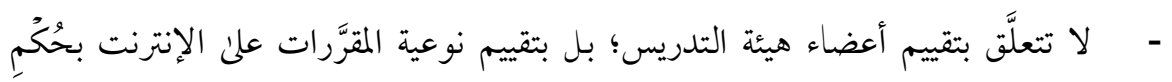

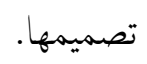

- ل ليست مَبْنيَّة علنى أساس الفوز والخسارة، أو النجاح والفشل.

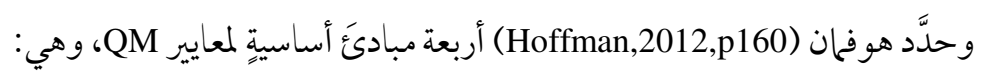

ا ـ الاستمرار: فعملية مر اجعة المقرر ات والبرامج وتحسينها عملية مستمرَّة، وهذا أساس عملية

$$
\text { الجودة. }
$$

r. التركيز: ترتكز عملية مراجعة المقر رات علن المعايير التي تم اشتقاقها وتطويرهامن الأبحاث

$$
\text { العلمية، ونتائج المؤتمرات، ومبادئ التصميم التعليمي. }
$$

ب.الجماعية: تســئ عملية مراجعة النظر اء في معاير كو التي ماترز (QM) لأن تكون جماعيَّةً،

حيث يتكوَّن فريق المراجعة من رئيس الفريق، وعضو للمر اجعة، وخبير للمحتوئ.

ع. التعاونية: فمراجعة المقررات تتم من خلال تعاون فريق المراجعة في مراجعة المقررات

\section{الإلكترونية.}

وترى الباحثة أن جميع المبادئ السابقة مهمَّة، وتركّز علنئ الاستمرارية ومر اجعة النظراء (فريق

$$
\text { المراجعة)، وعلن جودة وتحسين المقررات الإلكترونية. }
$$

مهامٌ إدارة الجحودة كوالتي ماترز Quality Matters: معائ

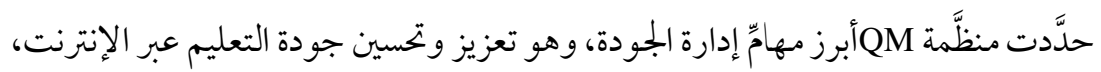
وتعلُّم الطلاب علني المستويينِ الوطني والدولي من خلال: 
تطوير معايير الجمودة الحالية المعتمِدة علنى الأبحاث والممارسات المستِندة إلى الممارسة وأدوات

$$
\text { وإجراءات التقييم المناسبة. }
$$

الاعتراف بالخبرة في مجال ضمان جودة التعليم عبر الإنترنت وتقييمه.

تعزيز ثقافة التحسين المستمرّ من خلال دمج معايير وإجر اءات إدارة الجودة في الخطط

$$
\text { التنظيمية لتحسين جودة التعليم عبر الإنترنت. }
$$

توفير التطوير المهني في استخدام القواعد والأدوات والممارسات؛ لتحسين جودة التعليم

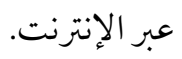

Maryland مراجعة الأقران وإصدار الشهادات للجودة في التعليم عبر الإنترنت

.(Online,2018)

فوائد معايير كو التي ماترز Quality Matters:

حدَّدت منظَّمة QM العديد من الفو ائد التي تتميَّز بها، وهي على النحو التالي:

$$
\text { إثبات الالتز ام بالتعلُّم الجيد عبر الإنترنت. }
$$

تحسين البرامج من خلال عملية التأهُّل لشهادة إدارة الجودة.

استخدام شهادة إدارة الجمودة لتسليط الضوء علن جودة البرامج عبر الإنترنت لأصحاب

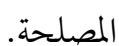

$$
\text { تبسيط الإعداد للاعتماد الإقليمي أو المهني. }
$$

ويضيف هوفمان (Hoffman,2012,p164) أن كوالتي ماترز QM ساعدت علن تطوير بيئة التعلُّم، ونظَّمتها تنظيًا جيدًا، كما أنها متكاملة مع التَّكرار اللازم الذي يحافظ على حماس الطلاب وانتباههم.

ومن الفوائد أيضًا: المناقشات التي تتم من خلال المراجعات بشأن المقياس الحقيقي للإنتاجات التعليمية (Sullivan, Mackie, Massy, Sinha,2012,p79)، فهذه المناقشات والاجتهاعات تُثري المراجعين و أعضاء هيئة التدريس بالمعارف والمهارات، وتطوِّر من قدراتهم. 
ويرى لوفهان والتهان (Loafman, Altman,2014,p21) أن من الفوائد التي توفِّها QM: اعتمادها علئ نطاق واسع، والاعترافَ بها، والتحسين المستمرَّ لضمان جودة البرامج والمقررات. وتشير الباحثة إلى أن أهمَّ فو ائد معايي QM بالنسبة للطالب وعضو هيئة التدريس (المراجِع) م بالنسبة للطالب: - 20 - تساعد علن تصميم مقرر يناسب جميع فئات المجتمع. - تساعد وتحفِّ عملية التعلُّم من خلال تنوُّع الوسائط التعليمية، و المصادر، والأنشطة التعليمية، وأساليب التقويم. - - تقديم تغذية راجعة للطالب لكل عمل ونشاط يقوم به؛ بمايَزيد دافعيته للتعلُّم.

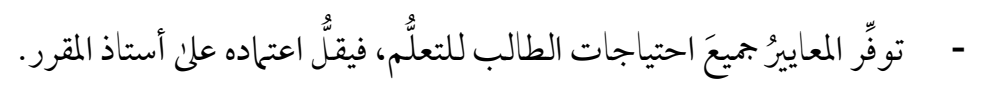
م بالنسبة لعضو هيئة التدريس (المراجِع) : - يكصل علن دورات تدريبية ليتمكَّن من الانضمام إلى فريق المراجعة.

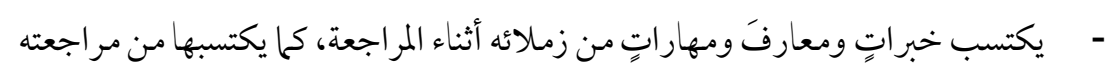
للمقرر نفسه. - عصوله علن شهادات من منظمة كو التي ماترز QM عند المر اجعة، أو عند اعتمادمقرره.

معايير كوالتي ماترز Quality Matters: حدَّدت منظمة QM في طبعتها الخامسة، عِدَّةَ مستويات حسَبَ المراحل العمرية، فثَمَّةَ معاييرُ للمرحلة المتوسِّة والثانويَّة، ومعايير للتعليم العالي، كما وَضَعت معايِرَ للناشرين، ومعاييرَ للمدرِّب

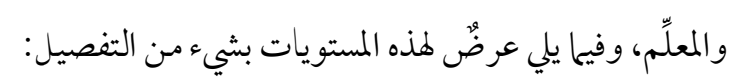

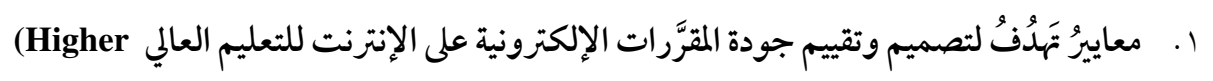
ED Rubric Standards) 
التعلُّم، و التقييم و القياس، وأنشطةِ المقَّرَ، وتفاعل المتعلِّم، واستخدامُ التِّنِيَّات في المقرَّر والموادِّ التعليمية، وسهولة الوصول والاستخدام) (Maryland Online,2011).

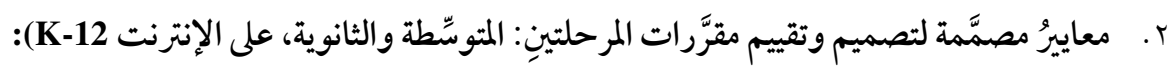
Secondary Rubric Standards)

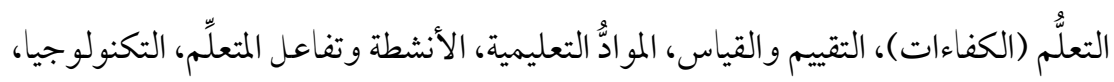
دَعْمُ المتعلِّم، سهولة الاستخدام، وإمكانية الوصول (Maryland Online,2018).

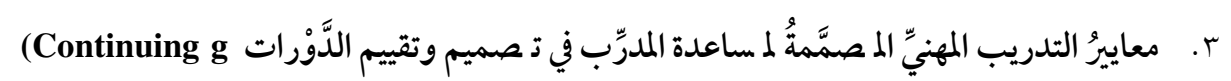

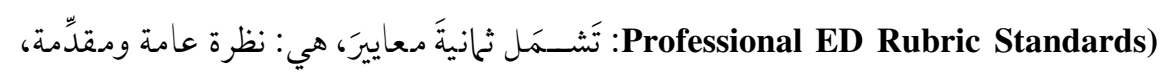
أهداف التعلُّم (الكفاءات)، التقييم والقياس، المو ادُّ التعليمية، أنشطة الدورة، التكنولوجيا، دعم المتعلِّم، سهولة الاستخدام، وإمكانية الوصول (Maryland Online,2017). ع. . معاير للناشر (Higher ED Publisher Rubric Standards): ثَمَََّ بجمو عةٌ معاييرَ لتوجيهِ

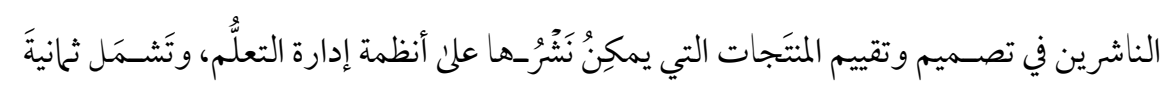
معاييرَ، هي: نظرةٌ عامَّةٌ ومقدِّمة، أهداف التعلُّم (الكفاءات)، التقييم و القياس، المو الدّ التعليمية،

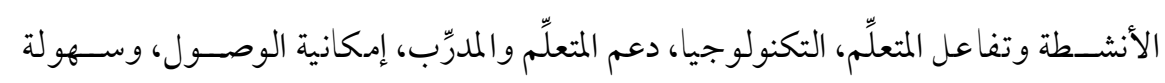
الاستخدام (Maryland Online,2017). ه. معايرُ للدَّورُرات المنشورة على الإنترنت والمخلوطة المُعَدَّة لمدارس المرحلتين: المتوسِّطة والثانوية “(K-12 Publisher Rubric Standards) أهداف التعلُّم (الكفاءات)، التقييم والقياس، الموادُّ التعليمية، الأنشطة وتفاعل المتعلمّ،

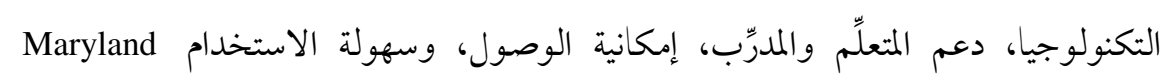
(Online,2017) 
ז. . معاييرُ مهارات التدريب (Online Instructor Skills Set):

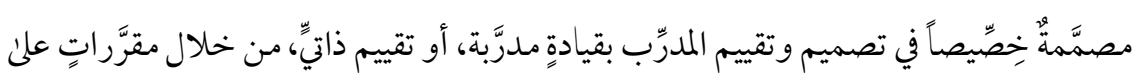

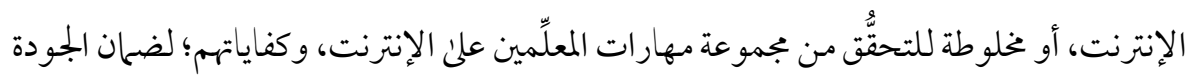

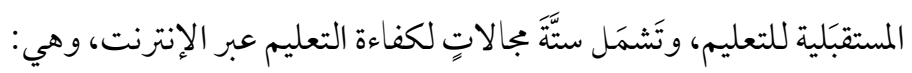

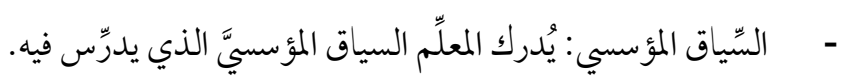

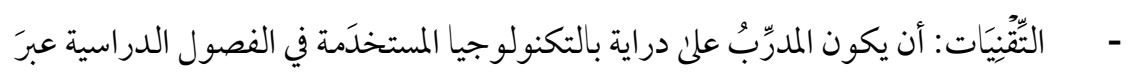

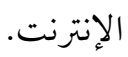

- التصميم التعليمي: يَفْهم المدرِّبُ متطلَّبَاتِ التصميم التعليمي لدورة تدريبية عبر الإنترنت.

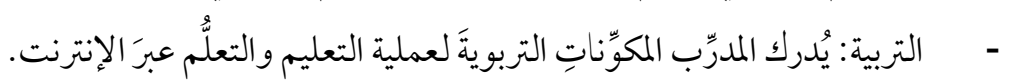

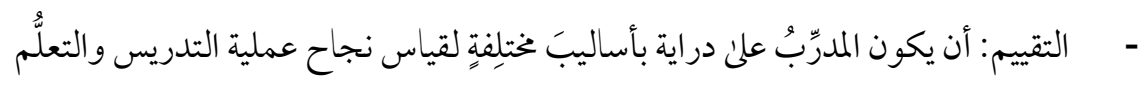
في الفصول الدراسية عبر الإنترنت.

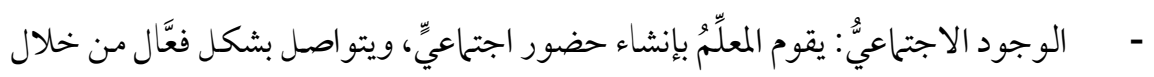
الكتابة أو الصوت أو الفيديو (Maryland Online,2016). استخدمت الباحثة في تصميمها معاييرَ تصميم وتقييم جودة المقرَّرات الإلكترونية على الإنترنت للتعليم العلي (Higher ED Rubric Standards)، لمناسبتها هذه الدر اسةَ، حيث صميمُ مقرر إلكتروني للتقويم التربويٍ لطالبات كلية التربية في ضوئها.

مراجعة المقررات والدورات الإلكترونية في ضوء معايير كو التي ماترز Quality Matters: مر اجعة المقررات والدَّورات الإلكترونية تكون من خلال مر اجعة النظر اء، وهو فريق مدرَّب

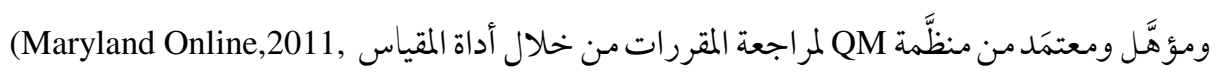

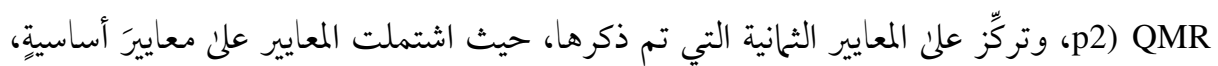

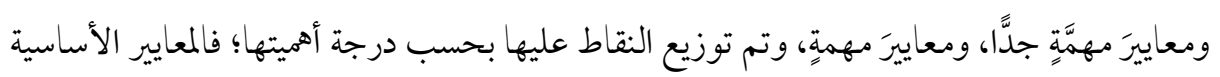

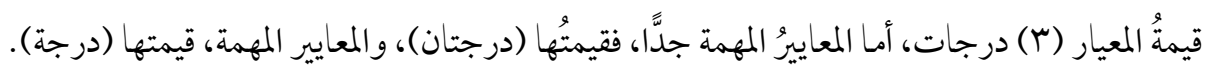


جدول يوضح آلية توزيع النقاط علن معايير كو التي ماترز QM حسب أهميتها

\begin{tabular}{|c|c|c|}
\hline ق قيمة المعيار & عدد المعايير لهذه الفئة & درجة أهمية المعيار \\
\hline r برجات & YI & أساسي \\
\hline درجتان & $1 \varepsilon$ & مهم جداً \\
\hline درجة & $\wedge$ & مهم \\
\hline 99 درجة & r זـ معيار & الإجمالي \\
\hline
\end{tabular}

وثَمَََّ طريقتان لاستخدام برنامج إدارة الجودة QM؛ إحداهما: مر اجعات داخلية غير رسمية بواسطة مراجع واحدِ أو أكثر، ويمكِن لأيِّ مؤسسة المشاركةٌ فيها، والثانية: مراجعات رسمية؛

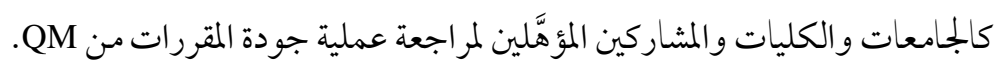

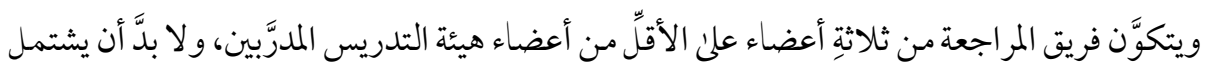
الفريق علن: (رئيس فريق واحد، وخبير مختصٍ بالمحتوىن ومناسب للتخصُّص، ومراجع خارجيٍّ) .(Roehrs, Wang, Kendrick,2013,p53)

وتتم عملية المراجعة للمقررات والبرامـج الإلكترونية بخطوتين؛ الخطوة الأولى: تحديد أهمِّ النقاط التي حصل عليها المقرر في كل معيار من معايير QM، والخطوة الثانية: تقديم تعليقات واقتراحات جوهرية وبنَّاءة ومحلَّدة فيما يتعلَّق بنقاط القوَّة والتحسين المستمرِّ للمقرر الإلكتروني. ويُشترَط لحصول المقرر الإلكتروني علن الاعتهاد من منظَّمة QM، استيفاؤه لجميع المعايير الأساسية التي قيمتها (r) درجات؛ فَعَمُ إتمام معيار واحدمن المعايير الأساسية يمنع المقر من الاعتماد

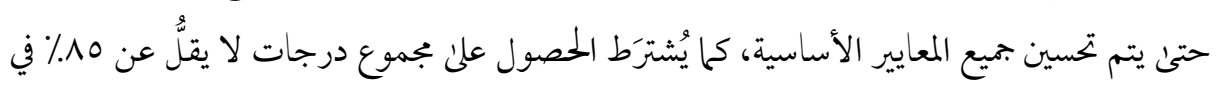
جميع المعايير لاعتماد المقرر، والحصول علن شهادة الاعتماد (Harris,2018,p6). 
Prof. Dr. Ahmad Mohammed Saad AL Hussein \& Dr. Noora Abdullah Hamad Al-Rasheed Volume (4) No. (1) 2021

شكل يوضح علامات الاعتحادمن QM

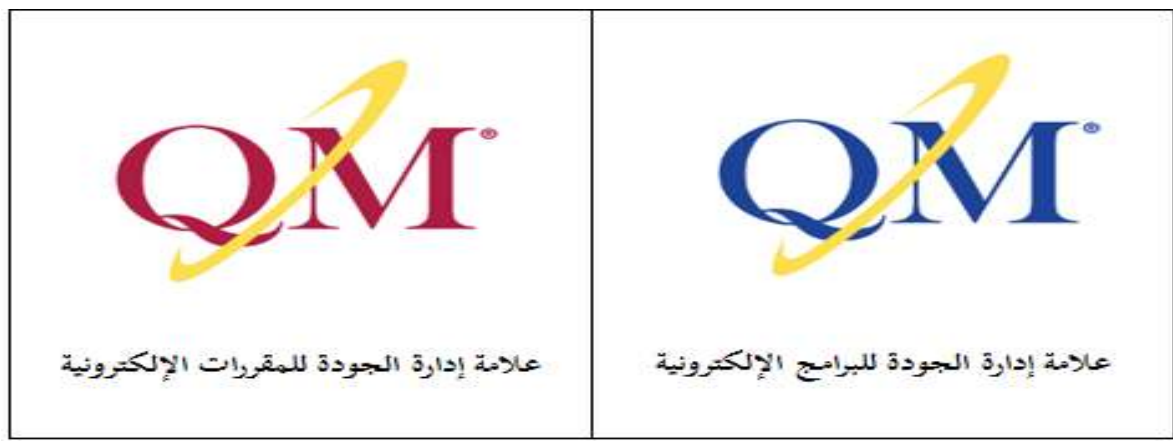

وتتم عملية مر اجعة نموذج التقييم وأداة القياس QMR بالكامل كلَّ سنتين إلى ثلاث سنو ات،

(Shattuck, من خلال خمس خُطوات تم تحديدها من قِبَل كاي شاتوك، وزيمرمان، وأدير Zimmerman, \& Adair, 2014,p29)

QMل شوضح خطوات عملية مراجعة تقييم إدارة الجودة

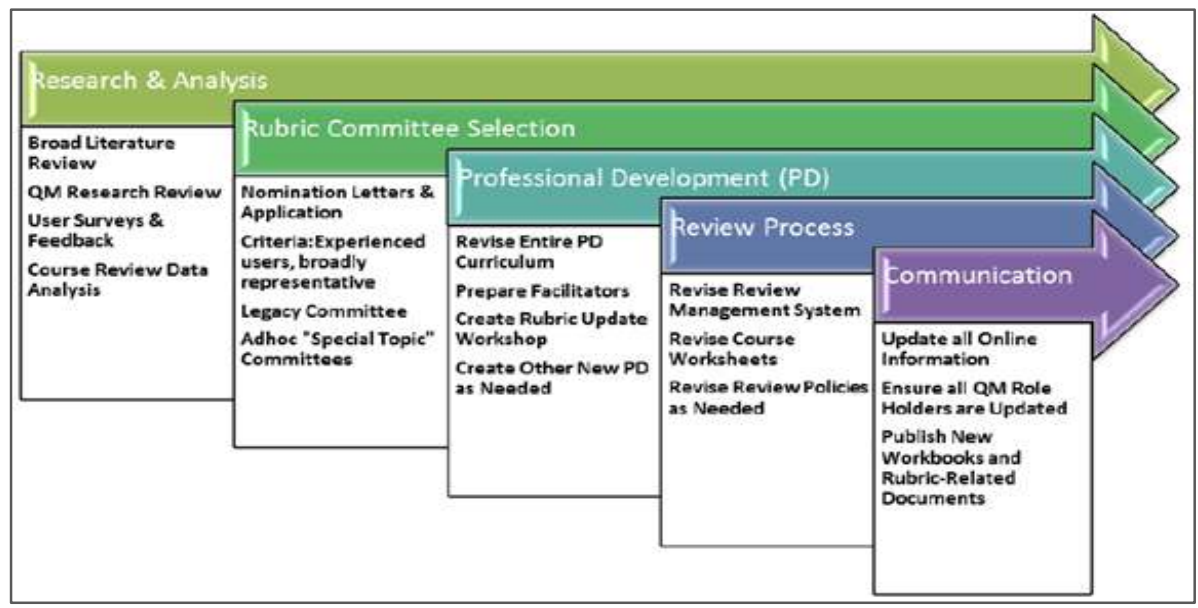

$$
\begin{aligned}
& \text { وترجمة الخطوات السابقة، هي: } \\
& \text { ا ـ البحث والتحليل: وتتضمَّن ما يلي: }
\end{aligned}
$$

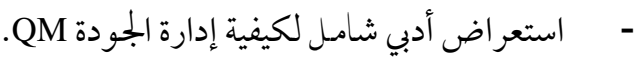

$$
\begin{aligned}
& \text { - مراجعة البحوث و الدراسات السابقة لبرنامج مM. }
\end{aligned}
$$


- - استطلاع آراء مستخدمي البرنامج QM والحصول علن التغذية الراجعة منهم.

$$
\begin{aligned}
& \text { - - تحليل البيانات ومراجعتها. } \\
& \text { r. اختيار لجنة المراجعة: وتتضمَّن ما يلي: } \\
& \text { - - إرسال خطابات ترشيح أعضاء لجنة المراجعة. }
\end{aligned}
$$

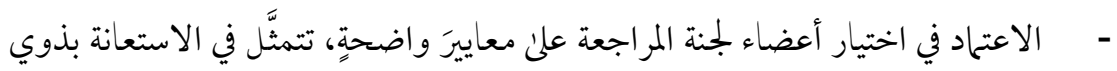

الخبرة، وعلى فئات كبيرة من المستخدِمين.

$$
\text { - مشكيل لجنة المراجعة الرئيسة. }
$$

- تشكيل اللجان ومجموعات العمل الفرعية.

r. التنمية المهنية: وتتضمَّن ما يلي:

- مر اجعة كافة أجزاء منهج البرنامج في التنمية المهنية.

- إعداد المُيسِرِين الذين يُشرفون علن التطبيق العملي.

- مقد ورش عمل لتحديث نموذج التقييم QMR.

- ابتكار وسائَل جديدةٍ للتنمية المهنية حسب الحاجة.

ع. عملية المراجعة: وتتضمَّن ما يلي:

- - مراجعة معايير تقويم جودة نظم إدارة المقررات الإلكترونية.

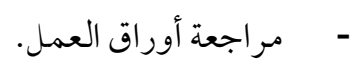

- مر اجعة السياسات المتّبَّعة في ضمان الجودة حسب الحاجة.

ه. تعميم نتائج المراجعة: وتتضمَّن ما يلي:

- تحديث جميع المعلومات عن معايير البرنامج على شبكة الإنترنت.

- ضمان تحديث كافة البيانات بشكل دوريٍّ.

- شر بطاقات المعايير الجديدة والوثائق المتعلِّة بنماذج التقييم. 
Prof. Dr. Ahmad Mohammed Saad AL Hussein \& Dr. Noora Abdullah Hamad Al-Rasheed Volume (4) No. (1) 2021

وترى الباحثة أن هذه الخُطُواتِ تتَّهِف بالاستمرارية؛ فلمر اجعة مستمرَّةُ طوال العام، كما أن مراجعة الدراسات والبحوث تكون بصفة مستمرة للاستفادة من نتائج هذه الدراسات في تطوير إدارة الجودة، وأيضًا عملية اختيار المراجِعين تكون مستمرةً علن حسب المؤسسات والهيئات التي تنضَمُّ وتشارك مع إدارة الجودة في المراجعات الرسمية.

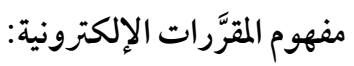
مع الاتجاهات الحديثة في بجال تكنولوجيا التعليم، ظهرت المقررات الإلكترونية كبديل عن المقررات التقليدية، التي تعبِّ عن تطبيق الطالب أو المستخدم لمحتوّك ما، باستخدام أدوات وتطبيقات

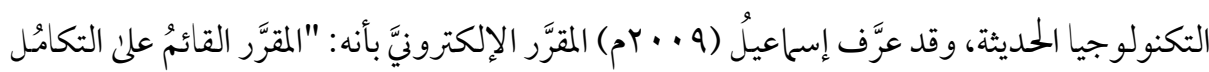
بين المادة التعليمية، وتكنولوجيا التعليم الإلكتروني في تصميمه وإنشائه وتطبيقه وتقويمه، ويَدرُس الطالب محتوياتِه تكنولوجيًّا وتفاعليًّا مع عضو هيئة التدريس، في أيِّ وقت، وفي أيِّ مكان يُريد" (ص) (صT)

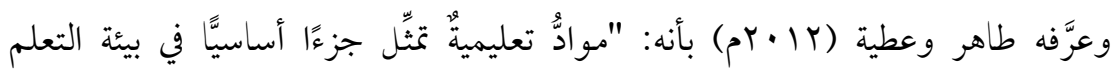
الإلكتروني، وتشمل أساليبَ متنوِّعةً تُستخدَم لشرح الدروس والمعلومات التي يمكِن استدعاؤها من الشبكة، مع التدعيم بعناصر الوسائط المتعدِّدة التفاعلية" (ص (7) ). ومن خلال التعريفات السابقة، ترئ الباحثة أن المقررات الإلكترونية جزء أساسٌ في منظومة التعليم الإلكتروني، تتضمَّن محتوكئ قائًا على الوسائط المتعدِّة، ويُستخدَم فيها أنشطةُ، ومو ادُّ تعليمية، و أساليب تقويم، تَعتمِد علئ الحاسب الآلي وير بجياته، منها مـا هو معتمِد علن الإنترنت، ومنها ما هو غير معتمد.

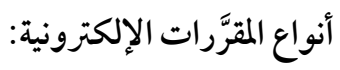
من خلال التعريفات السابقة يتَّضِح لنا أنواع متعلِّدة من المقررات الإلكترونية، تقسَّم بحسب الِّب

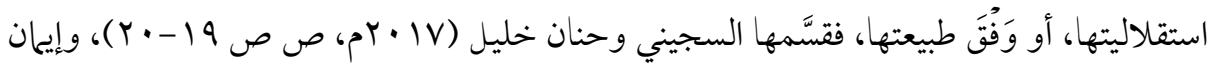

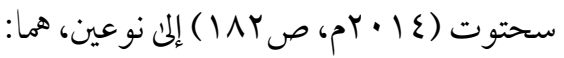




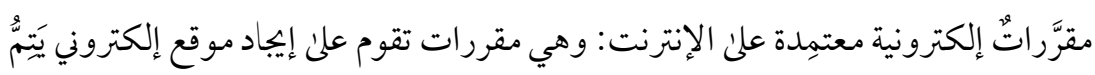

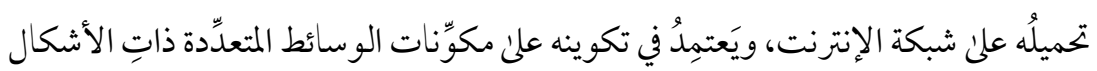
المختلِفة من نصوص خاصة بالمقرر، وتعمل هذه المقررات علن الترابط بين الطالب وزملائه ومعلّمه، سواء من خلال البريد الإلكتروني، أو من خلال التحاور.

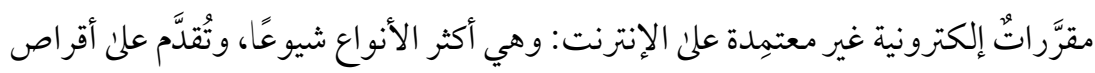

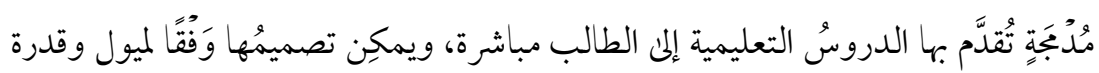

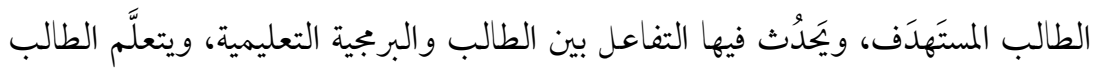

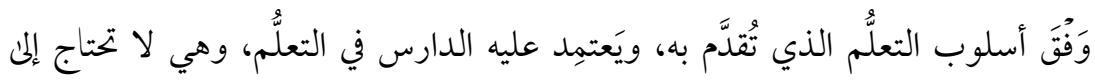

$$
\text { المدرّّس، إلا في مهارات حاسوبية قليلة. }
$$

وأضاف مصطفي (10 • بم، ص ^) إلى الأنواع السابقة: "المقررات الإلكترونية المدجة بين

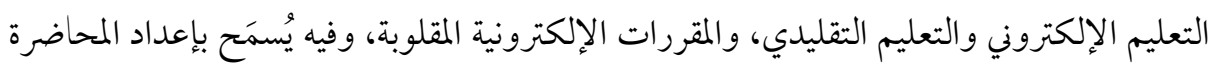

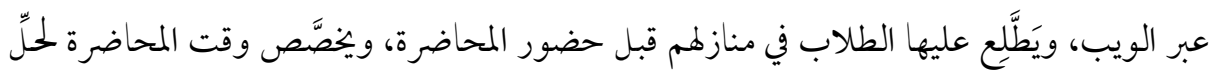
الأسئلة، ومناقشة تكليفات المقرر".

وتتبنَّ الباحثة في هذه الدراسة المقر رات الإلكترونية المقلوبة؛ حيث ضمانُ الاستغلال الجِيّّ

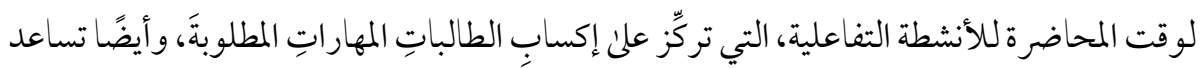
الطالبات علن إعادة المحاضرات أكثرَّمن منرّةٌٍ؛ بناءُ علن فروقهن الفردية.

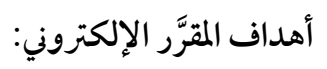

عَهَدُفُ المقرر الإلكتروني إلمن تحسين العملية التعليمية، من خلال بناء بيئة تعليمية تعاونية،

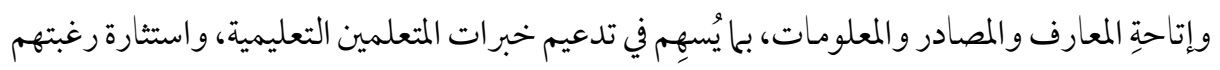

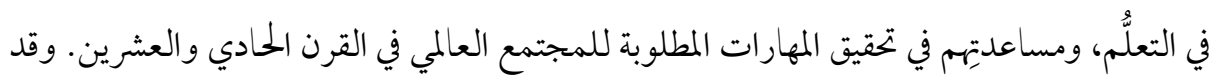

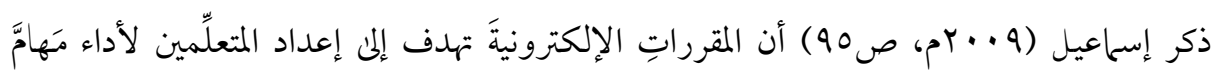

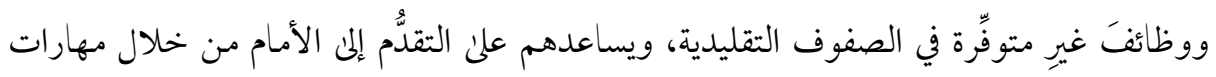


Prof. Dr. Ahmad Mohammed Saad AL Hussein \& Dr. Noora Abdullah Hamad Al-Rasheed Volume (4) No. (1) 2021

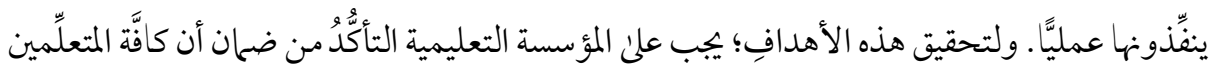

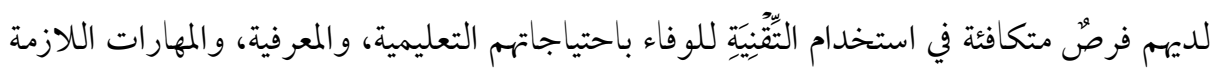
لاستخدامها بفعالية في عملية التعليم والتعلُّم.

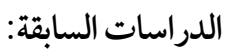

ما تزال الدراسات والبحوث العربية التي تناولت معايير كو التي ماترز Quality Matters في

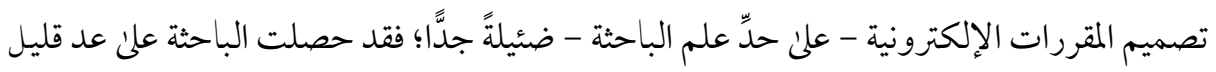

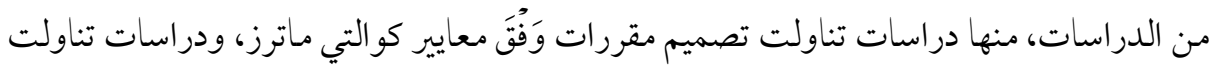

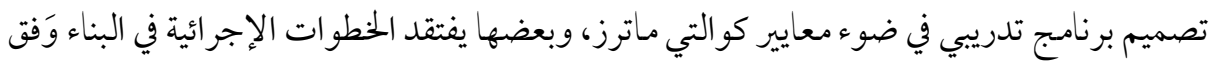

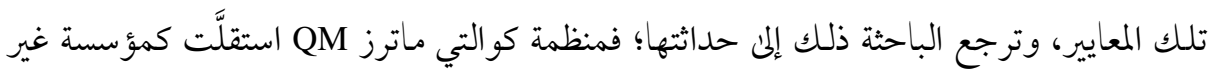

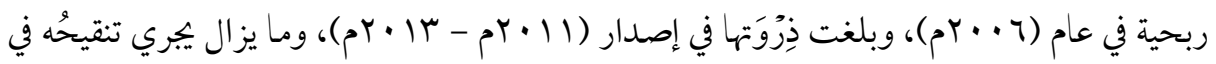
مؤسَّسة ميريلاند، كما تقدَّم ذكره في الإطار النظري. ونلفي.

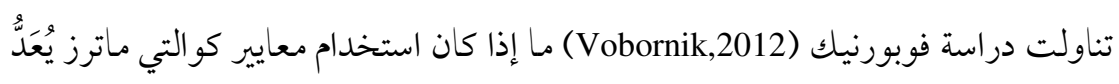
مؤشِّرًا لرضا الطلاب عن المقررات الإلكترونية. وللوصول لهدف البحث؛ استخدم الباحث استبيانًا

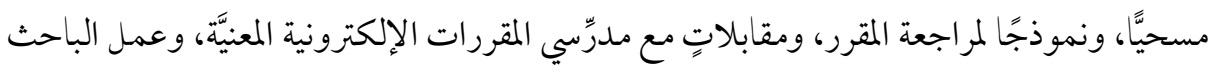

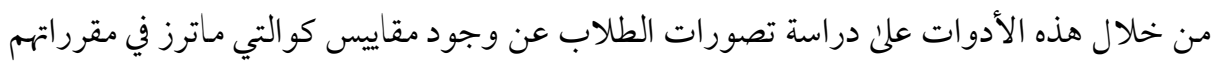

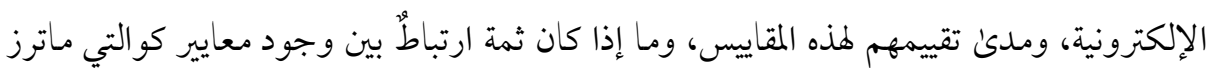

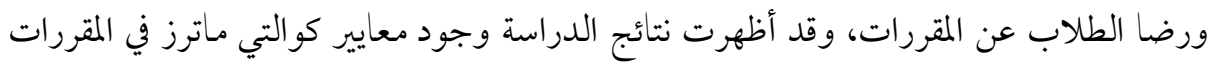

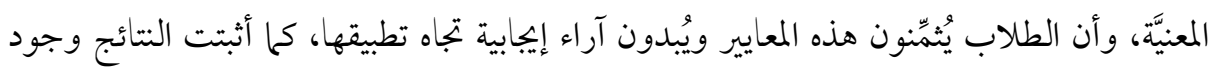
ارتباط طردي بين وجود معايير كوالتي ماترز ومستويات رضا الطلاب عن هذه المقررات.

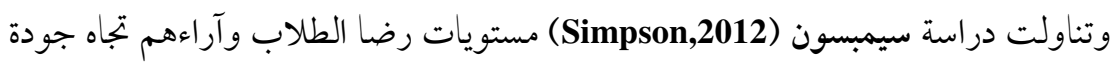
المقررات الإلكترونية، حيث بحثت عن العلاقة ما بين رضا الطلاب عن جودة المقر رات الإلكترونية،

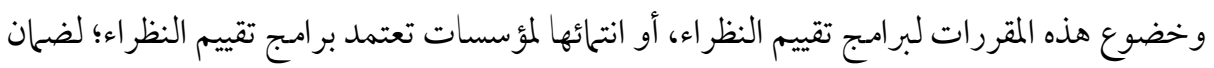


جودة المقرر ات الإلكترونية، كما تَّتّ دراسة أيّ من عو امل ضمان الجودة هلا ارتباطُ أكثر بزيادة مستويات الرضا لدىن الطلاب، وتم جمع بيانات الدراسة باستخدام استبيانينِ موجَّهين للطلاب ولمصمَّمي المقررات. وقد أظهرت نتائج الدراسة أن المقر رات التي تخضع لبرامج تقييم النظراء قد نالت مستويات رضا أكبر، كما دلت نتائج استبيان الطلاب أن مستويات رضاهم عن مقررات التعليم يرتبط بمدني ارتياحهم مع هذه المقررات، وملاعمة هذه المقررات لهم، وأظهرت نتائج الدراسة أيضًا انخفاض

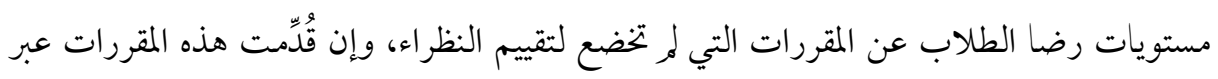
مؤسسات تشارك في برامـج التقييم. وأجرئ بلونديل (Blund ell,2015) دراسة هدفت إلى معرفة مستويات الرضا عند أعضاء هيئة التدريس تجاه المقررات المصمَّمة علن شبكة الإنترنت باستخدام معاييرِ كوالتي ماترز (QM)، بالمقارنة مع مستويات رضا أعضاء هيئة التدريس تجاه المقررات المصمَّمة علن شبكة الإنترنت دون استخدام معايير (QM)، واستخدمت الدراسة المنهج الكميَّ المقارن، وتمثَّلت أداتها في مقياس مكوَّن

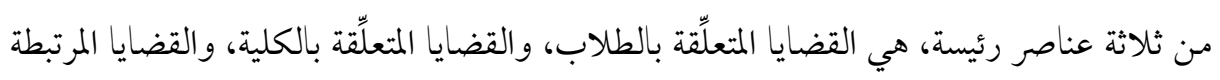

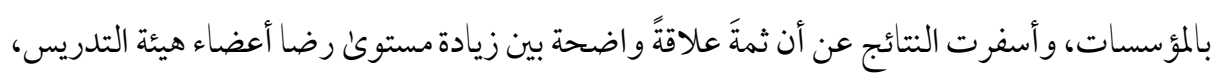

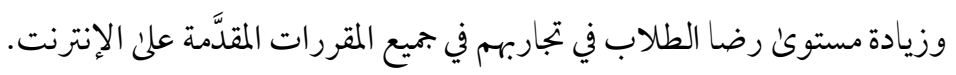

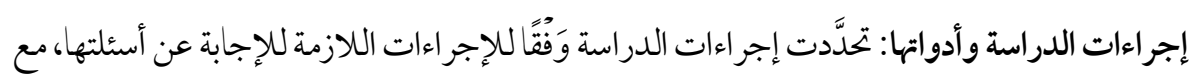
توضيح المنهج المتّبَع، والأداة المحقِّقة لأهدافها، كالتالي:

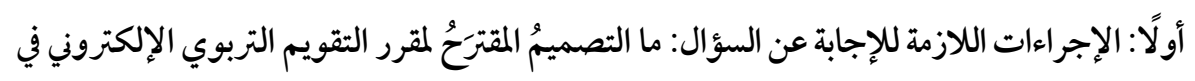
ضوء معايير كوالتي ماترز (Quality Matters)؟ استخدمت الباحثة المنهج الوصفيَّ في تتبّع الأدبيات المتاحة في مجال تصميم المقررات الإلكترونية بصفة عامة، ومعايير كو التي ماترز (QM) بصفة خاصة، وفي مجال التقويم الإلكتروني، وقد

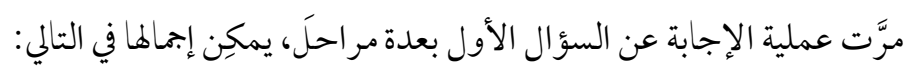


Prof. Dr. Ahmad Mohammed Saad AL Hussein \& Dr. Noora Abdullah Hamad Al-Rasheed

$$
\text { 1. - منطلقات تصميم المقرر: }
$$

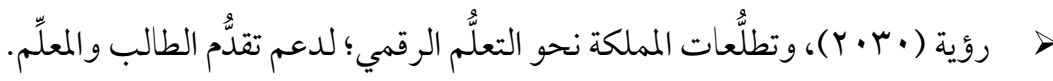

$$
\text { > مهار ات القرن الحادي و العشرين. }
$$

r. مصادر تصميم المقرر : استُند إلم مجموعة من المصادر العلمية، وهي:

وثيقة معايير كو التي ماترز (QM)، وما اشتَمَتَت عليه من معايِرَ ومبادئ خاصةٍ بتصميم

$$
\text { المقررات في ضوئها. }
$$

البحوث والدراسات التربوية السابقة التي تناولت معايير كوالتي ماترز (QM) في تصميم المقررات الإلكترونية؛ للاسترشاد بكيفية توظيف المعايير والإفادة منها. المراجع الأصيلة، والدراسات التربوية السابقة، التي تناولت تصميم المقررات الإلكترونية؛ للاستفادة من نماذجها ونظرياتها، وأهدافِها وأسس تصميمها. المراجع الأصيلة، والدراسات التربوية السابقة، التي تناولت التقويم التربوي عامة، و التقويم الإلكتروني خاصة؛ للاستفادة منها في تحديد أهمّ مهارات التقويم الإلكتروني، وتحديد محتوى المقرر.

آراء الخبراء والمختصِّين في مجال المناهج وطرق التدريس، وتِقنيَّات التعليم، وعلم النفس

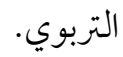
> توصيفات الجامعات الأمريكية التي اعتمدت مهارات التقويم الإلكتروني في مقرر التقويم التربوي؛ للاستفادة من أهدافها ومحتواها في بناء المقر ؛؛ مثل: - جامعة إيه أند إم A\& M university: ومن أهم الموضوعات التي تطرَّقت إليها: مفاهيم في التقويم، والتقويم الإلكتروني (Miller,2015). - - Mامعة ميشيغان Michigan university: ومن أهم الموضوعات التي تطرَّقت إليها: التمييز بين القياس والتقويم، والأهداف التعليمية وطريقة صياغتها، وبناء الاختبارات الإلكترونية وملفات الإنجاز (Applegate,2017). 
- (James,2017) التدريبُ علن أساليب التقويم الإلكترونية، والمناقشات عبر الإنترنت.

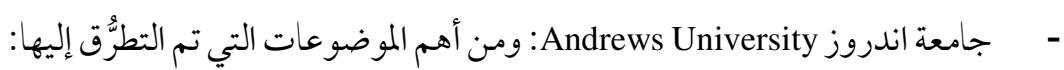
مفهوم التقويم التربوي، والأهداف التعليمية وربطها بالتقويم، وملفات الإنجاز Andrews ) Modle الإلكترونية، والاختبار ات الإلكترونية على منصة إدارة التعلم

.(University,2015

واختارت الباحثة توصيف مقرر التقويم التربوي في الجامعات الأمريكية والاستفادة منها؛

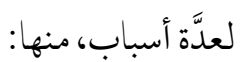
- - الجامعات الأمريكية من الجامعات المتقدِّمة في التعليم.

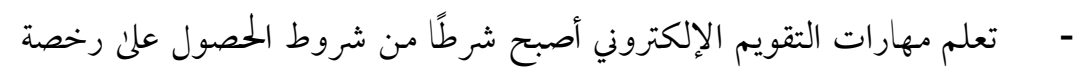
لمارسة مهنة التدريس في الولايات المتحدة الأمريكية. - مقرر التقويم والقياس لديها لا يخلو من مهارات التقويم الإلكتروني، وأكثر

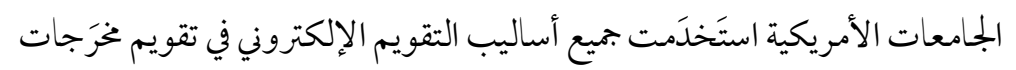
. - منظَّمة كوالتي ماترز من المنظَّات العالمية التي اهتمَّت بمعايير تصميم وتقويم

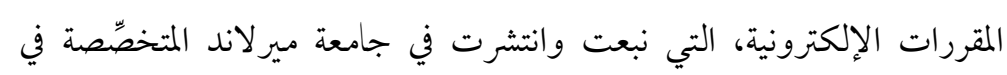

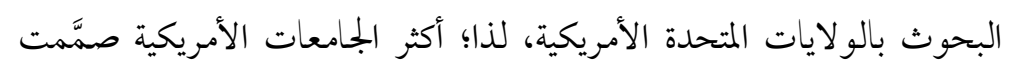

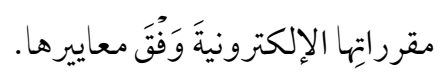

r. الأسس والنظرية في تصميم المقرر: اعتمدت الباحثة في تصميمها لمحتوى مقرر التقويم

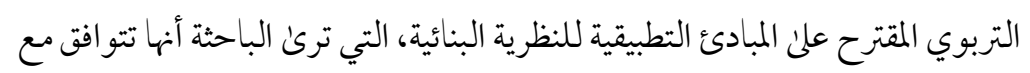

$$
\text { معايير (QM) و لا تتعارض معها، ومن أهم مبادئها: }
$$


Prof. Dr. Ahmad Mohammed Saad AL Hussein \& Dr. Noora Abdullah Hamad Al-Rasheed Volume (4) No. (1) 2021

- قبول ذاتية المتعلِّم ومبادراته، وذلك بتشجيعه علن تنمية قدراته، وتهيئة المواقف الملائمة له؛ فالمتعلم مشارك بشكل أساسي في تصميم المحتوك من خلال استجاباته وآرائه، وبحثه في مصادر التعلم عن أهمّ المعارف المتخصِّمة في المقرر.

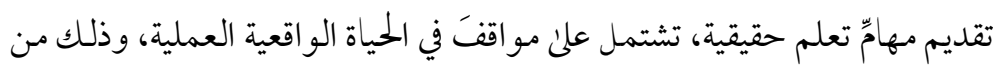
خلال أنشطة تعلم تساعد الطالبة على أداء مهارات التقويم الإلكتروني، وتهيئها

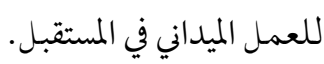
تدفع بيئات التعلم الميداني المتعلم إلى التفكير في بجالات المعرفة، كما أن التعلم في هذه البيئات يَحُْث من خلال الممارسة العملية. - مَدعَم البنائيةٌ بيئة التعلم التعاوني، الذي يهدف إلى تكوين وجهات نظر متعدِّدة حول موضوع معيَّن. - تنظر البنائية إلى أن كل متعلم مستقلّ بخصائصه، لذا؛ فإن أساليب التقويم ليست واحدة؛ بل متنوِّة؛؛ لتوجيه عملية التعليم والتعلم. ع. نموذج تصميم المقرر المقترح: بعد مراجعة نحاذج التصميم التي عُرضت في الفصل الثاني،

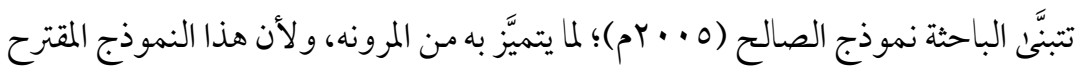

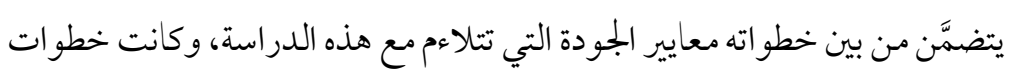

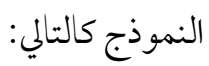

أ- مرحلة التحليل: وتتضمن مرحلة التحليل عددًا من المهامّ، نلخِّصها فيها يلي: 1. تعريف المقرر والمستفيدين: المقرر الذي سيجري تصميمه هو مقرر التقويم التربوي الذي يدرَّس في كليات التربية بجامعة الملك سعود، بو اقع ساعتين من كل أسبوع في الأقسام التالية: الدراسات الإسلامية، وعلم النفس، والتربية الفنية، والتربية الخاصة، والطفولة المبكرة، والدراسات القرآنية، والمناهج وطرق التدريس (تخصص اللغة الإنجليزية، والفيزياء، والحاسب الآلي، والرياضيات)، ويختلف المستوكئ الذي يدرَّس فيه المقرر من قسم إلى آخر. 
والمستفيد من هذا المقرر هنَّ طالبات كلية التربية في جامعة الملك سعود، فضلاً عن إمكان استفادة سائر كليات التربية في جامعات المملكة العربية السعودية أيضًا منه.

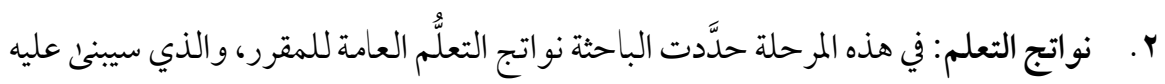

$$
\text { موضوعات محتوى المقرر، وفيها يلي توضيح لنواتج التعلم: }
$$

نواتج التعلم العامة للمقرر : عند الانتهاء بنجاح من هذا المقرر، فإن الطالبة ستكون قادرة على أن:

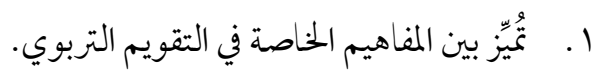
r. ت تعرف أبرز التوجُهات الحديثة في التقويم التربوي. ب. تَعِيٍّ بين أدوات وأساليب التقويم الإلكتروني. ع. تستتج مميزات وصعوبات كل أداة من أدوات التقويم الإلكتروني. 0. تصمّم أدوات التقويم الإلكتروني بمهارة. r. التعريف بالطالبات المستفيدات: يتمُّ التعريف بالطالبات من ثلاثة جوانبَ، هي: معرفة الطالبات بمحتوئ المقرر المصمَّم؟ وذلك بهدف تقديم مادة ملائمة لهن، ليست بسيطةً فتكون مُمِلَّة، ولا صعبةً فتكون مخبطة، لذا؛ حَرَصت الباحثة أن يكون المقرر المصمَّم يحتوي

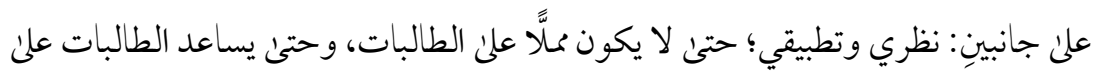

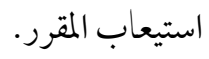
معرفة مستوكئ المهارات الحاسوبية لدئ الطالبات، وقد تم مقابلة طالبات كلية التربية بجامعة

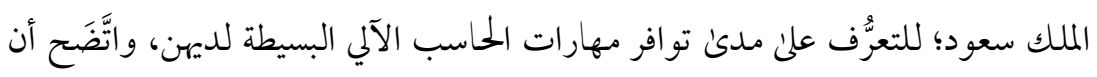

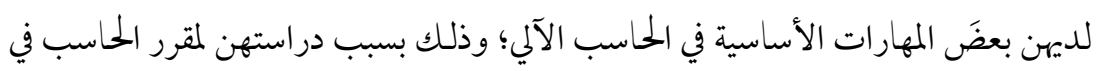
السنة التحضيرية، ودراسة مقرر تقنيات التعليم في المستويات الأولنى قبل دراسة مقرر التقويم التربوي. معرفة اتجاهات الطالبات نحو التعلم الإلكتروني بواسطة نظام التعلم الإلكتروني (البلاك بورد)، ولمعرفة اتجاهاتهن؛ قامت الباحثة بعمل استبانة لتتعَّف من خلالها على اتجاهات 
Prof. Dr. Ahmad Mohammed Saad AL Hussein \& Dr. Noora Abdullah Hamad Al-Rasheed Volume (4) No. (1) 2021

طالبات كلية التربية بجامعة الملك سعود نحو استخدام نظام إدارة التعلم (البلاك بورد)، وتبيَّن أن لدى الطالبات اتجاهاتٍ إيجابيةً نحوَ استخدامه. ـ. تعريف بيئة التعلم: اعتمدت الباحثة بيئة التعلم المدمج الذي يَدمج بين التعلم في القاعة

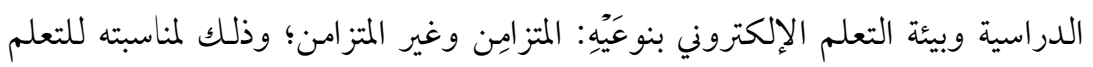
الرسمي في جامعات المملكة العربية السعودية، واعتمدت الباحثة التعلم العكسيَّ الذي هو أحد أنماط التعلم المدمج؛ لماله من فو ائدَ تربويةٍ عديدة في تحسين تحصيل الطالبات وتطوير استيعابهن؛ حيث تُعرض لهن المادة العلمية علن نظام التعلم (البلاكُ بورد)، ويتم في القاعة

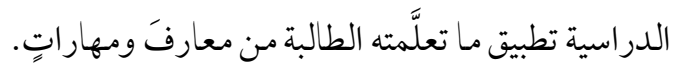
ه. تعريف البنية التقنية: تعتمد دراسة المقرر علن أجهزة الحاسب الآلي والمودم، وبعض البرامج والمو اقع الإلكترونية؛ لتصميم أدوات التقويم الإلكتروني. I. اختيار نظام التعلم الإلكتروني: في هذه المرحلة يتم تحديد أفضل طريقة لتوصيل التعلم الإلكتروني، وقد اختارت الباحثة نظام التعلم الإلكتروني (البلاكك بورد) المستخدم من قِبَل أكثر الجامعات السعودية، خاصَّةً جامعةً الملك سعود. V. مجال التعلم: حلَّدت الباحثة نو اتج التعلم المعرفيَّة الحاصة بالمهارات المعرفية التي صنِّت في مستويات، هي: (التذكُّر، والفَهم، والتطبيق فما فوق)، و التي يتطلَّب كل منها أسلوبًا مختلفًا

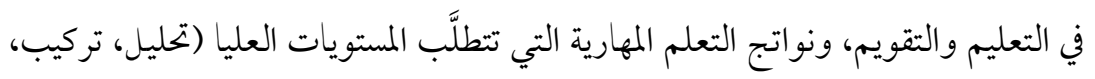
تقويم)، كما تتطلَّب تطبيقات متكرّرة وتغذية راجعة مستمرة؛ من أجل إتقان هذه المهارات. وقد حددت الباحثة نواتج التعلم الخاصة بكل وحدة، مع تحديد النو اتج المرتبطة في كل وَحدة

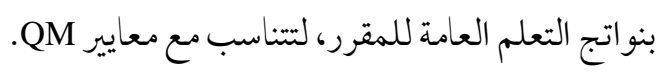
A. تحديد معاير ضمان الجودة: تتبنَّى الباحثة معايير جودة تصميم وتقويم المقررات الإلكترونية، وهي معايير كوالتي ماترز (Quality matters) في عملية تصميم المقرر المقترح، وبعد الاطّلاع علن موقع منظمة (QM)، وعلن الدراسات السابقة التي تناولت المعايي؛ كدراسة 
فوبورنيك (Vobornik,2012)، ودراسة سيمبسون (Simpson,2012)، ودراسة القحطاني

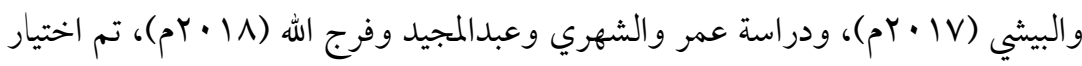
معايير تصميم مقررات التعليم العالي (HIGHER ED RUBRIC STANDARDS)

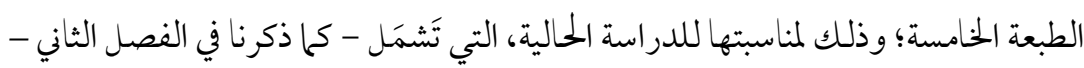

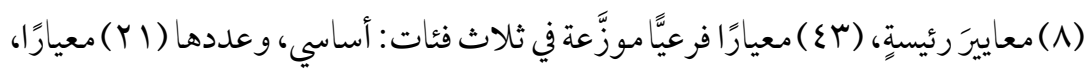

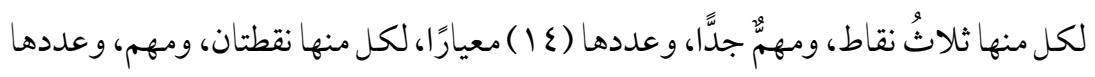
(1) معيارًا، لكل منها نقطة واحدة، وبهذا يكون المجموع الكلي للنقاط (10) نقطة، وهي: معايير مقدِّمة المقرر، ومعايير أهداف التعلم (الكفاءات)، ومعايير التقييم والقياس، ومعايير

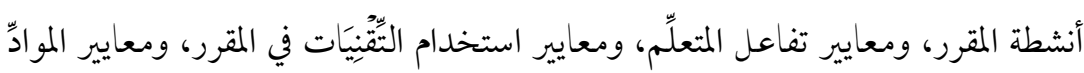
التعليمية، ومعايير إمكانية الوصول وسهولة الاستخدام، والجدول الآتي يوضحها: جدول يوضح معاييرQuality matters الرئيسة والفرعية مع النقاط

\begin{tabular}{|c|c|c|}
\hline 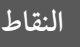 & الفئة & المعايير \\
\hline & & المعيار العام (1 ): التصميم العام للمقرر واضح للمتعلمين منذ بداية المقرر \\
\hline r & أساسي & 1- التعليمات توضح كيفية البدء في المقرر، ومكان وجود مكونات المقرر المتنوعة. \\
\hline r & أساسي & r - ا يتم تعريف المتعلمين باهدف الرئيس للمقرر وبنيته. \\
\hline r & مهم جداً & أدوات آداب وقو اعد سلوك استخدام الانترنت أثناء النقاشات الإلكترونية والبريد الإلكتروني وغيرها من \\
\hline$r$ & مهم جداً & ع - أويتم تزويد المتعلم برات المقرر / أو سياسات الجلكتعة التي يتوقع من المتعلم الالتزام بها منصوص عليها بكل وضوح \\
\hline r & مهم جداً & ه - ا الحد الأدنى من المتطلبات التكنولوجية واضح، مع تقديم التعليهات الضرورية لاستخدامها. \\
\hline 1 & 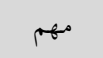 & 7 - 1 متطلبات التعلم السابقة من المعارف أو المهارات في مجال التخصص واضحة. \\
\hline 1 & مهم & V- الحد الأدنى من المهارات التقنية المتوقع أن يتقنها المتعلم لتجاوز المقرر بسهولة واضح. \\
\hline 1 & مهم & 1- ا استاذ المقرر يعرف نفسه بطريقة مناسبة مع إتاحة هذا التعريف داخل المقرر. \\
\hline 1 & مهtم & 9- ايُطلب من المتعلمين التعريف بأنفسهم لزملائهم. \\
\hline
\end{tabular}


Prof. Dr. Ahmad Mohammed Saad AL Hussein \& Dr. Noora Abdullah Hamad Al-Rasheed

Volume (4) No. (1) 2021

\section{النقاط}

الفئة

المعايير

المعيار العام (Y) : مخرجات التعلم: أهداف المقرر تصف ما سيكون المثعلم قادراً على فعله عند إنهائه للمقرر

\begin{tabular}{|c|c|c|}
\hline r & أساسي & 1 Y أهداف المقرر تصف خخرجات تعلم قابلة للقياس. \\
\hline$r$ & أساسي & التع-r أهداف المقرر علن مستوئ الوحدات تصف خخرجات تعلم قبلة للقياس ومتسقة مع الأهداف \\
\hline r & أساسي & r-r الأهداف التعليمية مصاغة بشكل واضح وتتمركز حول الطالب. \\
\hline$r$ & أساسي & ع-r العلاقة بين أهداف التعلم وأنشطة المقرر مصاغة بشكل واضح. \\
\hline$r$ & أساسي & ب- ب أهداف المقرر مصممة بشكل يتناسب مع مستوئ المقرر. \\
\hline
\end{tabular}

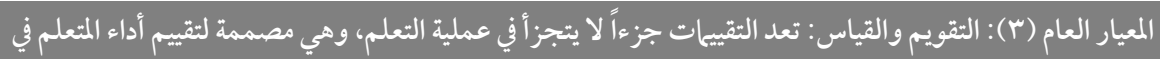

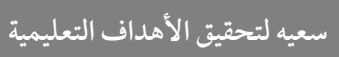

\begin{tabular}{|c|c|c|}
\hline$r$ & أساسي & r-1 تقيس وسائل التقييم مدئ تحقق الأهداف التعليمية المعلنة. \\
\hline$r$ & أساسي & r-r r سياسة رصد وتقدير الدرجات في المقرر واضحة. \\
\hline$r$ & أساسي & r-r معايير تقييم أداء المتعلمين ومشاركتهم محددة ومقننة ومرتبطة بسياسة تقدير الدرجات. \\
\hline$r$ & مهم جداً & ع - r اختيار أدوات تقييم منتظمة ومتنوعة وتناسب المهام التي يتم تقييمها. \\
\hline$r$ & مهم جداً & 0 - ب التقييات تتيح عدة فرص للمتعلمين لمعرفة مدئ تطور التعلم لديهم. \\
\hline & & المعيار العام (ع ) : تمكن المواد التعليمية المتعلمين من تحقيق الأهداف المعلنة \\
\hline r & أساسي & 1- ـ تساهم المواد التعليمية في تحقيق أهداف التعلم المعلنة على مستوئ المقرر وعلن مستوى الوحدات. \\
\hline r & 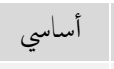 & r - ع يوجد شرح واضح للغرض من المواد التعليمية، و كيفية استخدامها في الأنشطة التعليمية. \\
\hline r & 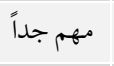 & r-ع جميع المواد والمصادر التعليمية المستخلمة في المقرر موثقة بشكل صحيح. \\
\hline$r$ & مهم جداً & ع - ع تتصف المواد التعليمية بالحداثة. \\
\hline r & مهم جداً & 0- ـ تتصف المو اد التعليمية المضمنة في المقرر بالتنوع. \\
\hline 1 & مهم & ح - ع يوجد شرح واضح لتمبيز المواد التعليمية المطلوبة والمواد التعليمية الاختيارية. \\
\hline \multicolumn{3}{|c|}{ المعيار العام (ه) : أنشطة المقرر وتفاعل المتعلم: أشكال التفاعل الموظفة في المقرر تسهل وتحفز المتعلمين على التفاعل } \\
\hline r & أساسي & 1-0 - تعمل الأنشطة التعليمية على تحفيز تحقيق أهداف التعلم المعلنة. \\
\hline r & 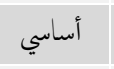 & r-o تقدم الأنشطة التعليمية فرص عديدة للتفاعل بما يدعم التعلم النشط. . \\
\hline r & أساسي & استجاب توجد خطة واضحة ومعلنة لتوقيت الرد علئ المتعلمين وتقديم التغذية الراجعة لما يقلمونه من \\
\hline$r$ & مهم جداً & ع -ه متطلبات تفاعل المتعلم معلنة وواضحة. \\
\hline
\end{tabular}




\section{المعيار العام (7) : تقنيات المقرر : تقنيات المقر رتعزز تحقيق المتعلم لأهداف المقرر}

\begin{tabular}{|c|c|c|}
\hline r & أساسي & 1-7 تدعم الأدوات المستخدمة في المقرر تحقيق الأهداف التعليمية. \\
\hline r & 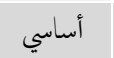 & ץ-7 تعزز الادوات المستخدمة مشاركة التعلم في المقرر وتدعم التعلم الفعال. \\
\hline r & مهم جداً & ب-7 يمكن للمتعلمين الوصول بسهولة إلى التقنية المطلوبة. \\
\hline 1 & مهt & ع -7 التقنيات المستخدمة في المقرر حديثة. \\
\hline 1 & 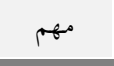 & ه-7 يتم توفير روابط سياسات الخصوصية لجميع الأدوات المضافة من خارج \\
\hline
\end{tabular}

المعيار العام (V) : دعم المتعلم: المقرر يحقق سهولة وصول المثعلم إلى خدمات الدعم الجامعي الأساسية اللازمة لنجاحه

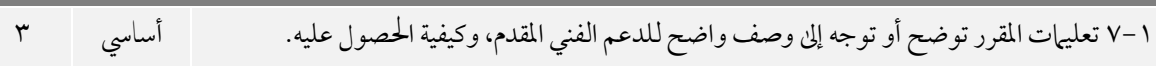

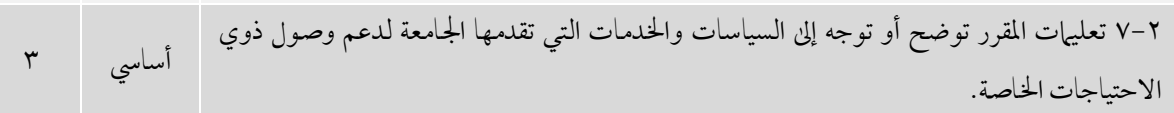

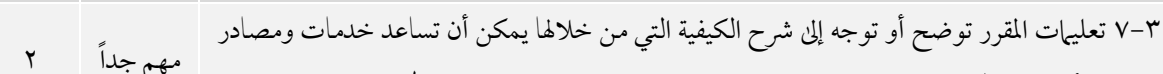
الدعم الأكاديمي الجامعي المتعلمين لتجاوز المقرر بنجاح وكيف يمكن للمتعلمين الحصول المعل عليها.

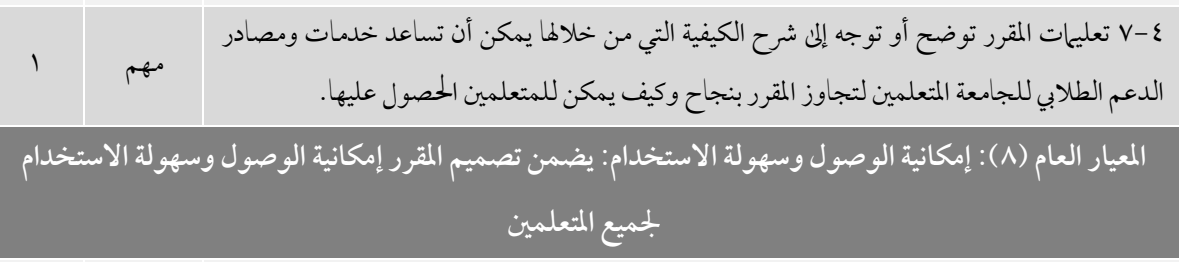

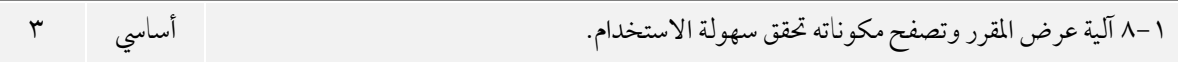

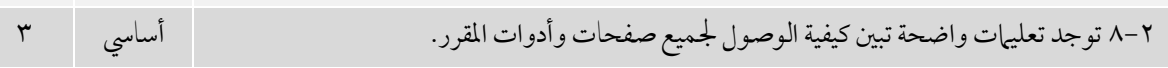

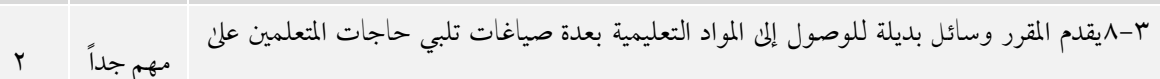

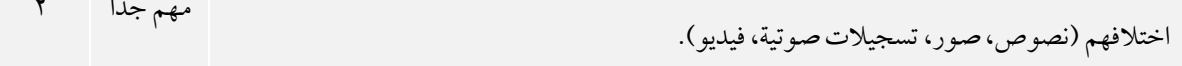

ع-1 الوسائط المضمنة في المقرر تحقق سهولة الاستخدام.

بـ- مرحلة التصميم: تشمل مرحلة التصميم العديد من المهامِّ التي يمكِن تنظيمها في وثائق تخطيط،

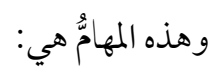

ا. بناء المحتوى الإلكتروني: من خلال المصادر السابقة التي اطلَّعت عليها الباحثة، تم تحديد مو ضوعات المقرر التي تساعد على تحقيق نواتج التعلم، وهي: 
Prof. Dr. Ahmad Mohammed Saad AL Hussein \& Dr. Noora Abdullah Hamad Al-Rasheed

Volume (4) No. (1) 2021

$$
\begin{aligned}
& \text { > الوَحدة الأولن: التقويم التربوي والتوجُهات الحميثة. } \\
& \text { > الوَحدة الثانية: التقويم الإلكتروني. }
\end{aligned}
$$

> الوَحُدة الثالثة: تصنيف التقويم علن ضوء نتائج التعلم: تقويم نو اتج التعلم المعرفية.

$$
\begin{aligned}
& \text { > > اوَحُدة الرابعة: تقويم نواتج التعلم المهارية. } \\
& \text { > الوَحُدة الخامسة: تقويم نواتج التعلم الوجدانية. }
\end{aligned}
$$

وتشمل مرحلة التصميم لبناء المحتوئ الإلكتروني بجموعةً من العناصر، وهي كالتالي:

المقدِّمة: وفيها الفكرة العامَّة عن المقرر، ومتطلباته التقنية، وقواعد وآداب استخدامه، وكيفية دراسته، والسيرة الذاتية لأستاذة المقرر، كحا تشتمل علن توصيف للمقرر الذي يشتمل علن بيانات المقرر، ونو اتج التعلم العامة والخاصة بكل وحدة، وقائمة بموضوعاته، و إستراتيجيات التدريس، وأساليب التقويم، وتقسيم الدرجات، والبرامج التقنية المستخدمة في المقرر، ومصادر التعلم. م تحديد البنية المفاهيمية للمحتوىن: بعد مراجعة المراجع الأصيلة والحديثة، والدراسات السابقة التي تناولت التقويم الإلكتروني، وتوصيفات مقرر التقويم التربوي في الجامعات الأمريكية، وآراء بعض المختصِّين في مجال التقويم التربوي، حلَّدت الباحثة أبرز المهارات المعرفية والمهارية التي يُتطلَّب إتقانها من طالبات كلية التربية بجامعة الملك سعود. اختيار التسلسل الأفضل للمحتوىن ونشاطاته: تم تصميم محتوئ المقرر علن هيئة وحدات تعلم صغيرة، فقد صمَّمت الباحثة (0) وَحَدات تعليمية، اشتملت علن أنشطة ومههات أدائية تساعد

$$
\text { عملية التعلم، وراعت الباحثة تنظيم المحتوئ بناءً علن: }
$$
- المدخل المنطقي: الذي يركّز علن المادة العلمية وتسلسلها وترابطها، ويناسب المتعلمات؛ لأنه

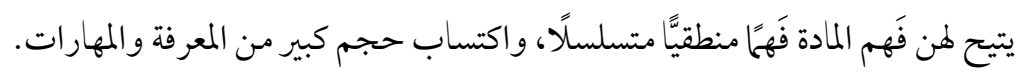
- المدخل الوظيفي: الذي يركّز علن تحقيق التكيُّف بين الإنسان والوسط الذي يعيش فيه، من خلال المعرفة وتطبيقاتها في الو اقع الذي يعيشه المتعلم، من خلال إيحانه بأن المعرفة ستظلّ قليلةً

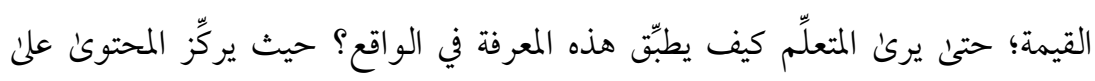


موضوعات توفِّر للطالبة اكتساب مهارة تمكِّها من تطبيقها في التدريس. أما الأنشطة، فقد صممت نهاية كل مادة علمية، وبطريقة متسلسلة منظَّمة، تبعًا لتسلسل نو اتج التعلم. تحديد الإستراتيجيات التعليمية: تنوَّعت الاستراتيجيات التي تربط بين النظرية والتطبيق،

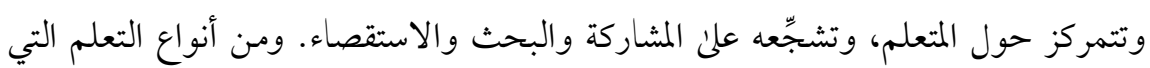
تناسب المقرر: - n

م التعلُّم الذاتيّ: وذلك من خلال تعلم الطالبة قبل المحاضرة في بيئة التعلم الإلكتروني، عن طريق الملفات المعروضة، وعروض البَوَربوينت، ومقاطع الفيديو. م التعلم التعاونيّ: من خلال مشاركة الطالبة زميلاتها في عملية التعلم.

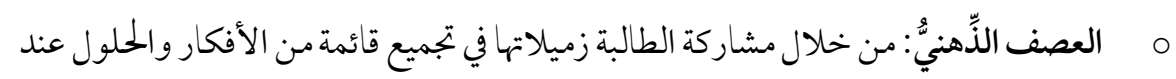
الإجابة على الأنشطة.

م التعلم التأمّليٌّ: من خلال التأمُّات الذاتية التي تتعلَّمها في بيئة التعلم الإلكتروني (بلاك بورد)، ومن خلال تأمُّات الطالبة في ملف الإنجاز.

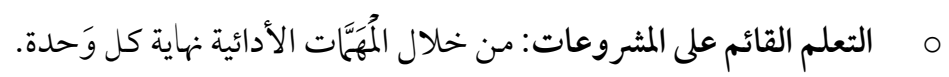
وفي هذه المرحلة، تم تحديد أسلوب سير عملية التعليم والتعلم، التي تتضمن أربعَمر احلَ رئيسةٍ، هي: م عرض المعارف و المعلومات؛ ليطَّلع عليها الطالبات في منازلهن، أو في أي مكان آخر، باستعمال حواسيبهن، أو هواتفهن الذكية، أو أجهزتهن اللوحية، قبل المحاضرة بوقت كافٍ. م توجيه وإرشاد الطالبات أثناء عملية التعلم في البيئة الإلكترونية، والقاعة. م تلخيص أبرز الأفكار الرئيسة في القاعة الدراسية، ومناقشة الطالبات فيها، وتطبيق ما تم

$$
\text { م التعلُّه في البيئة الإلكترونية من خلال الأنشطة والتدريبات و المشاريع. }
$$


Prof. Dr. Ahmad Mohammed Saad AL Hussein \& Dr. Noora Abdullah Hamad Al-Rasheed Volume (4) No. (1) 2021

كما تم تحديد إستراتيجيات ما قبل التدريس: التي تَهُدف إلى تهيئة الطالبة لتعلم المهارات والمعرفة المطلوبة، ومن هذه الاستراتيجيات: أسئلة قبلية لرفع وعي الطالبة بالمحتونى، ونواتج تعلم محَّدة لإشعار الطالبة بدقة ما هو متوقَّع منها، ومقدِّمة لتهيئة الطالبة لمهامّ التعلم. تحديد وسائل عرض المحتوىن: عرض المحتون من خلال ملفات pdf، وعروض البوربوينت، والمواد الإثرائية، ومقاطع الفيديو، و الوسائط الأخرىن. تحديد دور الطالبة: تشارك الطالبة في دراسة المقرر من خلال قراءتها الذاتية لمحتوئ المقرر، ومشاركتها في قاعة التدريس، من خلال الأنشطة والتطبيقات، وفي تنفيذ متطلبات المقرر، و المناقشات في منتدى البلاكك بورد. تحديد نمط التفاعل بين الأستاذ الجامعي ويين الطلاب: اختارت الباحثة التفاعلات الثلاثة الرئيسة في نظم التعلم الإلكتروني، وهي: > تفاعل الطالبة مع المحتوى: من خلال تقديم المواد الدراسية بصيغ متعدِّة من ملفات نَصِّية وفيديو. تفاعل الطالبة مع الطالبات: من خلال توفير الاتصال بينهن، من خلال المناقشات في المنتدى'. > تفاعل الطالبة مع أستاذة المقرر: يكون التفاعل في القاعة من خلال تقديم تغذية راجعة حول الأنشطة والاختبارات والمشاريع، و الساعات المكتبية التي تحدِّدها الأستاذة. تحديد أسلوب التقويم: استخدمت الباحثة أساليبَ وأدواتِ متعدِّدةً للتقويم، وهي: م التقويم التشخيصي: باستخدام أدوات الدراسة كتقويم ذاتيٍ قبل كل وحدة تعليمية؛

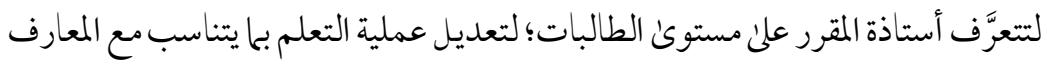
والمهارات التي تمتلكنها. م التقويم التكويني: ويتمثَّل في المناقشات من خلال بيئة التعلم، أو في القاعة الدراسية، وفي الأنشة التي تقدَّم للطالبات في بيئة التعلم أو في المحاضرة، ومن أبرز الأدوات 
المستخدمة في المقرر المقترح: (التقويم الذاتيّ، ملف الإنجاز الإلكتروني، تقويم الأقران،

خر ائط المفاهيم، الاختبار ات الإلكترونية القصيرة، المتتدى).

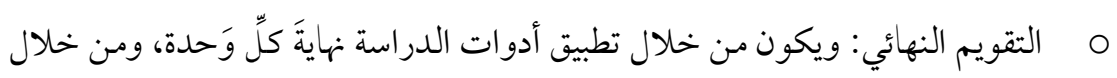

$$
\text { تقويم المُهََّّات الأدائية. }
$$

ت- مرحلة التطوير: تشتمل هذه المرحلة على:

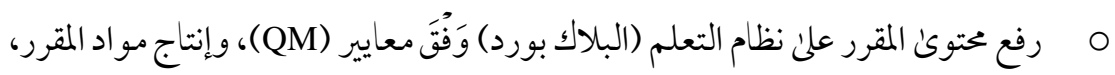

$$
\text { و والوسائط المتعدِّدة. }
$$

م تحديد سيناريو للمقرر: يتمثَّل في إتاحة الفرصة للطالبة أن تتنقل بين مكوِّنات المقرر بطريقة تحقِّق لها الاستفادة المِثالية، فقسَّمت الباحثة قائمة التنقّل في نظام إدارة التعلم

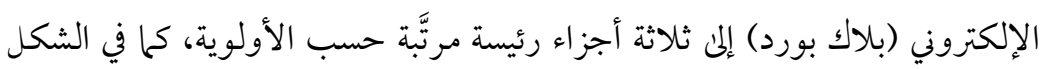

التالي:

$$
\text { شكل (r-r ) يوضح التنقل في نظام بلاك بورد }
$$

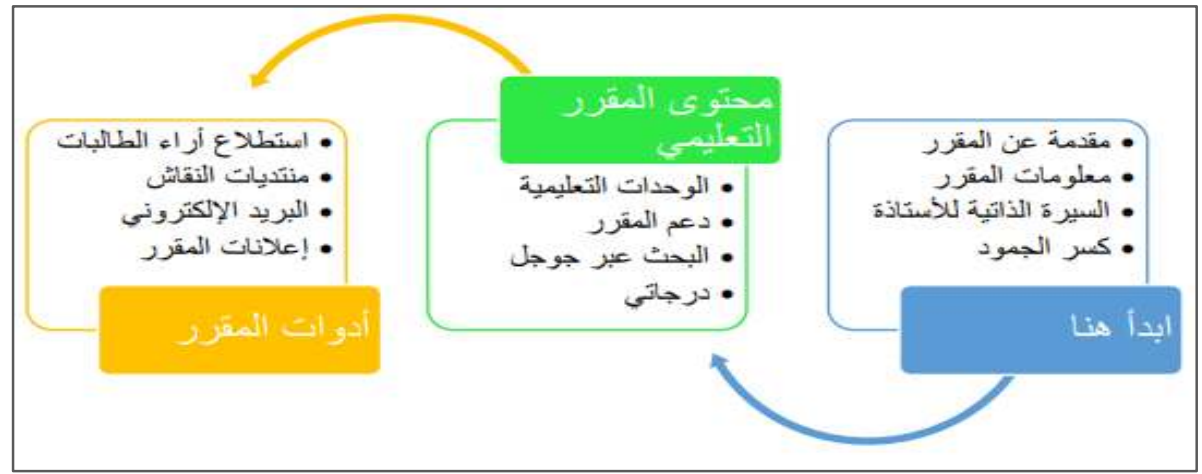

قُصِد من هذا التقسيم أن تبتدئ الطالبة بأخذ فكرة عامة عن المقرر، وأخذ فكرة تفصيلية عنه، وعن أستاذة المقرر، ثم تقدِّم نفسها لبقية الطالبات، وتتعرف عليهن؛ لخلق جوِّ من الألفة بين الطالبات

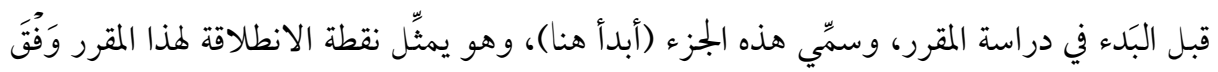
معايير (QM)، ويشتمل علن التفاصيل التالية: 
Prof. Dr. Ahmad Mohammed Saad AL Hussein \& Dr. Noora Abdullah Hamad Al-Rasheed

Volume (4) No. (1) 2021

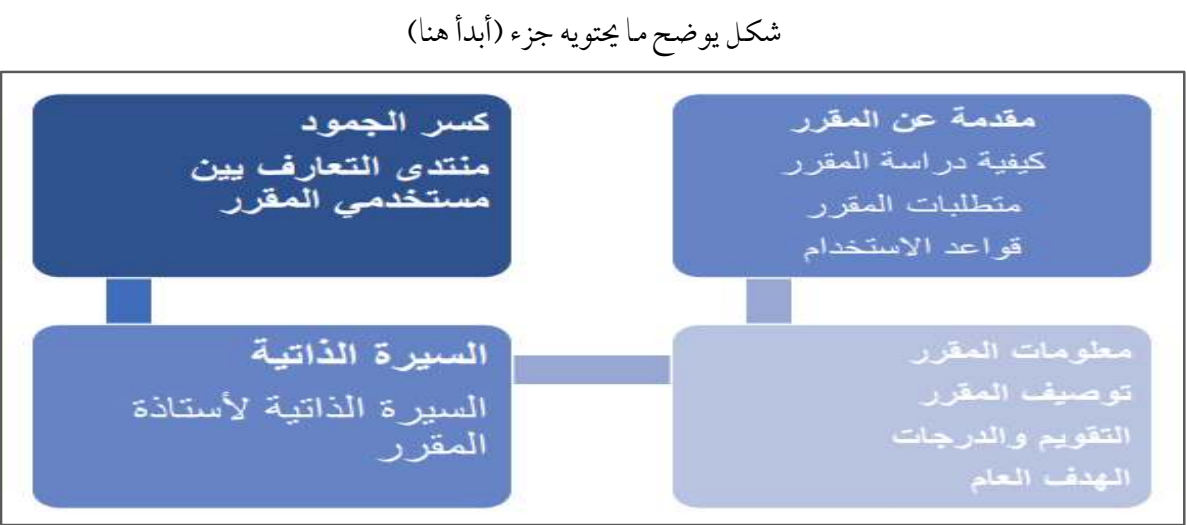

ويشمل الجزء الثاني من المقرر (المحتوئ التعليمي) للمحادة، حيث يحوي خختلف الموارد التعليمية، والمو اد الإثرائية، والأنشطة التطبيقية التي رتِّت بطريقة تمكِّن الطالبة من الانتقال التدريجي بين مكوّنّات

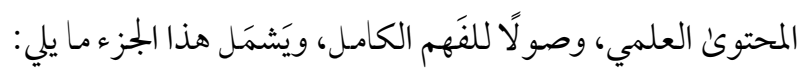
شكل يوضح متويات المقرر

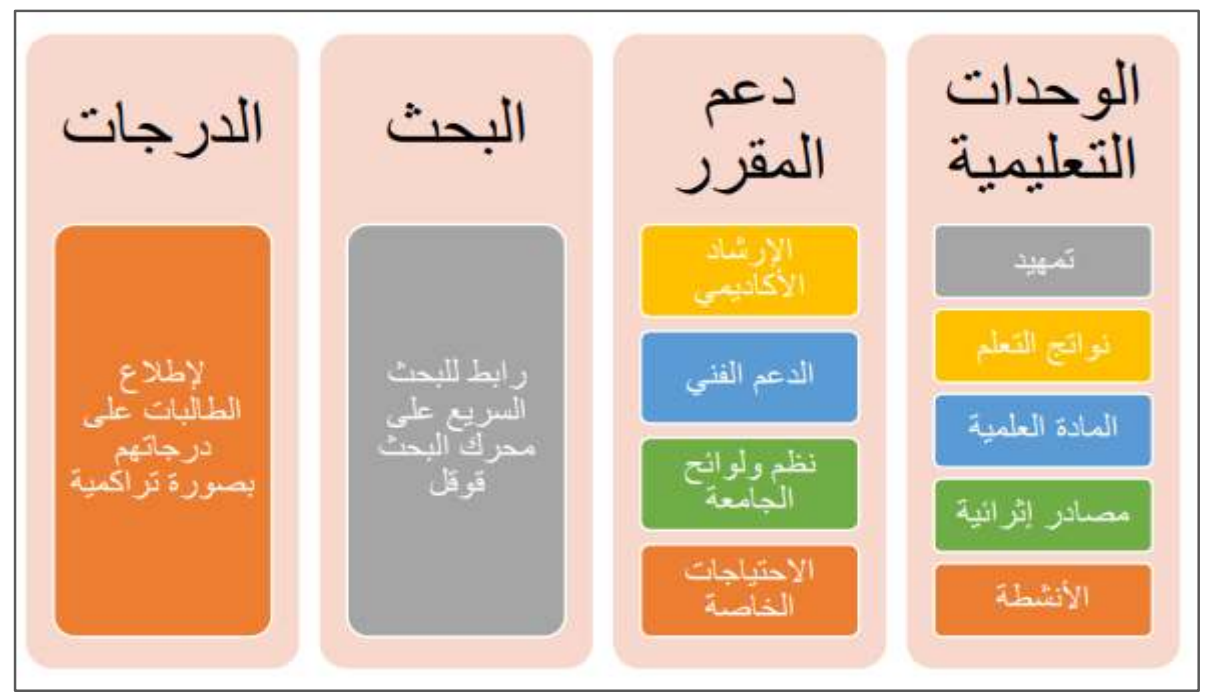

http://dx.doi.org/10.29009/ijres.4.1.9 
ويقدّم الجلزء الأخير من هذا المقرر أدواتِ لتقييم المقرر، وتسهيل التو اصلل مع أستاذة المقرر،

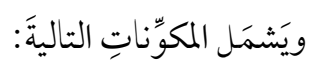

شكل يوضح اساليب التقويم المتبعة في المقرر

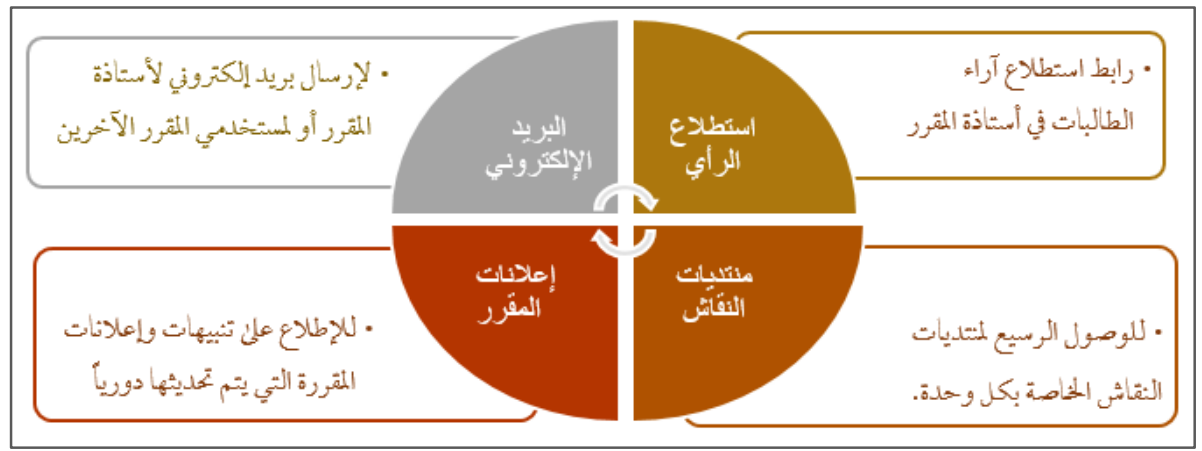

يُتوقَّع من الطالبات تحقيق الاستفادة الكاملة عند اتِّباع السيناريو المصمَّم لتصفُّح هذا المقرر،

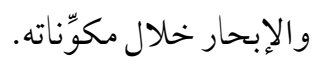

O مع مكونات المقرر، قبل البدء بتنفيذه. ث- مرحلة التنفيذ: في هذه المرحلة تم تجريب المقرر علن عدد من الطالبات؛ للتأكّدّ من سهولة

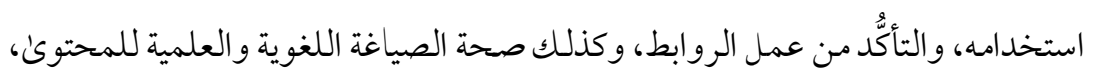

$$
\text { وترتيب الخطو ات، واتخاذ القرارات الملائمة لتعديلها. }
$$

ج- مرحلة التقويم: اشتملت هذه المرحلة علن: - عرض محتوى المقرر على عدد من المحكِّمين؛ للتأكَّد من مناسبته لطالبات كلية التربية

$$
\text { بجامعة الملك سعود. }
$$

-

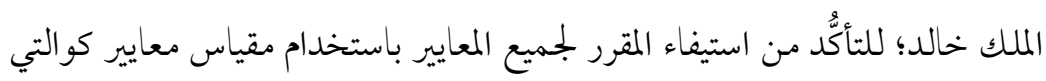

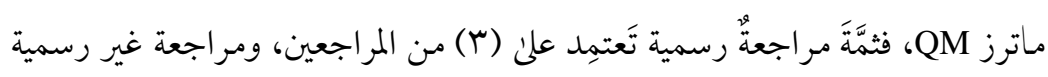

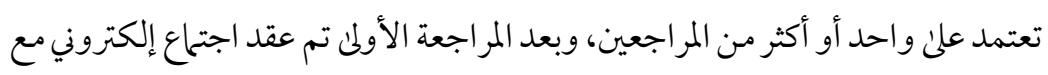
الأعضاء المراجعين للمقرر؛ لشرح ملاحظاتهم حوله، فتبين أن المراجعة تمت في ضوء 
Prof. Dr. Ahmad Mohammed Saad AL Hussein \& Dr. Noora Abdullah Hamad Al-Rasheed Volume (4) No. (1) 2021

معايير الطبعة السادسة، وهي أحدث من الطبعة التي بني عليها المقرر، لذا؛ تم تعديل جميع الملاحظات التي وردت من لجنة المراجعة حتى يتم مو ائمته مع المعايير، وقد جاءت أبرز ملاحظاتهم علن النحو التلاي: ربط كل شريحة من شرائح البوربوينت بنواتج التعلم العامة والخاصة.

$$
\begin{aligned}
& \text { • تحديد معايير تقويم الأنشطة وأوراق العمل. } \\
& \text { وضع وصف مبسَّط عن روابط الدعم الفني. } \\
& \text { توظيف الفصل الافتراضي في المقرر. }
\end{aligned}
$$

مع إعطاء الباحثة مدة زمنية لتعديل هذه الملاحظات، ورفعها مرة أخرى للمر اجعين؛ للتأكُّد

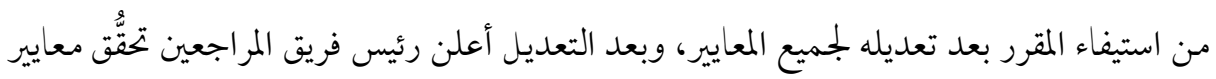
كو التي ماترز في المقرر المقترح، ويوصي برفعه لمنظمة كو التي ماترز لاعتهاده. ثانياً: الإجر اءات اللازمة للإجابة عن السؤال الثاني: ما فاعليَّة مقَّرّر التقويم التربوي المقترح في تنمية طالبات كلية التربية في الجوانب المعرفية لمهارات التقويم الإلكترونيّ بجامعة الملك سعود؟ لقياس فاعلية المقرر في تنمية الجوانب المعرفية لدنا طالبات كلية التربية - عيّة الدراسة بجامعة الملك سعود؛ تم استخدام المنهج شبِ التجريبي ذي التصميم (القَبلي/ البَعدي) للمجموعة

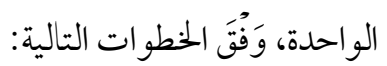
أولًا: تحديد أهم الجوانب المعرفية للتقويم الإلكتروني: تم تحديد أهم الجو انب المعرفية للتقويم الإلكتروني في مرحلة تصميم محتون المقرر، وعرضها للمختصِّين في بجال المناهج وطرق التدريس، وبجال التقويم و القياس؛ لأخذ رأههم وملاحظاتهم حولها، حتى ظهرت قائمة بأهم المهارات المعرفية للتقويم الإلكتروني. ثانيًا: بناء الاختبار: بعد تحديد الجوانب المعرفية، قامت الباحثة ببناء اختبار يقيس الجوانب المعرفية

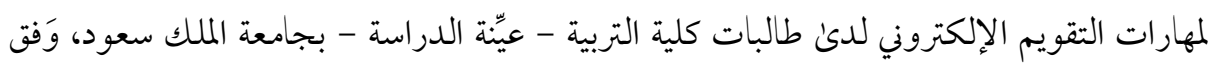
الخطوات التالية: (تحديد الهدف من الاختبار، إعداد جدول المواصفات، صياغة مفردات الاختبار، بناء 
مفتاح لتصحيح الاختبار، تعليات الاختبار، صدق وثبات الاختبار، التجريب الاستطلاعيٌ لالاختبار).

ثالثًا: الإجراءات اللازمة للإجابة عن السؤال الثاني: ما فاعليَّةُ مقرَّرِ التقويم التربوي المقترح في تنمية طالبات كليَّة التربية في الجوانب المهارية لمهارات التقويم الإلكترونيّ بجامعة الملك سعود؟ مرَّت عملية الإجابة عن هذا السؤال بعدَّة مر احلَ يمكِن إجماها في التالي: أولاًا: تحديد قائمة المهارات المهارية: قامت الباحثة بتحديد أهمّ الجوانب المهارية للتقويم الإلكتروني في

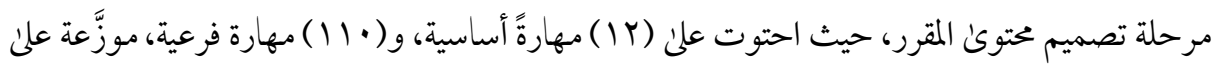
ثلاث بطاقات ملاحظة.

ثانيًا: بناء بطاقة الملاحظة: بعد بناء قائمة المهارات المهارية، قامت الباحثة ببناء ثلاث بطاقات ملاحظة؛

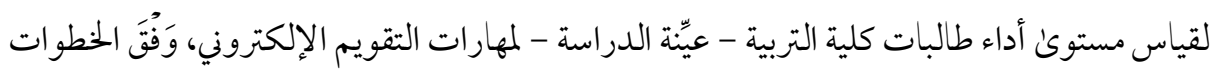
التالية:

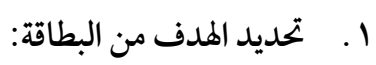

م بطاقة الملاحظة الأولى: هدفت هذه البطاقة إلى قياس مستوئ أداء طالبات كلية التربية بجامعة الملك سعود - عيّنة الدراسة - لمهارات الاختبار الإلكتروني.

م بطاقة الملاحظة الثانية: هدفت هذه البطاقة إلى قياس مستوى أداء طالبات كلية التربية بجامعة الملك سعود - عيّنة الدراسة - لمهارات ملف الإنجاز الإلكتروني. م بطاقة الملاحظة الثالثة: هدفت هذه البطاقة إلى قياس مستوى أداء طالبات كلية التربية بجامعة الملك سعود - عيِّة الدراسة - لمهارات الاستبانة الإلكترونية.

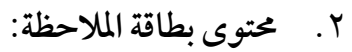
م بطاقة الملاحظة الأولى: أَعَدَّتِ الباحثة بطاقة ملاحظة للاختبارات الإلكترونية، حيث تتكوَّن البطاقة من (ع 7) مهارةً فرعية للأداء، وهذه المهارات الفرعية تقيس (ع ) مهارات

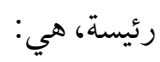


https://www.classmarker.com -

$$
\text { وتتكوَّن من (r) مهارات فرعية. }
$$

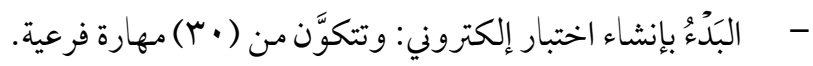

$$
\begin{aligned}
& \text { - إضافة الطالبات: وتتكوَّن من (0) مهارات فرعية. } \\
& \text { - نشر الاختبار: وتتكوَّن من (Y (Y) مهارةً فرعية. }
\end{aligned}
$$

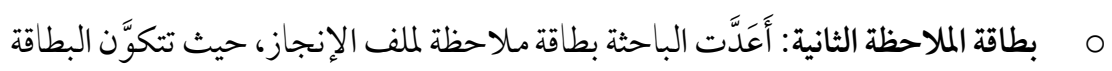
من ( · ( ) مهارةً فرعية للأداء، وهذه المهارات الفرعية تقيس (ع) مهارات رئيسة، هي: - الدخول إلى تطبيقات جوجل عبر الرابط http://sites.google.com وتتكوَّن من

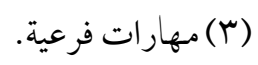

$$
\text { - - - م إنشاء ملف الإنجاز الإلكتروني: وتتكوَّن من ( • ) مهارات فرعية. }
$$

- شر ملف الإنجاز : وتتكوَّن من مهارة فرعية واحدة فقط.

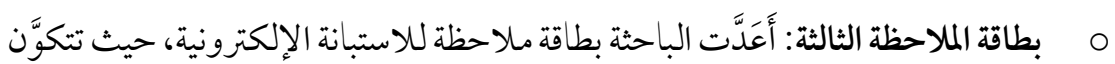
البطاقة من (Y Y ) مهارة فرعية للأداء، وهذه المهار ات الفرعية تقيس (ع ) مهارات رئيسة،

- - الدخول إلى تطبيقات جوجل عبر موقع docs.google.com: وتتكوَّن من (0)

$$
\begin{aligned}
& \text { مهارات فرعية. } \\
& \text { - - } \\
& \text { - شر الاستبانة: وتتكوَّن من (r) مهارات فرعية. } \\
& \text { - معايير خاصة بالاستبانة: وتتكوَّن من (ع ) مهارات فرعية. }
\end{aligned}
$$




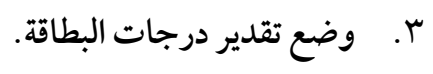

ع. تعليهات بطاقة الملاحظة: تم مراعاة توفير تعليهات لبطاقات الملاحظة، بحيث تكون واضحةً

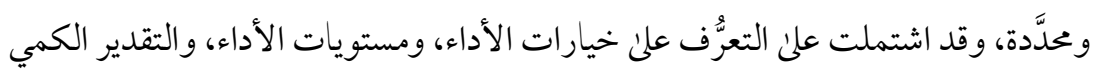

لكل مستوىن.

هـ ضبط بطاقة الملاحظة: ويُقصَد بها التحقُق من صدق البطاقة وثباتها، وقد تم التحقُق منها بعرضها علن (9) من المحكّمين والمختصِّين؛ بهدف أخذ ملاحظاتهم وآرائهم حول إمكانية

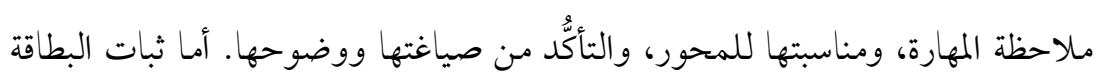
الملاحظة، من خلال ملاحظة الباحثة وأستاذة المقرر لأداء ( V) طالبة من طالبات كلية التربية

$$
\text { بجامعة الملك سعود }
$$

رابعًا: تطبيق تجربة الدراسة: بعد أن أصبح المقرر المقترح وأدواته جاهزًا للتطبيق الميداني، قامت الباحثة برفعه للقسم؛ للحصول علن الموافقة الر سمية؛ لتتمكَّن من تطبيق الدرا سة، التي ا ستغرقت شهرين كاملين، بواقع ساعة في القاعة الدرا سية، و ساعتين في نظام التعلم الإلكتروني (البلاك بورد) من كل أسبوع. مناقشة النتائج: عرض ومناقشة نتائج السؤال الأول، ونصُّه: ما التصميمُ المقترَح لمقرَّر إلكترونيِّ للتقويم التربويِّ في ضوء معايير كو التي ماترز (Quality Matters)؟ للإجابة عن هذا السؤال؛ قدَّمت الباحثة في الفصل الثالث عرضًا مفصَّلًا لخطو ات تصميم

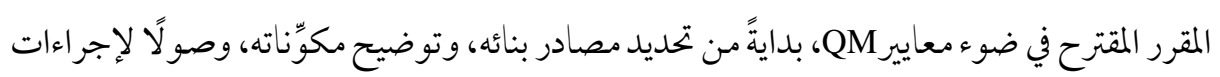
ضبطه، وصلاحيته للتطبيق على عيّّة الدراسة. عرض ومناقشة نتائج السؤال الثاني، ونصُّه: ما فاعليةٌ مقرَّرِ التقويم التربوي المقترح في تنمية طالباتِ كلية التربية الجوانبَ المعرفية، لمهارات التقويم الإلكترونيّ بجامعة الملك سعود؟ 
للتمكُّن من الإجابة عن السؤال الثاني؛ تم فرض فروض موجَّهة، وباختبار صحتها يمكِن الإجابة عنه،

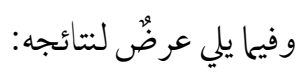

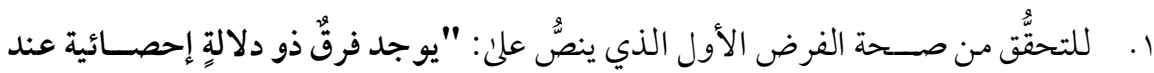

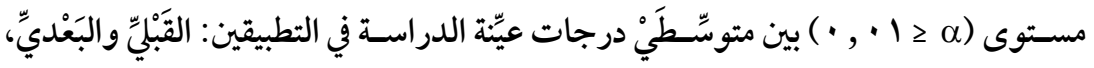
للاختبار التحصيليّ للجانب المعرفيّ، لمهارات التقويم الإلكترونيّ"؛ تم استخدام: اختبار (ت) Paired-Samples T-test للعيّنتين المرتبطتين.

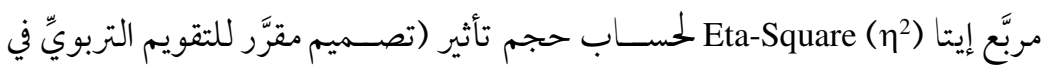
ضوء معاييرِ (Quality Matters) في تنميَّة الجحانب المعرفيّ، لمهارات التقويم الإلكتروني، لمقرر التقويم التربوي.

ولحساب فاعلية (تصميم مقرَّر للتقويم التربويٍ في ضوء معاييرِ (Quality Matters)) في تنمية الجانب المعرفيّ، لمهارات التقويم الإلكتروني، لمقرر التقويم التربوي؛ تم حساب

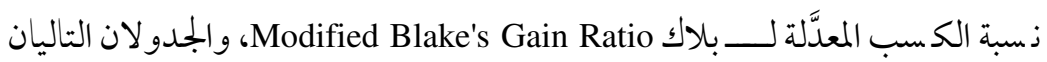

$$
\text { يوضِّحان نتائج هذا الفرض: }
$$

جدول يوضح مربَّع إيتا ونتائج اختبار (ت) لدلالة الفرق بين متوسِّطَّ درجات عيِّة الدراسة (المجموعة التجريبية) في

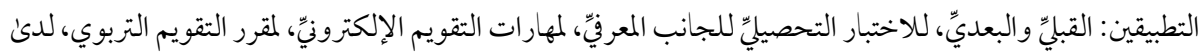

\begin{tabular}{|c|c|c|c|c|c|c|}
\hline \multirow{2}{*}{ مربع إيتا } & \multirow{2}{*}{ قولالتهة (ت) } & \multicolumn{2}{|c|}{ التطبيق البعدي } & \multicolumn{2}{|c|}{ التطبيق القبلي } & \multirow[b]{2}{*}{ المتغـــير } \\
\hline & & الانحر اف & المتوسط & المعياري & المتوسط & \\
\hline$\cdot, 90 \mathrm{Vr}$ & $* * r \cdot, r r$ & $1, \varepsilon_{0}$ & $r \cdot, o v$ & $\varepsilon,{ }_{\Lambda}$ & $11,7 \varepsilon$ & التقويم الإلكتروني لمقرر التقويم التربوي \\
\hline
\end{tabular}
طالبات كلية التربية بجامعة الملك سعود (ن= r ع ) 


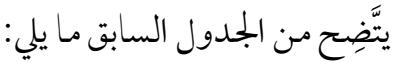

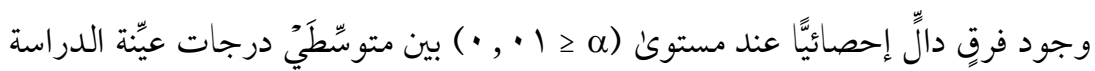

(المجموعة التجريبية) في التطبيقين: القبليٍ والبعديّ، للاختبار التحصيليِ للجانب المعرفيّة،

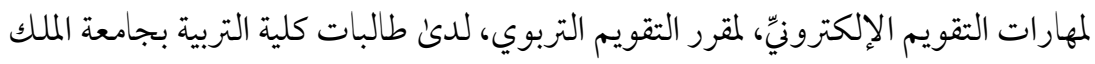

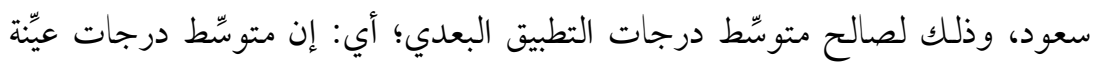
الدراسة (المجموعة التجريبية) في التطبيق البعدي للاختبار التحصيلِّ للجانب المعرفيّ،

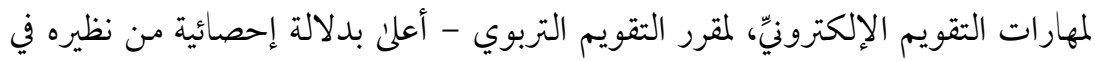

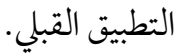

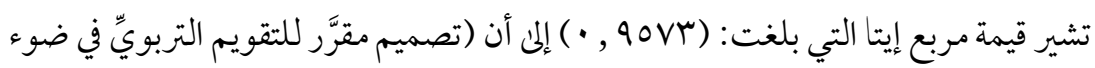

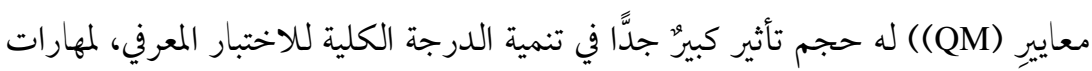

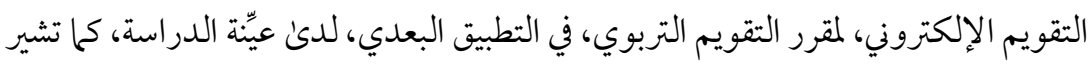

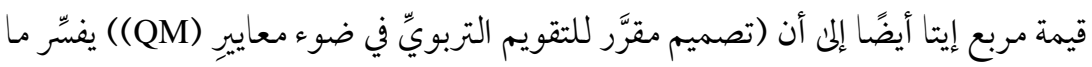

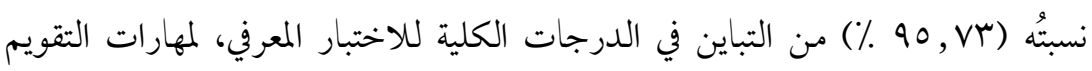
الإلكتروني، لمقرر التقويم التربوي، في التطبيق البعدي، لدني عيّة الدراسة (المجموعة

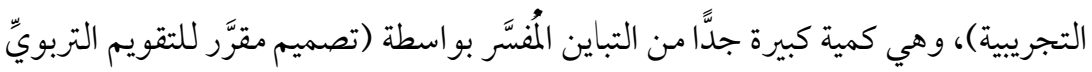
في ضوء معايير (QM))، لدئ عيّة الدراسة من طالبات كلية التربية بجامعة الملك سعود. ويوضح الشكل الآتي متوسطي درجات عيّنة الدِّراسة (المجموعة التجريبية) في التطبيقين

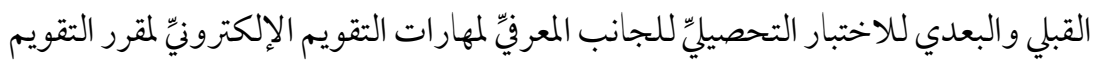

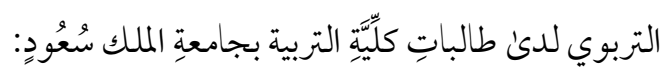


Prof. Dr. Ahmad Mohammed Saad AL Hussein \& Dr. Noora Abdullah Hamad Al-Rasheed Volume (4) No. (1) 2021

شكل يوضح متو سطا درجات عيّّة الدِّراسة في التطبيقين القبلي والبعدي للاختبار التحصيليّ للجانب المعرفيّ لمهارات

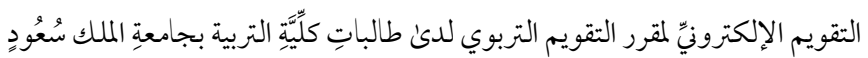

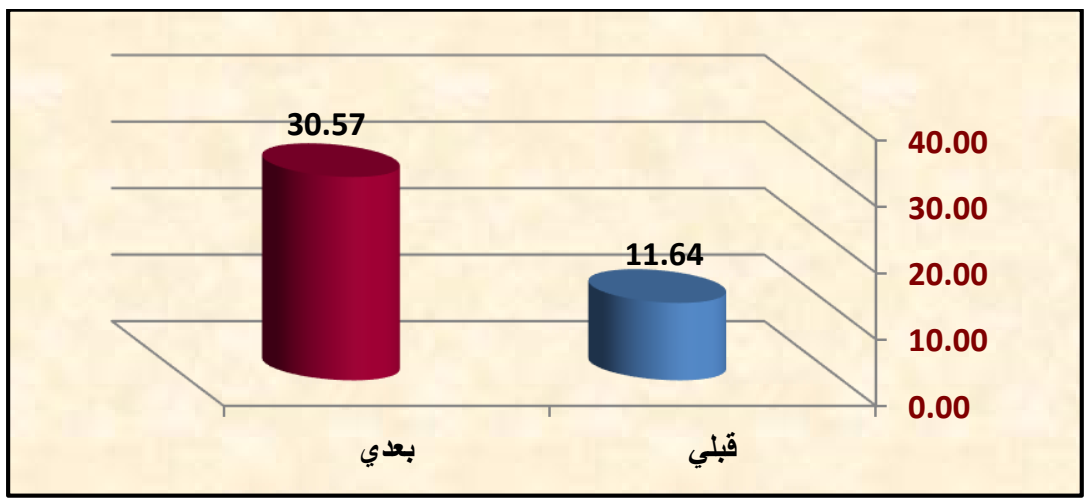

جدول يوضح نسبة الكسب المعدَّلة لـ بلاك، ونسبة الكسب المصحَّحة لـ عزت، عند دراسة الفرق بين متوسِّطي درجات المجموعة التجريبية في التطبيقين: القبليّ والبعديّ، للاختبار المعرفي، لمهارات التقويم الإلكتروني، لمقرر التقويم التربوي، لدئ طالبات كلية التربية بجامعة الملك سعود (ن = ع ع )

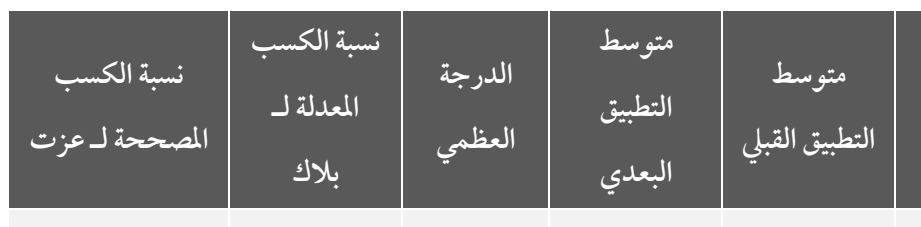

\begin{tabular}{|c|c|c|c|c|c|}
\hline$r, 1 \varepsilon$ & 1 , or & ru & $r \cdot, o v$ & $11,7 \varepsilon$ & لمهارات التقويم الإلكتروني \\
\hline
\end{tabular}

يتَّضِح من الجمدول السابق ما يلي:

• أن قيمة نسبة الكسب المعدلة لـبلاكك في حالة الدرجة الكلية للاختبار المعرفي، لمهارات التقويم

الإلكتروني، لمقرر التقويم التربوي - بلغت ( r ه , ) )، وهي قيم أكبر من القيمة (r , I ) التي

اقترحها بالك للحكم على فاعلية البرنامسج؛ مما يشير إلى أن (تصميم مقرَّر للتقويم التربويِّ في ضوء معاييرِ (QM) فعَّال في تنمية الجحانب المعرفي، لمهارات التقويم الإلكتروني، لمقرر التقويم التربوي، لدى' عيّنة الدراسة من طالبات كلية التربية بجامعة الملك سعود. 
• أن قيمة نسبة الكسب المعدلة لـ بلاك في حالة الدرجة الكلية للاختبار المعرفي، لمهارات التقويم

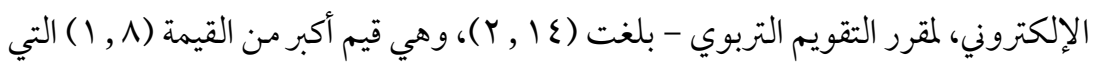

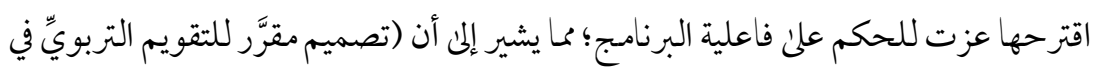

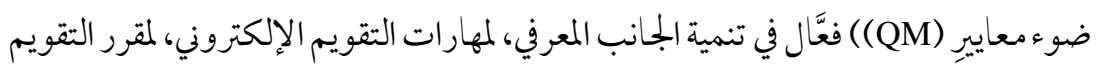

$$
\text { ومن إجماليّ نتائج الفرض التربئ عيّنة الدراسة من طالبات كلية التربية بجامعة الملك سعود. }
$$

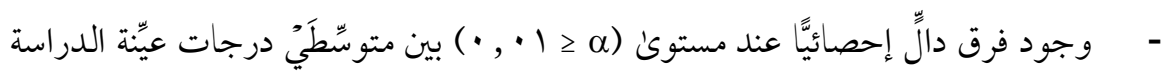
(المجموعة التجريبية) في التطبيقين: القبليّ والبعديّ، للاختبار التحصيليّ للجانب المعرفيّ، لمهارات التقويم الإلكترونيّ، لمقرر التقويم التربوي، لدى طالبات كلية التربية بجامعة الملك سعود، وذلك لصالح متوسّط درجات التطبيق البعديّ. - أن (تصميم مقرَّر للتقويم التربويِّ في ضوء معابيرِ (QM)) له حجم تأثير كبيرٌ جدًّا في تنمية الدرجة الكلية للاختبار المعرفي، لمهارات التقويم الإلكتروني، لمقرر التقويم التربوي في التطبيق البعدي، لدىن عيّنة الدراسة التجريبية من طالبات كلية التربية بجامعة الملك سعود. - - أن (تصميم مقَّر للتقويم التربويٍ في ضوء معاييرِ (QM)) فعَّل في تنمية الدرجة الكلية

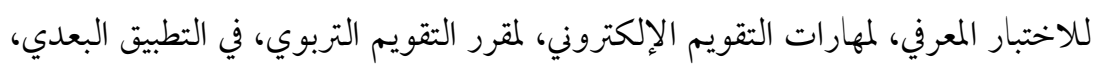
لدىن عيّة الدراسة التجريبية من طالبات كلية التربية بجامعة الملك سعود. مناقثة نتائج السؤال الثاني: بيَّنت النتائج المستخلَصة فعالية المقرر المقترح للتقويم التربوي في تنمية مهارات التقويم الإلكتروني من الجانب المعرفي، لدىن طالبات كلية التربية بجامعة الملك سعود.

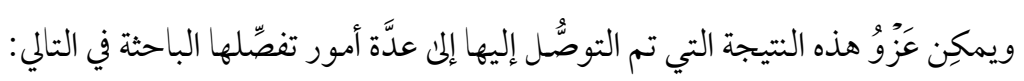
تصميم المقرر وَفُقَمعايير كو التي ماترز (QM)؛ فالمقر رات الإلكترونية عمومًا تساعد الطالباتِ

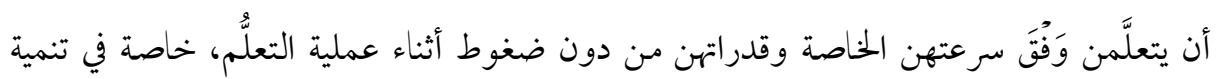

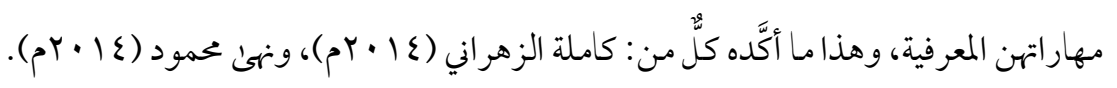


Prof. Dr. Ahmad Mohammed Saad AL Hussein \& Dr. Noora Abdullah Hamad Al-Rasheed Volume (4) No. (1) 2021

تصميم المقرر الإلكتروني بطريقة عكسية (مقلوب) ساعد الطالباتِ كثيرًا في عملية التعلُّم،

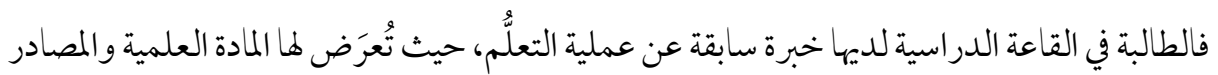

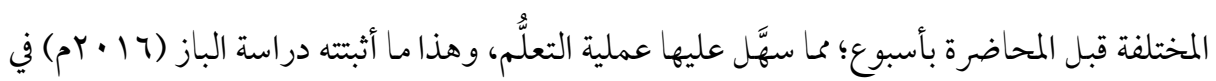
أن المقرر الإلكتروني المقلوب بوسائطَ متعدِّدةٍ وأنشطة ومَهَّات ساعدت الطلاب المعلِّمين على التعلُّم أثناء الحضور في القاعة الدراسية بدلًا من إلقاء محاضرة نظرية، حيث كان وقت المحاضرة مخصَّصًا لإجراء التكليفات والمُهَّات التشاركية عبر الإنترنت. كما أن معايير كو التي ماترز (QM) تُعَدُّ من الأمور المهمَّة والأساسية التي ساعدت الطالباتِ علنى رفع مستو اهن التحصيلي في مهارات التقويم الإلكتروني؛ فالمعايير جعلت بيئة التعلُّم في البلاك بورد

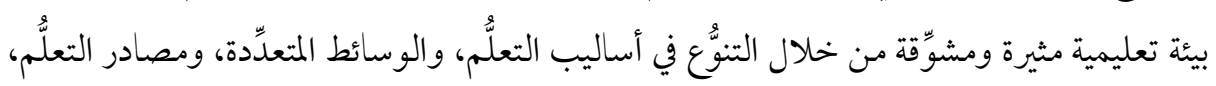
وأساليب التقويم. ووفَّرَت للطالبات القواعدَ والكيفية المناسبة لدراسة المقرر، مع النتيجة والمقابل من فئن الأنشطة والمُهََّّات الأدائية والاختبار وات؛ مما دفعهن إلى التعامل معه بكل جِدِّ واجتهاد. كما وفَّرت كل ما تحتاجه الطالبة لأنشطة المقرر، من أيقونة للبحث في قوقل؛ حتى تستطيع البحث في مصادر التعلُّم المختلفة، ومكتبة الجحامعة؛ للحصول على المصادر الموثوقة من رسائلَ علميةٍ

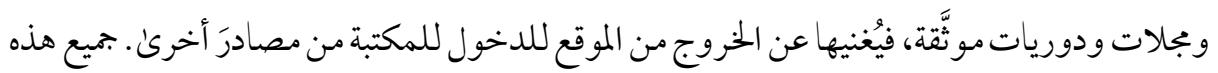
المميزات التي وفَّرتها المعايير ساعدت علن رفع الجانب المعرفي لدنئ الطالبات، وهذا مـا أكَّدته دراسة

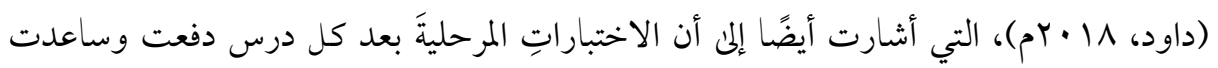
الطلاب إلى تحصيل أكبر قدر من المعلومات. كما أشارت دراسة سوان وآخرين (Swan, et al (2010)

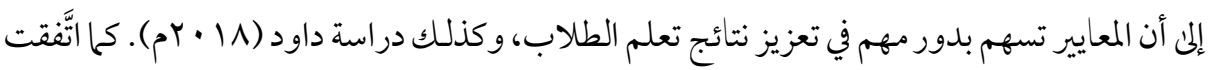

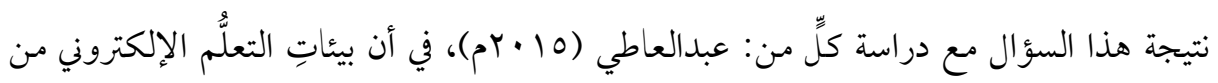
مقررات أو برامج إلكترونية أو مِنَصَّات، ساعدت علن تنمية مهارات التقويم الإلكتروني (الاختبار

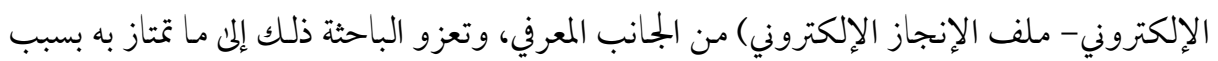


بيئات التعلُّم الإلكتروني من تنوُّع لعرض المادة العلمية من نصوص وفيديو وعروض بوربوينت، التي أدَّت إلمن تنوُع في المحتوى ليناسب الأنماط المعرفية المختلفة للطالبات. كما أدَّى تصميم محتوكل مقرر التقويم التربوي بطريقة منظَّمة ومرتَّبة إلى زيادة تحصيل الطالبات،

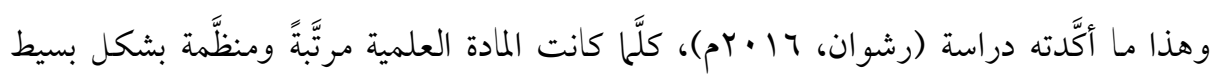
ومنطقيِّ، زادت فعالية التعلُّم.

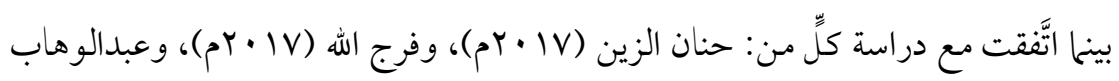

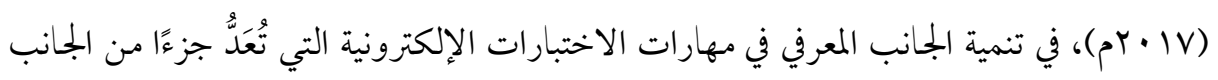
المعرفي لهذه الدراسة، واتَّفَت مع دراسة البسيوني (7 ( ا rم) في تنمية الجانب المعرفي لملف الإنجاز الإلكتروني فقط، الذي يُعَدُّ جزءًا من الجحانب المعرفي لهذه الدراسة.

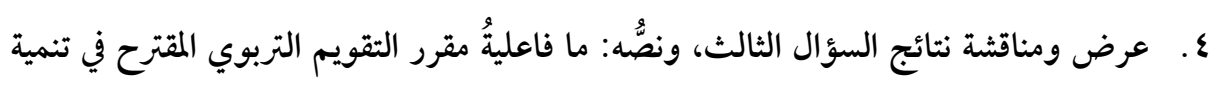
طالبات كلية التربية الجوانبَ المهارية، لمهارات التقويم الإلكترونيّ بجامعة الملك سعود؟ لَّك للتمكُّن من الإجابة عن السؤال الثالث؛ تم فرض فروض موجَّهة، وباختبار صحتها يمكِين الإجابة عليه، وفيما يلي عرضٌ لنتائجه.

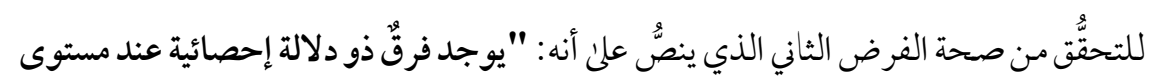

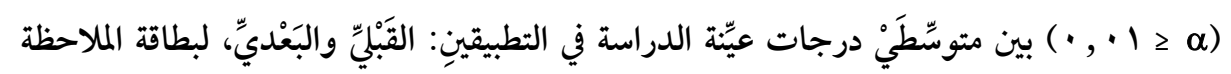

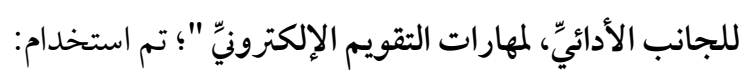

$$
\text { اختبار (ت) Paired-Samples T-test للعيّنتين المرتبطتين. }
$$

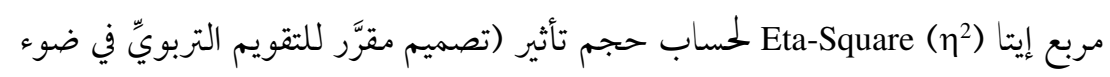
معاييرِ (Quality Matters) في تنميَة الجانب الأدائيّ، لمهارات التقويم الإلكتروني، لمقرر

$$
\text { التقويم التربوي. }
$$

ولحساب فاعلية (تصميم مقَّر للتقويم التربويٍ في ضوء معاييرِ (Quality Matters)) في تنمية الجانب الأدائيّ، لمهارات التقويم الإلكتروني، لمقرر التقويم التربوي؛ تم حساب نسبة 
Prof. Dr. Ahmad Mohammed Saad AL Hussein \& Dr. Noora Abdullah Hamad Al-Rasheed Volume (4) No. (1) 2021

الكسب المعدلة لـ بلاك Modified Blake's Gain Ratio، والجحدولان التاليان يوضِّحان نتائج هذا الفرض:

جدول يوضح مربع إيتا ونتائج اختبار (ت) لدلالة الفرق بين متوسّّطَيْ درجات طالبات المجموعة: التجريبة، في

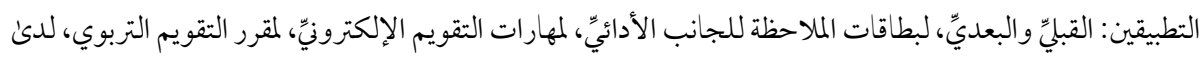
طالبات كلية التربية بجامعة الملك سعود (ن= ك ع )

\begin{tabular}{|c|c|c|c|c|c|c|c|}
\hline \multirow{2}{*}{$\begin{array}{l}\text { مربع إيتا } \\
\left(\eta^{2}\right)\end{array}$} & \multirow{2}{*}{ قيمة (ت) } & \multicolumn{2}{|c|}{ التطبيق البعدي } & \multicolumn{2}{|c|}{ التطبيق القبلي } & \multirow[b]{2}{*}{ المهـارات } & \multirow[b]{2}{*}{ p } \\
\hline & & الانحراف & المتوسط & 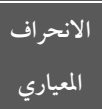 & المتوسط & & \\
\hline$\cdot, 999 \mathrm{~V}$ & ***rVV,, & $\cdot, 10$ & $\wedge, 9 \wedge$ & $\cdot, \cdots$ & $\cdot, \cdots$ & الإلكتروني الدخول إلى موقع تصميم الاختبار & 1 \\
\hline$\cdot, 9997$ & $* * * \omega \cdot 0, \wedge 9$ & $1, \wedge \Lambda$ & $\wedge \wedge, \vee ৭$ & $\cdot, \cdots$ & $\cdot, \cdots$ & البدء بإنشاء اختبار الكتروني & r \\
\hline$\cdot, 99 \cdot 0$ & *** $70, \varepsilon$. & 1, ₹1 & $1 \varepsilon, r \varepsilon$ & $\cdot, \cdots$ & $\cdot, \cdots$ & إضافة الطالبات & $r$ \\
\hline$\cdot, 99 \vee V$ & $* * 1 r r, \cdot v$ & $r, \pi r$ & $V \varepsilon, r r$ & $\cdot, \cdots$ & $\cdot, \cdots$ & نشر الاختبار & $\varepsilon$ \\
\hline •, १११. & $* * r \cdot v, 1 \varepsilon$ & $\bullet, \wedge r$ & 1AT, & $\cdot, \cdots$ & $\cdot, \cdots$ & الألدرجة الكلية للبطاقة ملاحظة الجانب للانبارات الإلكترونية & \\
\hline$\cdot, 9 \wedge 71$ & **or, 99 & $\cdot, 10$ & $1 \varepsilon, 91$ & 1,70 & $\cdot, 7 \varepsilon$ & 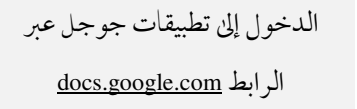 & 1 \\
\hline$\cdot, 9 \wedge \varepsilon \wedge$ & $* * * 01,0 \varepsilon$ & $\varepsilon, v 1$ & $r q, v r$ & $1, r_{1}$ & $\cdot,\{\wedge$ & انشاء الاستبانة & r \\
\hline 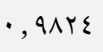 & $* * \varepsilon \vee, \vee \wedge$ & $\cdot, \wedge \cdot$ & $\wedge, \vee \varepsilon$ & $\cdot, 77$ & $\cdot, r \varepsilon$ & نشر الاستبانة & $r$ \\
\hline$\cdot, 9991$ & $* * 0 . r, \cdots$ & $\cdot, 10$ & 11,91 & $\cdot, \cdots$ & $\cdot, \cdots$ & معايير خاصة بالاستبانة & $\varepsilon$ \\
\hline •, १৭Y। & $* * \vee 1,77$ & $0, r_{1}$ & $\mathrm{~V} 0, \varepsilon \wedge$ & $r, r$ & $1, r 4$ & لألدرجة الكلية لبطاقة ملاحظة الجانب للاستبانة الإلكترونية & \\
\hline
\end{tabular}




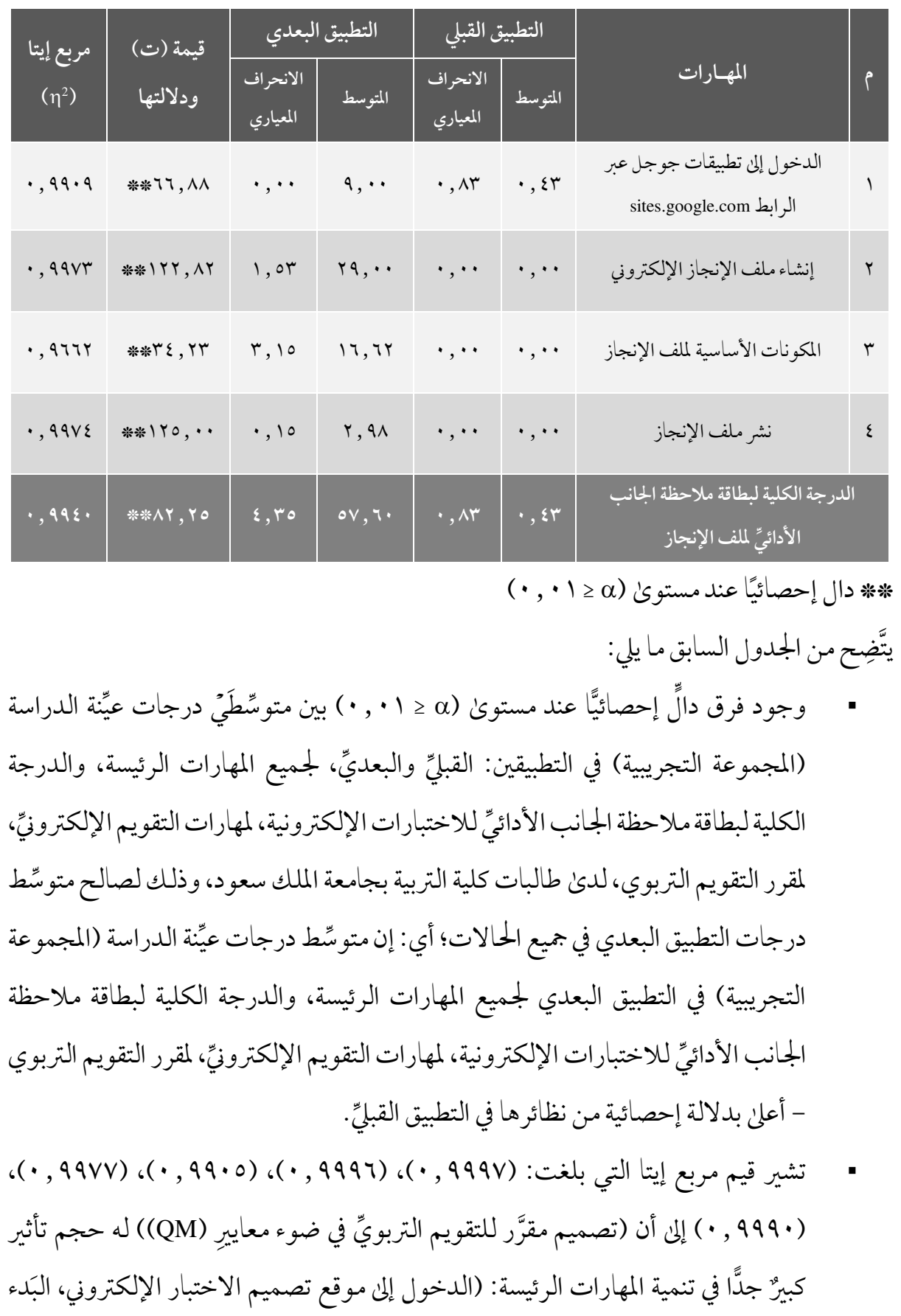


Prof. Dr. Ahmad Mohammed Saad AL Hussein \& Dr. Noora Abdullah Hamad Al-Rasheed Volume (4) No. (1) 2021

بإنشاء اختبار إلكتروني، إضافة الطالبات، نشر الاختبار)، والدرجة الكلية لبطاقة ملاحظة الجانب الأدائيّ للاختبارات الإلكترونية علن الترتيب، في التطبيق البعدي، لدىن عيّنة الدراسة. كما تشير قيم مربع إيتا أيضًا إلى أن (تصميم مقرَّر للتقويم التربويِّ في ضوء معاييرِ

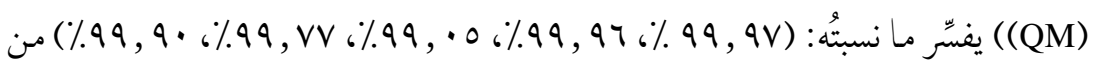
التباين في درجات المهارات الرئيسة: (الدخول إلى موقع تصميم الاختبار الإلكتروني، البَدَء بإنشاء اختبار إلكتروني، إضافة الطالبات، نشر الاختبار)، والدرجة الكلية لبطاقة ملاحظة الجانب الأدائيّ للاختبارات الإلكترونية علن الترتيب، وهي كمية كبيرة جدَّا من التباين المُفَّرَ بواسطة (تصميم مقرَّر للتقويم التربويِّ في ضوء معاييرِ (QM))، لدىن عيّنة الدراسة من طالبات كلية التربية بجامعة الملك سعود.

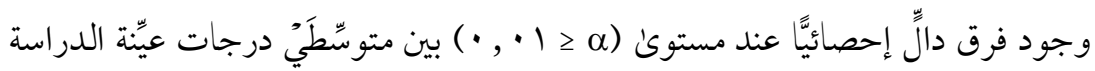
(المجموعة التجريبية) في التطبيقين: القبليِّ والبعديّ، لجميع المهارات الرئيسة، والدرجة الكلية لبطاقة ملاحظة الجانب الأدائيّ للاستبانة الإلكترونية، لمهارات التقويم الإلكترونيّ؛ لمقرر التقويم التربوي، لدىن طالبات كلية التربية بجامعة الملك سعود، وذلك لصالح متوسّط درجات التطبيق البعديّ في جميع الحالات؛ أي: إن متوسّط درجات عيّنة الدراسة (المجموعة التجريبية) في التطبيق البعديّ لجميع المهارات الرئيسة، والدرجة الكلية لبطاقة ملاحظة

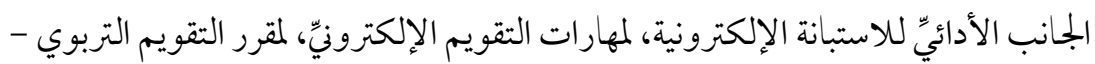
أعلن بدلالة إحصائية من نظائرها في التطبيق القبليّ.

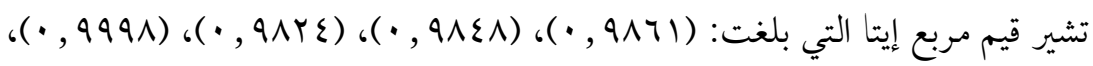

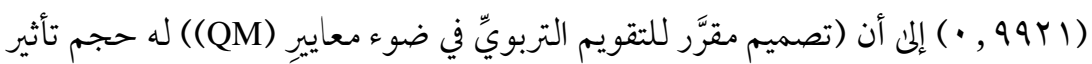
كبيرٌ جلَّا في تنمية المهارات الرئيسة: (الدخول إلى تطبيقات جوجل، إنشاء الاستبانة، نشر الاستبانة، معايير خاصة بالاستبانة)، والدرجة الكلية لبطاقة ملاحظة الجانب الأدائيّ للاستبانة الإلكترونية على الترتيب، في التطبيق البعدي، لدى عيّنة الدراسة. كما تشير قيم مربع 


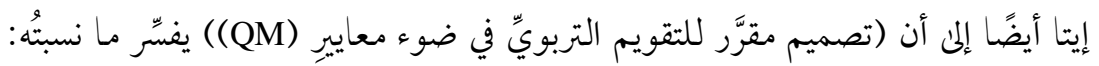

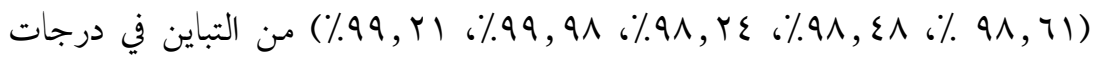
المهارات الرئيسة: (الدخول إلى تطبيقات جوجل، إنشاء الاستبانة، نشر الاستبانة، معايير خاصة بالاستبانة)، والدرجة الكلية لبطاقة ملاحظة الجحانب الأدائيّ للاستبانة الإلكترونية

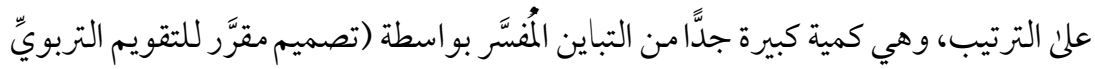

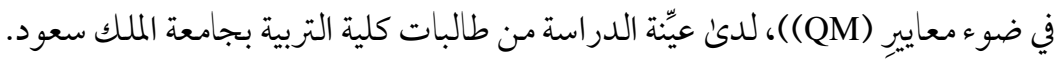

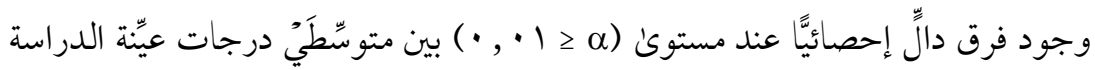

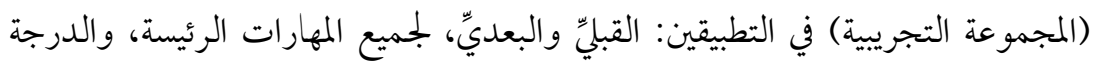

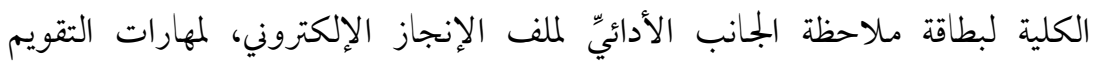

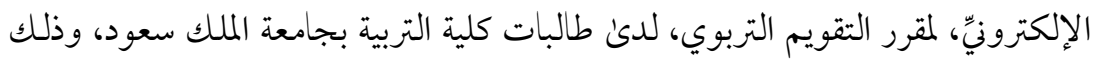

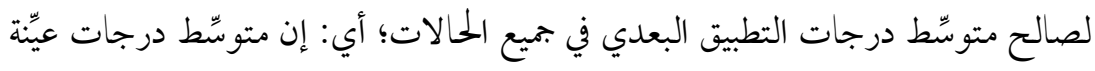

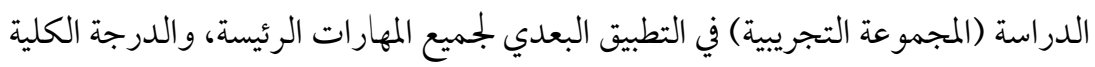
لبطاقة ملاحظة الجانب الأدائيّ لملف الإنجاز الإلكتروني، لمهارات التقويم الإلكترونيّ، لمقرر التقويم التربوي - أعلى بدلالة إحصائية من نظائر ها في التطبيق القبليّ.

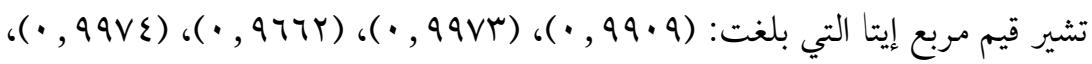

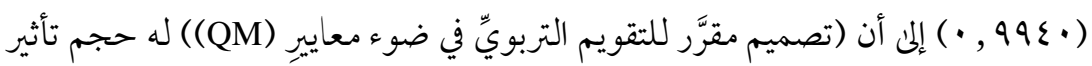

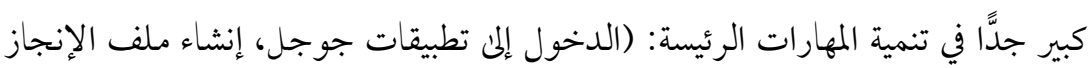

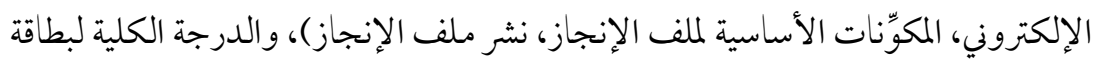

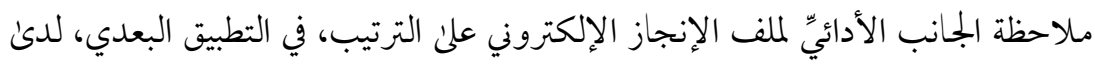

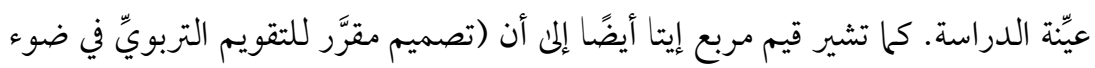

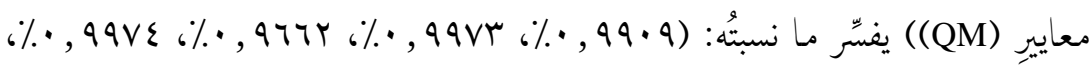

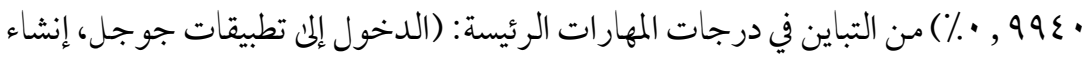


Prof. Dr. Ahmad Mohammed Saad AL Hussein \& Dr. Noora Abdullah Hamad Al-Rasheed Volume (4) No. (1) 2021

ملف الإنجاز الإلكتروني، المكوّنات الأساسية لملف الإنجاز، نشر ملف الإنجاز)، والدرجة الكلية لبطاقة ملاحظة الجانب الأدائيّ لملف الإنجاز الإلكتروني على الترتيب، وهي كمية

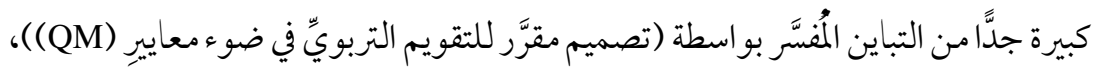

$$
\text { لدئ عيّنة الدراسة من طالبات كلية التربية بجامعة الملك سعود. }
$$

وتوضح الأشكال الآتية متوسطي درجات عيّنة الدِّراسة (المجموعة التجريبية) في التطبيقين القبلي والبعدي لبطاقات الملاحظة الثلاث للجانب الأدائيّ لمهارات التقويم الإلكترونيّ لمقرر التقويم

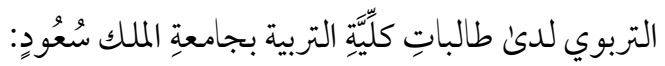

شكل يو ضح متوسطا درجات عيّنة الدِّراسة في التطبيقين القبلي والبعدي للدرجة الكلية لبطاقة ملاحظة الجانب الأدائيّ

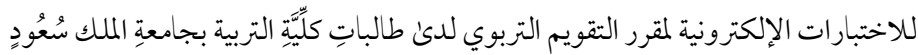

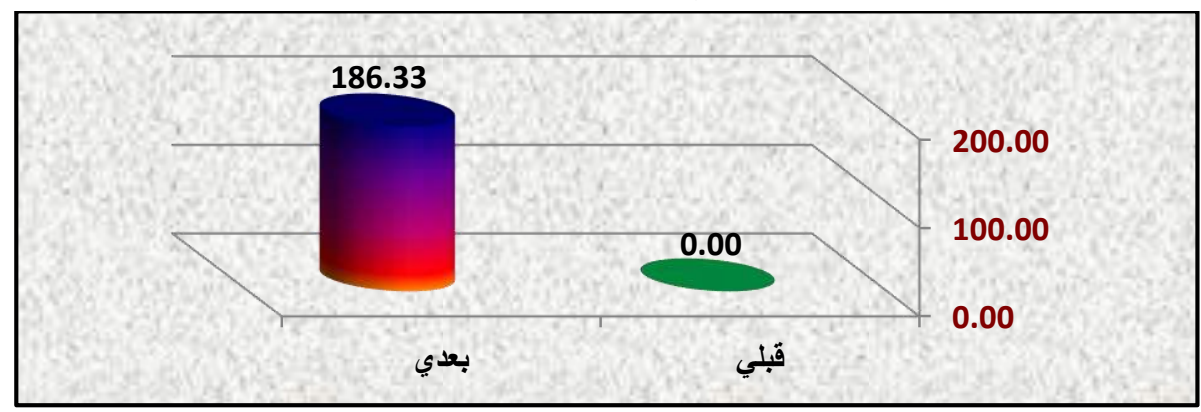

شكل يوضح متوسطا درجات عيّنة الدِّراسة في التطبيقين القبلي والبعدي للدرجة الكلية لبطاقة ملاحظة الجانب الأدائيّ

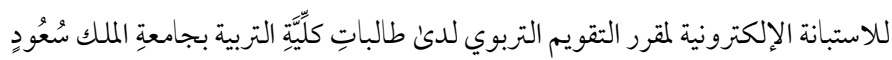

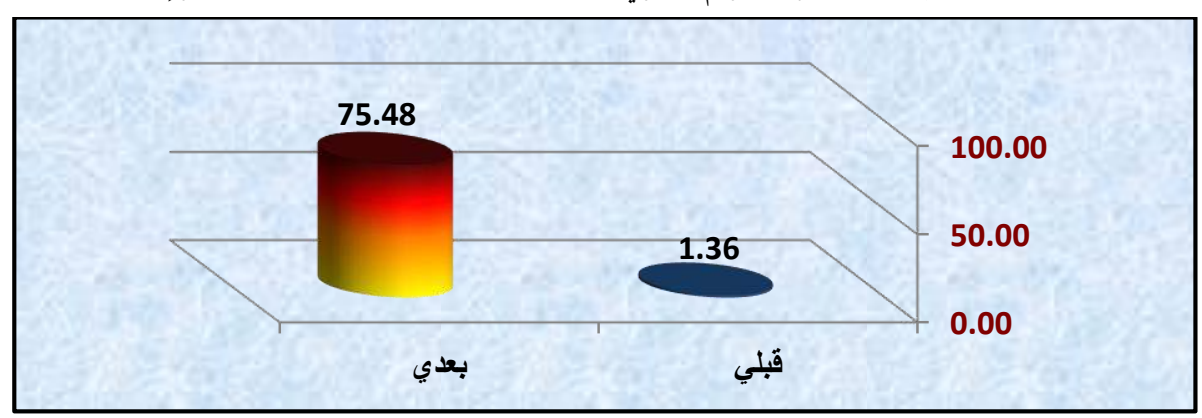

http://dx.doi.org/10.29009/ijres.4.1.9 
شكل يوضح متوسطا درجات عيّّة الدِّراسة في التطبيقين القبلي و البعدي للدرجة الكلية لبطاقة ملاحظة الجمانب الأدائيّ

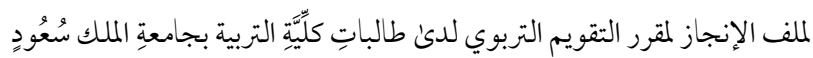

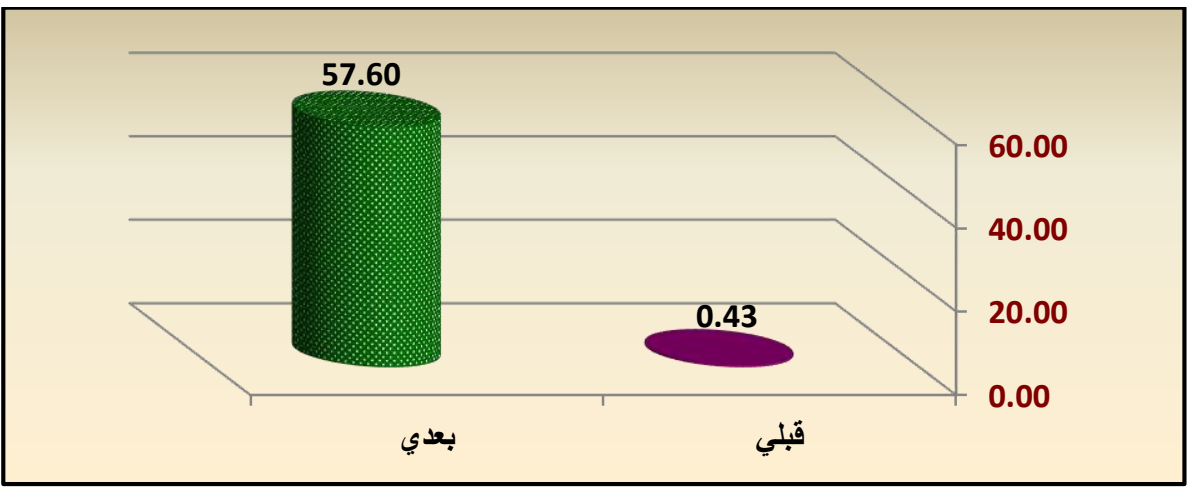

جدول يوضح نسبة الكسب المعدلة لـ بلاكك عند دراسة الفرق بين متوسِّكَّ درجات المجموعة التجريبية في التطبيقين: القبليّ و البعديّ، لبطاقات الملاحظة للجانب الأدائيّ، لمهارات التقويم الإلكترونيّ، لمقرر التقويم التربوي، لدني طالبات كلية التربية بجامعة الملك سعود (ن= ع ع )

\begin{tabular}{|c|c|c|c|c|c|}
\hline نسبة الكسب المعدلة & الدرجة & البعليق & التبيت & المهـارات & $\rho$ \\
\hline$r, \cdots$ & 9 & $\wedge, ৭ \wedge$ & $\cdot, \cdots$ & $\begin{array}{c}\text { الدخول إلى موقع تصميم الاختبار الإلكتروني } \\
\text { https://www.classmarker.com }\end{array}$ & 1 \\
\hline $1,9 v$ & 9. & $\wedge \wedge, \vee ৭$ & $\cdot, \cdots$ & البدء بإنشاء اختبار الكتروني & r \\
\hline $1,9$. & 10 & $1 \varepsilon, r \varepsilon$ & $\cdot, \cdots$ & إضافة الطالبات & r \\
\hline 1,91 & v^ & $V \varepsilon, r r$ & $\cdot, \cdots$ & ن شر الاختبار & $\varepsilon$ \\
\hline $1,9 \varepsilon$ & 194 & 1AT, $\mathrm{Mr}$ & $\cdot, \cdot$ & ئرجة الكلية لبطاقة ملاحظة الجانب الأدائيّ للاختبارات. & \\
\hline 1,90 & 10 & $1 \varepsilon, 91$ & $\cdot, 7 \varepsilon$ & $\begin{array}{c}\text { الدخول إلى تطبيقات جوجل عبر الر ابط } \\
\text { http://docs.google.com }\end{array}$ & 1 \\
\hline $1, \wedge \wedge$ & $\varepsilon r$ & $r q, v r$ & $\cdot,\{\wedge$ & انشاء الاستبانة & r \\
\hline 1,91 & 9 & $\wedge, \vee \varepsilon$ & $\cdot, r \varepsilon$ & ن اسر الاسبانة & r \\
\hline$r, \cdots$ & ir & 11,91 & $\cdot, \cdots$ & معايير خاصة بالاستبانة & $\varepsilon$ \\
\hline 1,94 & v^ & $v_{\bullet}, \varepsilon \wedge$ & $1, r 4$ & لدرجة الكلية لبطاقة ملاحظة الجانب الأدائيّ للاستبانة & \\
\hline
\end{tabular}


Prof. Dr. Ahmad Mohammed Saad AL Hussein \& Dr. Noora Abdullah Hamad Al-Rasheed Volume (4) No. (1) 2021

\begin{tabular}{|c|c|c|c|c|c|}
\hline نسبة الكسب المعدلة & الدرجة & البعبيت & التببيق & المهـارات & $\rho$ \\
\hline 1,90 & 9 & $9, \cdots$ & $\cdot, \varepsilon r$ & $\begin{array}{c}\text { الدخول إلى تطبيقات جوجل عبر الرابط } \\
\text { http://sites.google.com }\end{array}$ & 1 \\
\hline 1,94 & $r$. & rq, $\cdots$ & $\cdot, \cdots$ & إنشاء ملف الإنجاز الإلكتروني & r \\
\hline 1,10 & 11 & 17, & $\cdot, \cdots$ & المكونات الأساسية لملف الإنجاز & $r$ \\
\hline 1,99 & $r$ & $r, 91$ & $\cdot, \cdots$ & 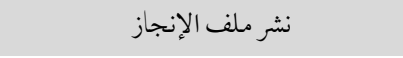 & $\varepsilon$ \\
\hline 1,91 & 7. & ov, 7 . & $\cdot, \varepsilon r$ & الكلية لبطاقة ملاحظة الجانب الأدائيّ لملف & \\
\hline
\end{tabular}

• أن قيم نسبة الكسب المعدلة لـ بلاك في حالة المهارات الرئيسة، والدرجة الكلية لبطاقة ملاحظة الجانب الأدائيّ للاختبارات الإلكترونية، لمهارات التقويم الإلكتروني، لمقرر التقويم

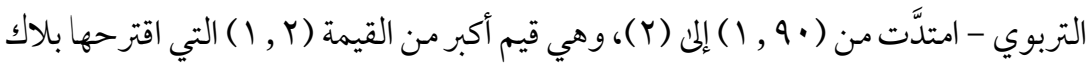
للحكم علن فاعلية البرنامج؛ مما يشير إلى أن (تصميم مقرَّر للتقويم التربويِّ في ضوء معاييرِ فغَّل في تنمية المهارات الرئيسة، والدرجة الكلية لبطاقة ملاحظة الجانب الأدائيِّ (QM) للاختبارات الإلكترونية، لمهارات التقويم الإلكتروني، لمقرر التقويم التربوي، لدىن عيّنة الدراسة من طالبات كلية التربية بجامعة الملك سعود. أن قيم نسبة الكسب المعدَّلة لـ عزت في حالة المهارات الرئيسة، والدرجة الكلية لبطاقة ملاحظة الجانب الأدائيّ للاختبارات الإلكترونية، لمهارات التقويم الإلكتروني، لمقرر التقويم

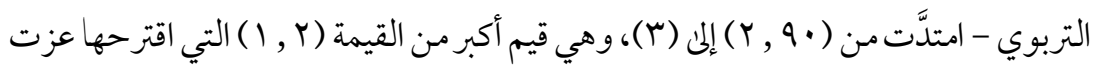
للحكم علن فاعلية البرنامج؛ مما يشير إلى أن (تصميم مقرَّر للتقويم التربويِّ في ضوء معاييرِ فعَّل في تنمية المهارات الرئيسة، والدرجة الكلية لبطاقة ملاحظة الجانب الأدائيِّ للاختبارات الإلكترونية، لمهارات التقويم الإلكتروني، لمقرر التقويم التربوي، لدئ عيّنة الدراسة من طالبات كلية التربية بجامعة الملك سعود. 
• أن قيم نسبة الكسب المعدلة لـ بلاك في حالة المهارات الرئيسة، والدرجة الكلية لبطاقة ملاحظة الجانب الأدائيّ للاستبانة الإلكترونية، لمهارات التقويم الإلكتروني، لمقرر التقويم

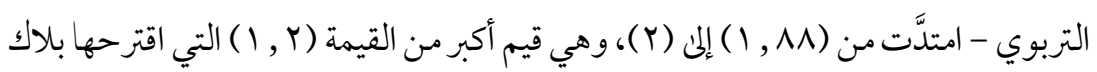
للحكم علن فاعلية البرنامج؛ مما يشير إلى أن (تصميم مقرَّر للتقويم التربويِّ في ضوء معاييرِ فعَّال في تنمية المهارات الرئيسة، والدرجة الكلية لبطاقة ملاحظة الجانب الأدائيِّ (QM) للاستبانة الإلكترونية، لمهارات التقويم الإلكتروني، لمقرر التقويم التربوي، لدئ عيّنة الدراسة من طالبات كلية التربية بجامعة الملك سعود. أن قيم نسبة الكسب المعدَّلة لـ بلاك في حالة المهارات الرئيسة، والدرجة الكلية لبطاقة ملاحظة الجانب الأدائيّ لملف الإنجاز الإلكتروني، لمهارات التقويم الإلكتروني، لمقرر التقويم

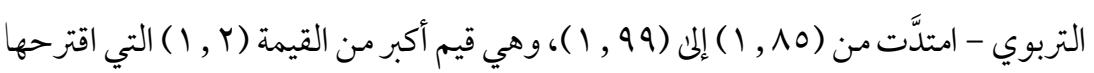
بلاك للحكم علن فاعلية البرنامج؛ مما يشير إلى أن (تصميم مقرَّر للتقويم التربويِّ في ضوء

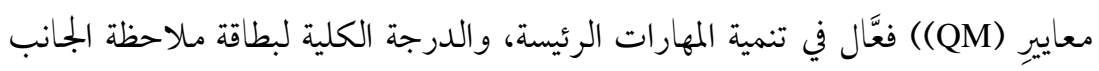
الأدائيّ لملف الإنجاز الإلكتروني، لمهارات التقويم الإلكتروني، لمقرر التقويم التربوي، لدئ عيِّة الدراسة من طالبات كلية التربية بجامعة الملك سعود. أن قيم نسبة الكسب المعدلة لـ عزت في حالة المهارات الرئيسة، والدرجة الكلية لبطاقة ملاحظة الجانب الأدائيّ لملف الإنجاز الإلكتروني، لمهارات التقويم الإلكتروني، لمقرر التقويم

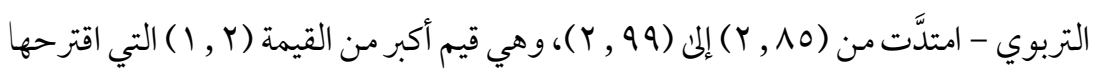
عزت للحكم علن فاعلية البرنامج؛ مما يشير إلى أن (تصميم مقرَّر للتقويم التربويِّ في ضوء

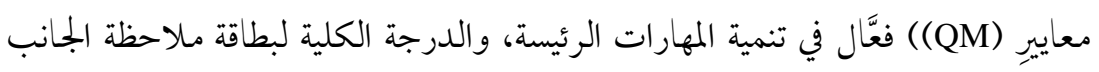
الأدائيّ لملف الإنجاز الإلكتروني، لمهارات التقويم الإلكتروني، لمقرر التقويم التربوي، لدني عيِّة الدراسة من طالبات كلية التربية بجامعة الملك سعود. ومن إجمالي نتائج الفرض الثاني يتَِّحِح ما يلي: 
Prof. Dr. Ahmad Mohammed Saad AL Hussein \& Dr. Noora Abdullah Hamad Al-Rasheed Volume (4) No. (1) 2021

- وجود فرق دالٍّ إحصائيَّا عند مستوىل ( (المجموعة التجريبية) في التطبيقين: القبليّ والبعديّي، لجميع المهارات الرئيسة، والدرجة الكلية لبطاقة ملاحظة الجانب الأدائيّ للاختبار ات الإلكترونية، لمهارات التقويم الإلكترونيّ، لمقرر التقويم التربوي، لدئ طالبات كلية التربية بجامعة الملك سعود، وذلك لصالح متوسّطط درجات التطبيق البعدي في جميع الحالات. أن (تصميم مقرَّر للتقويم التربويِّ في ضوء معايير (QM)) له حجم تأثير كبيرٌ جدًّا في تنمية المهارات الرئيسة: (الدخول إلن موقع تصميم الاختبار الإلكتروني، البَدَء بإنشاء اختبار إلكتروني، إضافة الطالبات، نشر الاختبار)، والدرجة الكلية لبطاقة ملاحظة الجانب الأدائيّ للاختبارات الإلكترونية.

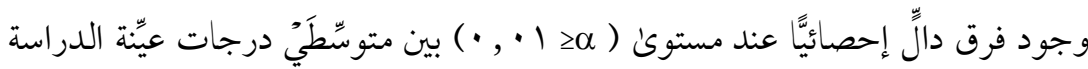
(المجموعة التجريبية) في التطبيقين: القبليِّ والبعديّ، لجميع المهارات الرئيسة، والدرجة الكلية لبطاقة ملاحظة الجانب الأدائيّ للاستبانة الإلكترونية، لمهارات التقويم الإلكترونيّ؛ لمقرر التقويم التربوي، لدىن طالبات كلية التربية بجامعة الملك سعود، وذلك لصالح متوسّط درجات التطبيق البعدي في جميع الحالات. أن (تصميم مقرَّر للتقويم التربويِّ في ضوء معاييرِ (QM)) له حجم تأثير كبيرٌ جدَّا في تنمية المهارات الرئيسة: (الدخول إلى تطبيقات جوجل، إنشاء الاستبانة، نشر الاستبانة، معايير خاصة بالاستبانة)، والدرجة الكلية لبطاقة ملاحظة الجانب الأدائيِ للاستبانة الإلكترونية. - وجود فرق دالٍّ إحصائيَّا عند مستوىل ( (المجموعة التجريبية) في التطبيقين: القبليّ والبعديّ، لجميع المهارات الرئيسة، والدرجة الكلية لبطاقة ملاحظة الجانب الأدائيّ لملف الإنجاز الإلكتروني، لمهارات التقويم الإلكترونيّ، لمقرر التقويم التربوي، لدنأ طالبات كلية التربية بجامعة الملك سعود، وذلك لصالح متوسّط درجات التطبيق البعدي في جميع الحالات. 
- أن (تصميم مقرَّر للتقويم التربويِّ في ضوء معايير (QM)) له حجمُ تأثيرِ كبيرٌ جدَّا في تنمية

المهارات الرئيسة: (الدخول إلى تطبيقات جوجل، إنشاء ملف الإنجاز الإلكتروني، المكوّنات

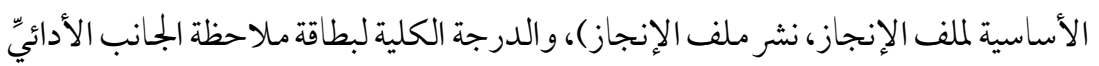
لملف الإنجاز الإلكتروني.

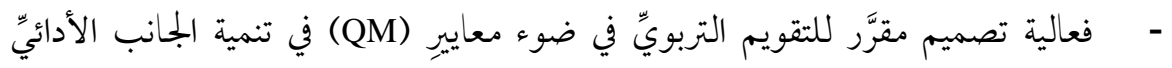

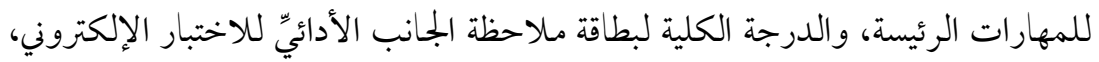

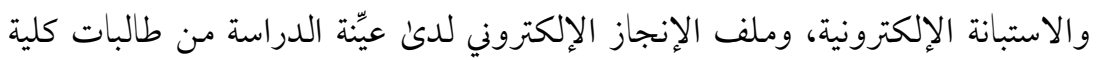

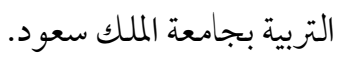

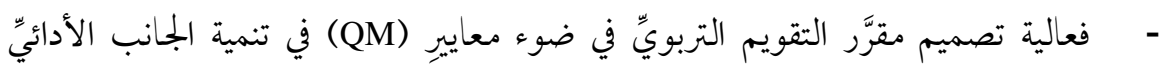
للمهارات الرئيسة، والدرجة الكلية لبطاقة ملاحظة الجانب الأدائيّ للاستبانة الإلكترونية، لدئ عيّة الدراسة من طالبات كلية التربية بجامعة الملك سعود.

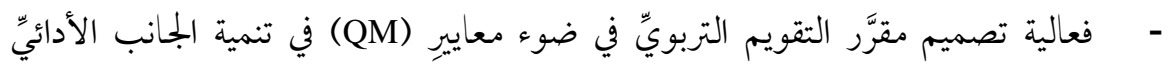

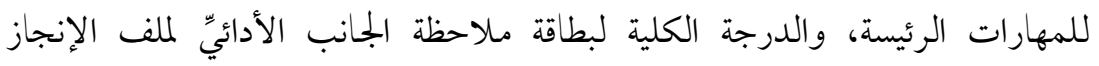

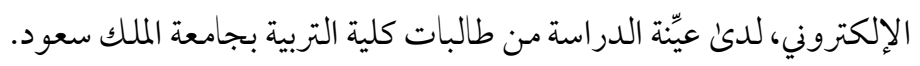

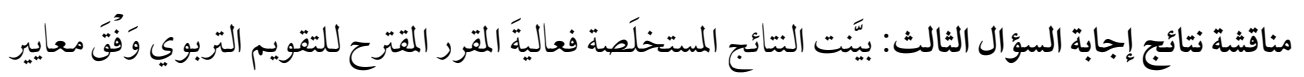

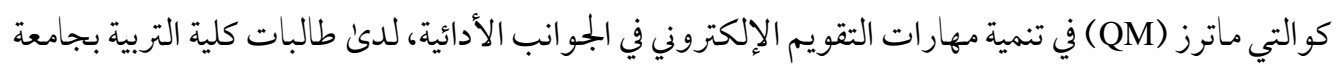

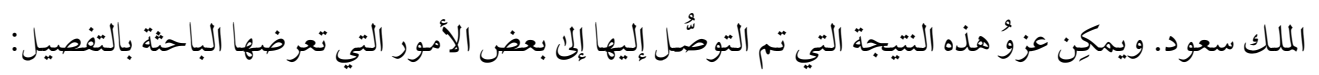

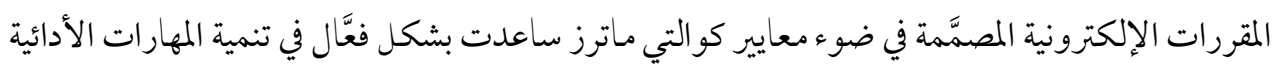

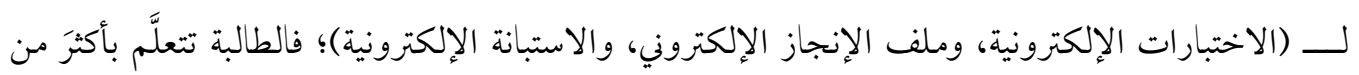

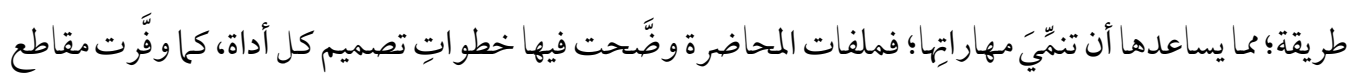

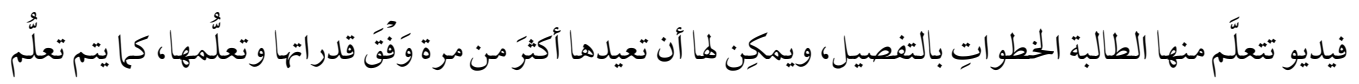

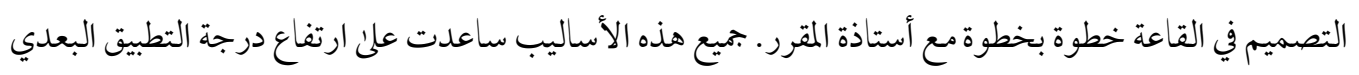


في جميع المهارات. كما أن تدعيم المحتون بالُهمَّات الأدائية للمهارات ساعد علن تنمية المهارات الأدائية للتقويم

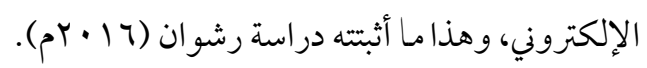

اختارت الباحثة في تصميم الاختبارات الإلكترونية موقع كلاس ماركر Class Marker، وهو برنامج يَدعَم

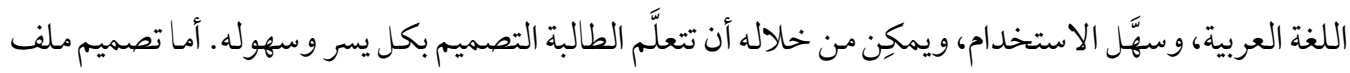
الإنجاز الإلكتروني، والاستبانات الإلكترونية، فتم اعتماد تطبيقات جوجل التي امتازت بالسهولة، ودعمها للُّغة

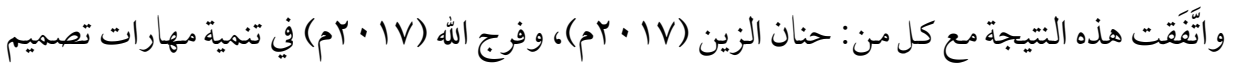
الاختبارات الإلكترونية. ومع البسيوني (7 ا • Yم) في تنمية مهارات ملف الإنجاز الإلكتروني.

$$
\text { أبرز النتائج التي توصَّلت إليها الدراسة: }
$$

- وجود فرق دال إحصائيًا عند مستوى ( التطبيقين القبلي والبعدي للاختبار التحصيليِ للجانب المعرفيّ لمهارات التقويم الإلكترونيّ

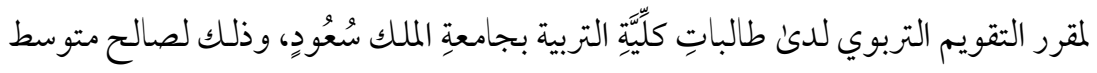

$$
\text { درجات التطبيق البعدي. }
$$

- وجود فرق دال إحصائيًا عند مستوى ( التطبيقين القبلي والبعدي لجميع المهارات الرئيسة والدرجة الكلية لبطاقات ملاحظة الجانب الأدائيّ (الاختبارات الإلكترونية، الاستبانة الإلكترونية، ملف الانجاز الإلكتروني) لمهارات

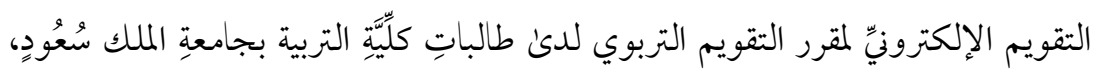

$$
\text { وذلك لصالح متوسط درجات التطبيق البعدي في جميع الحالات. }
$$

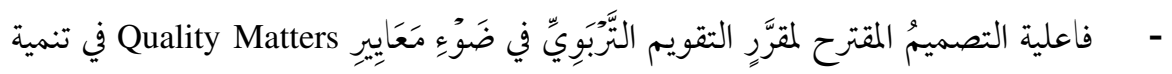
مهارات التقويم الإلكتروني لدى طالبات كلية التربية بجامعة الملك سعود. 


\section{توصيات الدراسة:}

في ضوء النتائج التي أسفرت عنها هذه الدراسة، تورد الباحثة عددًا من التوصيات، وهي:

ا. . تصميم مقررات كلية التربية وَفقُق معايير كوالتي ماترز (Quality Matters).

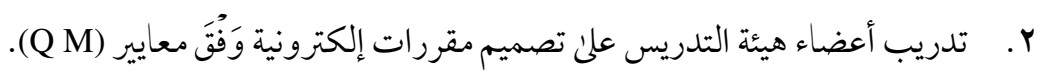

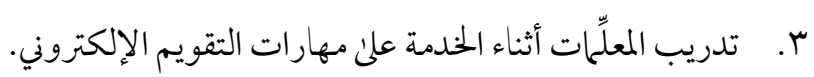

ع. الاهتحام بتنمية مهارات التقويم الإلكتروني لدنأ طالبات كلية التربية.

ه. شر ثقافة استخدام مهارات التقويم الإلكتروني بين أعضاء هيئة التدريس.

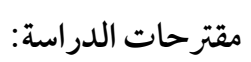

ا ـ دراسة فاعلية المقرر المقترح في تنمية متغيِّرات أخرى؛ مثل: (الكفايات اللازمة للتقويم، أو

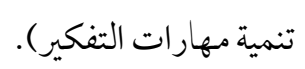

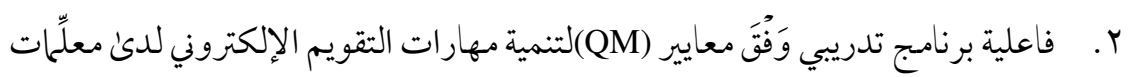

المرحلة الثانوية.

r. دراسة اتجاهات أعضاء هيئة التدريس والطالبات حول المقرر المقترح ومعِّققات تطبيقه. ع. دراسة تصميم مقر رات أخرى في كلية التربية وَفقَّ معايير (Q M) وفعاليتها في التحصيل

$$
\text { الدراسي. }
$$


Prof. Dr. Ahmad Mohammed Saad AL Hussein \& Dr. Noora Abdullah Hamad Al-Rasheed Volume (4) No. (1) 2021

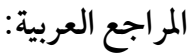

ا ـ أبو خطوة، السيد عبد المولى. (11 + آم). معايير ضمان الجمودة في تصميم المقررات الإلكترونية وإنتاجها. المؤتمر الدولي الثاني للتعلم الإلكتروني والتعليم عن بعد، الرياض، \1 - • ب ربيع

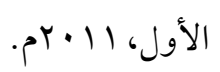

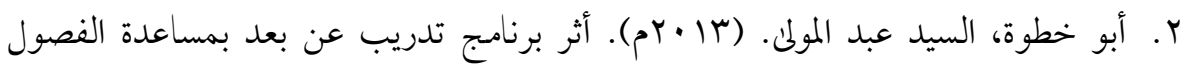
الافتراضية في تنمية مهارات التقويم الإلكتروني والاتجاه نحو التدريب عن بعد لدئ أعضاء

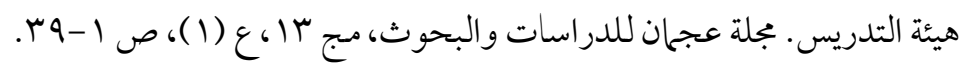

r. أحمد، هالة إبراهيم وسعيد، فيصل محمد.( عا +rrم). تقويم المقررات الإلكترونية بجامعة السودان المفتوحة في ضوء معايير جودة المقررات الإلكترونية. المجلة الفلسطينية للتعليم

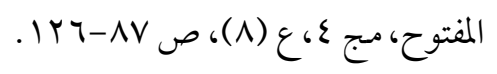

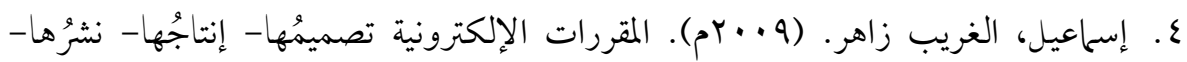

تطبيقهُ- تقويمُها. القاهرة: علاهر الكتب.

ه. الأصقة، حصة محمد؛ الدولات، عدنان سالر.(7 ( بام). درجة استخدام معلمات المرحلة المتوسطة لأساليب التقويم البديلة في تدريس العلوم في منطقة القصيم في المملكة العربية

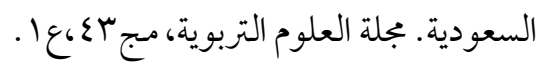

7 7. بسيوني، رفعت.(7 1 • rم).فاعلية بعض أدوات التقويم الإلكتروني في تطوير أداء معلمي

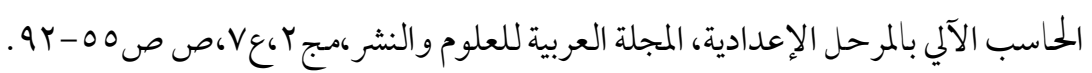

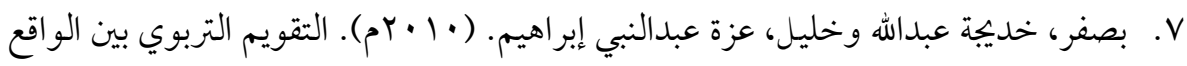
والمأمول في مؤسسات التعليم العالي النوعي. ورقة مقدمة إلى المؤتمر السنوي (العربي الخامس-الدولي الثاني) الاتجاهات الحديثة في تطوير الأداء المؤسسي والأكاديمي في مؤسسات التعليم العالي النوعي في مصر و العاله العربي، كلية التربية النوعية بالمنصورة، ع ا-ـ

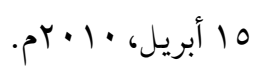


^. حسن، محيي الدين. (11 · rم). تطوير أساليب تقويم الطالب بكليات التربية وفقاً لنموذج

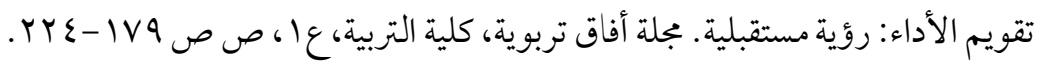

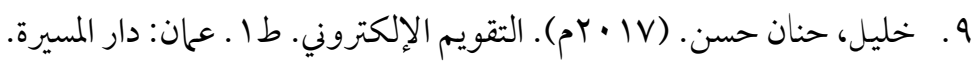

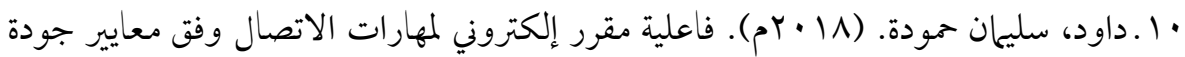
التعليم الإلكتروني في التحصيل الدراسي والاتجاه نحو المقرر لدني طلاب كلية الشريعة

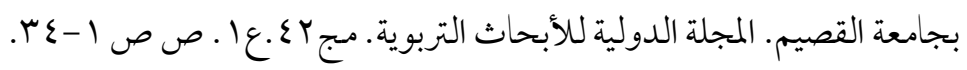

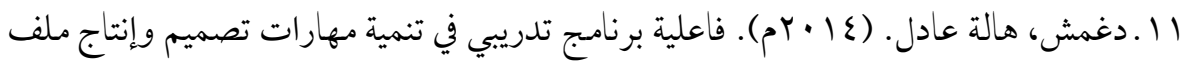
الإنجاز الإلكتروني والاتجاه نحوه لدئ طالبات كلية التربية بالجامعة الإسلامية بغزة. رسالة ماجستير غير منشورة، الجامعة الإسلامية، غزة.

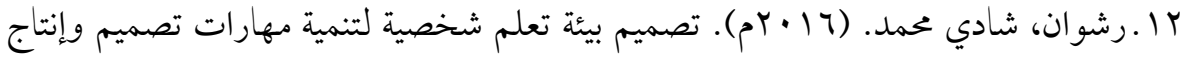
أدوات التقويم الإلكتروني لدىن معلمي الحاسب الآلي بالمرحلة الإعدادية. رسالة ماجستير غير منشورة، جامعة كفر الشيخ، محافظة كفر الشيخ مصر. با ـ الرويلي، مشعل مونس. (7 1 • rم). مهارات بناء الاختبارات التحصيلية لدئ الطلاب المعلمين بالمملكة العربية: دراسة تحليلية تشخيصية من وجهة نظرهم والمختصين. مجلة كلية التربية. جامعة الأزهر. ع ا ـ زين الدين، محمد محمود. (1 ا • rم). كفايات التعليم الإلكتروني. طب. الرياض: مكتبة الملك فهد الوطنية.

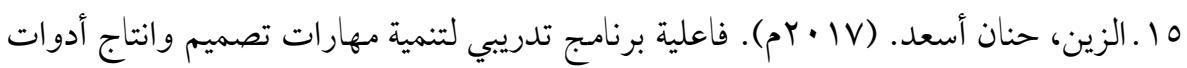
التقييم الإلكتروني لدىن أعضاء هيئة التدريس ومدئ رضاهن عنه. مجلة الجامعة الإسلامية

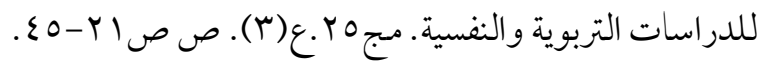

7 ا السجيني، وليد وخليل، حنان. (VV • r P). تصميم المناهج والمقررات الإلكترونية عبر شبكة

$$
\text { الويب. عمان: دار الميسرة. }
$$


Prof. Dr. Ahmad Mohammed Saad AL Hussein \& Dr. Noora Abdullah Hamad Al-Rasheed Volume (4) No. (1) 2021

V ا ـ سحتوت، إيحان محمد. (ع ا • rم). تصميم وإنتاج مصادر التعلم الإلكترونية. الرياض: مكتبة الرشد.

1 1 ـ السعدوي، عبدالله صالح. (7 ( • Yم). دراسة تقويمية لمقررات التقويم التربوي في كليات التربية في ضوء المعايير الوطنية للمعلمين بالمملكة العربية السعودية. الجمعية السعودية للعلوم

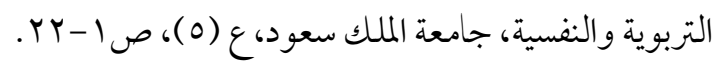

9 ا ـالسعودي، خالد والثوابية، أحمد. (7 1 • Y). معوقات تطبيق استراتيجيات التقويم الواقعي وأدواته من وجهة نظر معلمي التربية الاسلامية في محافظة الطفلية. مجلة العلوم التربوية.

$$
\text { م }
$$

المصطلحات العربية

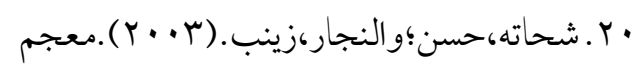

و النفسية.ط ا .القاهرة،الدار المصرية اللبنانية.

ا Y . الصالح، بدر عبدالله. (0 · · ). التصميم التعليمي وتطبيقه في تصميم التعليم الإلكتروني عن

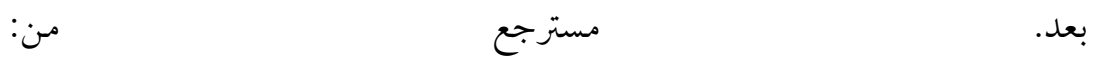

http://faculty.ksu.edu.sa/6544/Pages/Published_Papers.aspx

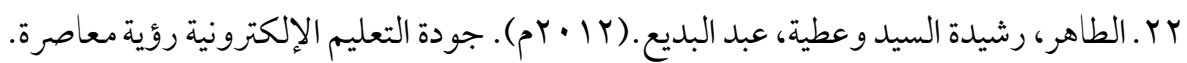

$$
\text { القاهرة: دار الجامعة لجديدة للنشر. }
$$

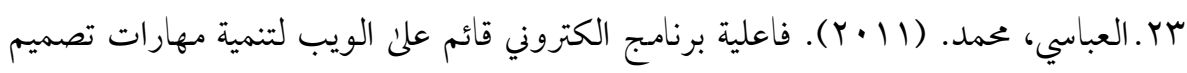
وانتاج بعض أدوات التقويم الإلكتروني لدئ طلاب كلية العلوم الاجتماعية. مجلة كلية

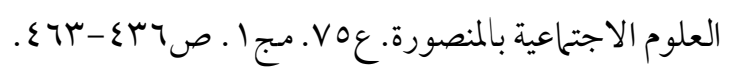

ع r. عبدالعاطي، حسن عبدالباتع. (0 · ). أنحاط دعم الأداء وقياس أثرها في إكساب أعضاء هيئة التدريس بجامعة الطائف مهارات التقويم الإلكتروني باستخدام منظومة إدارة التعلم "بلاكبورد" واتجاهاتهم نحوها، مجلة العلوم التربوية،عع، ص اسبr - • هـ. 


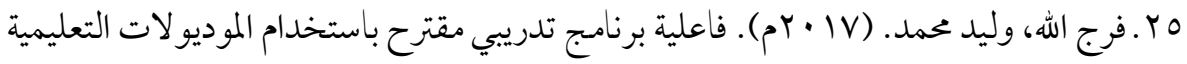
في تنمية مهارات التقييم الإلكتروني والاتجاه نحو لدئ الطلاب المعلمين تخصص دراسات

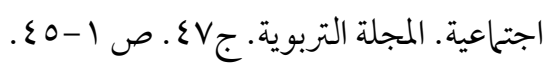

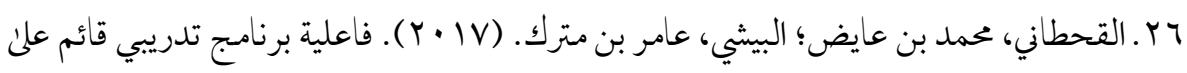

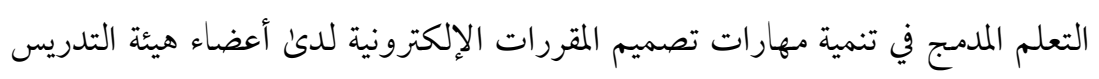
بجامعة الملك خالد في ضوء معايير الكو التي ماترز (Standard Rubric Matters Quality).

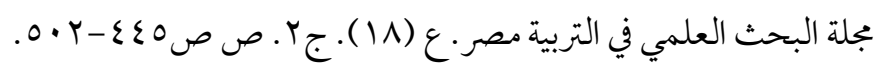

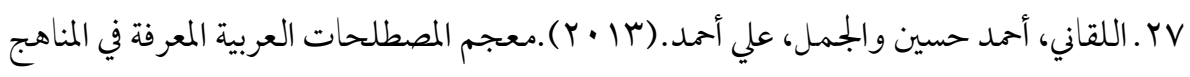
وطرق التدريس.طس،القاهرة:عالم الكتب

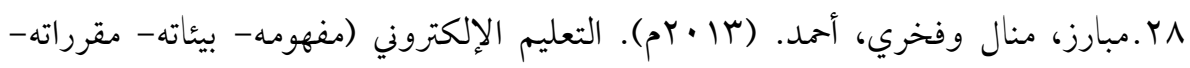
تقويمه- تطبيقاته المتقدمة). الرياض: دار الزهراء.

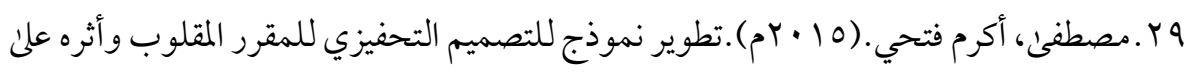
نواتج التعلم ومستوى تجهيز المعلومات وتقبل مستحدثات التكنولوجيا المساندة لذوي الاحتياجات الخاصة، المؤتمر الدولي الرابع للتعلم الإلكتروني والتعليم عن بعد، المملكة

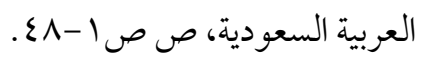

•r. المؤتمر الدولي الأول للقياس والتقويم. (r ا • بم).معايير القبول في مؤسسات التعليم العالي،

$$
\text { المملكة العربية السعودية، الفترة من ب- أع ديسمبر. }
$$

اب. المؤتمر الدولي الثاني للتعلم الإلكتروني والتعليم عن بعد. (11 • rم).تعلم فريد لجيل جديد،

$$
\text { الرياض- فندق الفيصلية، آب- ع ب فبراير. }
$$

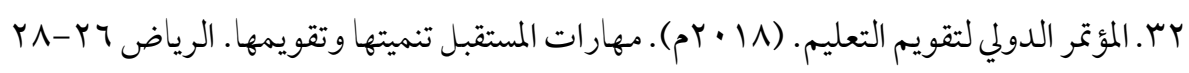

$$
\text { ربيع الأول. }
$$


سب. المؤتمر العلمي الحادي عشر للجمعية المصرية لتكنولوجيا التعليم.(1 · بـم). تكنولوجيا التعليم الإلكتروني وتحديات التطوير التربوي في الوطن العربي، في الفترة من جr - V Vمارس. ع r. المؤتمر العلمي الرابع عشر للجمعية المصرية لتكنولوجيا التعليم. (ع ا • rم). تكنولوجيا التعليم الإلكتروني والتدريب الإلكتروني، الجمعية المصرية لتكنولوجيا التعليم، ص ع عب- سجبم. هr. النمري، حنان سرحان. (rا • rم). واقع استخدام ملف الإنجاز البورتفليو في تقويم أداء

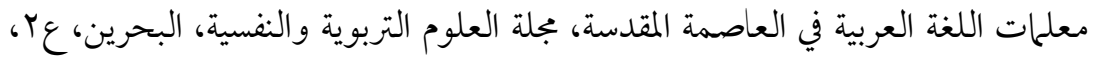
ص צr. هاشم، كمال والخليفة، حسن. (V V • Yم). التقويم التربوي مفهومه، أساليبه، مجالاته، توجهاته الحديثة. طج، الرياض: مكتبة الرشد.

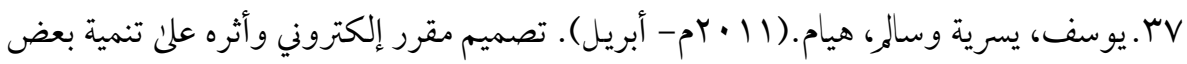

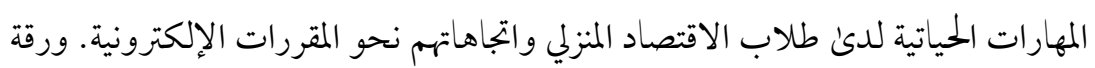
مقدمة إلى المؤتمر العلمي السنوي العربي السادس -الدولي الثالث تطوير برامج التعليم العلاي

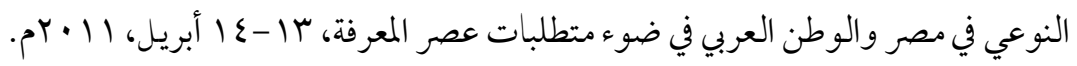




\section{References:}

- Abdulati, Hasan Abdulbati'. (2015). Patterns of Performance Support and Measuring their Impact in Providing Faculty Members at Taif University with Electronic Evaluation Skills Using "Blackboard" LMS and Their Attitudes towards Them. Journal of Educational Sciences, 4th issue, pp. 231350.

- Abu Khatwa, Alsayed Abdulmawla. (2011). Quality Standards in E-Course Design and production. Second Conference on E-Learning and Distance Education, Riyadh, Feb 21st - 23rd, 2011.

- Abu Khatwa, Alsayed Abdulmawla. (2013). The Effect of a Virtual-Class-

Assisted Distance Training Programme on Developing Electronic Evaluation Skills and Faculty Members' Attitudes towards Distance Training. Ajman Journal for Studies and Research. Vol. 13 (1), p 1-39.

- Ahmed, Halah Ibrahim; \& Saeed, Faisal Mohammad. (2014). E-Course Evaluation at Sudan Open University in the Light of E-Course Quality Standards. The Palestinian Journal for Open Education, Vol. 4(8), pp. 87126.

- $\quad$ Al Zumor, Abdul Wahed.(2015). Quality Matters Rubric Potential for Enhancing Online Foreign Language Education, International Education Studies; Vol. 8, No. 4; 2015, Published by Canadian Center of Science and Education, p173-178

- $\quad$ Alabbasi, Mohammad. (2011). The Efficacy of Web-based Electronic Software in Developing Design and production Skills of Some Electronic Evaluation Tools among College of Social Sciences Students. Journal of the Faculty of Social Sciences in Mansoura, vol. 1(75), pp. 436-463.

- $\quad$ AL-Asqah, Hessah Mohammad; \&Al-Doulat, Adnan. (2016). The Degree of Using Alternative Assessment Methods By Intermediate Stage' Female

Science Teachers In A-Qassem District In Saudi Arabia. Journal of Educational Sciences, 43th issue, pp37-48. 
- $\quad$ Allaqani, Ahmad Hussain; \& Aljamal, Ali Ahmad. (2013). Dictionary of the Defined Arabic Terms in Curricula and Teaching Methods. 3rd Ed., Cairo: Book World.

- Al-Nimri, Hanan Sarhan. (2013). The Reality of Using the Achievement Portfolio in Evaluating the Performance of Arabic Language Teachers in the Holy Capital. Journal of Educational and Psychological Sciences, Bahrain, issue 2, pp. 487-526.

- $\quad$ Alqahtani, Mohammad Ayidh; \& Albishi, Aámir Mutrik. (2017). The Efficacy of a Blended-Learning-Based Training Program in Developing E-Course Design Skills among Faculty Members at King Khalid University in the Light of Quality Matters Rubrics. Journal of Scientific Research in Education, Egypt, vol. 18(2), pp. 445-802.

- $\quad$ Alrewaili, Meshál Munis. (2016). Achievement Test Designing Skills among Student Teachers in the Kingdom of Saudi Arabia: A Diagnostic Analytical Study from the Students' and the Specialists' Perspective. Journal of the College of Education. Al-Azhar university.

- $\quad$ Alsajini, Waleed; \& Khaleel Hanan. (2017). Designing Online Curricula and ECourses. Amman, Almasira Press.

- $\quad$ Alsaudi, Khaled; \& Althwabiah, Ahmad. (2016). Barriers to Applying Realistic Evaluation Strategies and Tools from the perspectives of Islamic Education Teachers in Altufliyah Governate. Journal of Educational Sciences, vol. 43(1), pp. 265-280.

- $\quad$ Alzain, Hanan Asaád. (2017). The Efficacy of a Training Program in Developing the Skills of Designing and Producing Electronic Evaluation Tools among Faculty Members and their Satisfaction with It. The Islamic University Journal of Educational and Psychological Studies, vol. 25(3), pp. 21-45.

- $\quad$ Andrews University.(2015). OU: ED 370 Educational Test and Measurements WAU: EDUC 424 Educational Assessment. Retrieved from: https://www.andrews.edu/distance/courses/syllabi/educ424-921.pdf 
- $\quad$ Applegate, Brooks.(2017). EMR 5410 Introduction to Educational Measurement and Assessment. Michigan university. Retrieved from: https://wmich.edu/sites/default/files/attachments/u273/2018/EMR\%205 410\%20Applegate\%20Spr17.pdf

- Asaleh, Badr Abdullah. (2005). Instructional Design and its Implementation in designing Distance E-Learning. Retrieved from: http://faculty.ksu.edu.sa/6544/Pages/Published_Papers.aspx

- $\quad$ Basfar, Khadija Abdullaah; \& Khaleel, Azza Abdulnabi Ibrahim. (2010). The reality and Expectations of the Educational Evaluation at Qualitative Higher Education Institutions. A Paper submitted to the Second International - Fifth Arab Annual Conference on Modern Trends in Developing Institutional and Academic performance of Qualitative Higher Education Institutions in Egypt and the Arab World, Faculty of Qualitative Education, Mansoura, April 14th -15 th.

- $\quad$ Basyoni, Refaát, (2016), The Efficacy of Some Electronic Evaluation Tools in Developing Computer Studies Teachers' Performance at The Intermediate Stage. Arab Journal of Science and Publishing, vol. 2(7), pp. 55-92.

- Blundell, Gregory E.(2015). A Disruption of Online Learning Course design: Comparing Self-Reported Levels of Faculty Satisf Action With Online Courses Created Applying the 2011-2013 Edition of the Quality Maters ${ }^{\mathrm{TM}}$ Rubric Standards to Those Online Courses Created Without, from; https://etd.ohiolink.edu/!etd.send file ? accession =kent 1426268368 \&disposition =inlin e\%D9\%85\%D9\%86.

- $\quad$ Budzick, Danielle. (2014). EXAMINING THE RELATIONSHIP BETWEEN THE QUALITY MATTERS RUBRIC WORKSHOP AND FACULTY KNOWLEDGE AND PERCEPTIONS OF COURSE DESIGN: AN ACTION RESEARCH STUDY. Unpublished Ph.D. Dissertation. Capella University, U.S. 
- Daghmash, Halah Adil. (2014). The Efficacy of a Training Program in Developing the Skills of Designing and Producing Electronic Achievement Portfolio and the Attitudes of the Female Students of the Faculty of Education at the Islamic University of Gaza towards it. An Unpublished Master's Thesis, Islamic University, Gaza.

- Dawod, Sulaiman Hammoda. (2018). The Efficacy of An Electronic Course for Communication Skills According to the E-Learning Quality Standards in Academic Achievement and the Students' of The College of Sharia at Qassim University Attitudes towards the Course. International Journal of Educational Research, vol. 42(1), pp. 1-34.

- $\quad$ Farajullah, Waleed Mohammad. (2017). The Efficacy of a Proposed Training Program Using Educational Modules in Developing E-Evaluation Skills and the Social Studies Student Teachers' Attitudes towards it. The Educational Journal, vol. 47, pp. 1-45.

- $\quad$ Greenberg, Gary.(2010).Conceptions of Quality in Course Design for WebSupported Education,26th Annual Conference on Distance Teaching g Learning, from: http://www.uwex.edu/disted/conference/Resource_library/proceedings/ 28667_10.pdf

- $\quad$ Harris, Joseph.(2018). COURSE DESIGN ONLINE: HELPING STUDENTS PERFORM IN THE DIGITAL AGE. Unpublished Ph.D. Dissertation. Louisiana State University, U.S.A.

- $\quad$ Hasan, Mohyeddin. (2011). Developing Student Evaluation Methods in Colleges of Education According to the Performance Appraisal Model: A Future Vision. Afaq Educational Journal, College of Education, issue 1, pp. 179 224.

- Hashem, Kamal; and Khalifa, Hasan. (2017). Educational Evaluation, Its Concept, Methods, Fields, and Modern Trends. 6th Ed., Riyadh: Al-Rushd Bookstore. 
- Hoffman, G. (2012). Using the Quality Matters Rubric to Improve Online Cataloging Courses. Journal Cataloging \& Classification Quarterly. (Special Issue: Online Delivery of Cataloging and Classification Education and Instruction), 50(2-3), 158-171.

- Ismail, the curious Zahir. (2009). E-courses design - production - publication application - evaluation. Cairo: The World of Books.

- James, Donna.(2017).Educational Assessment. Catawba university.Retrieved from: https://catawba.edu/files/3214/8829/5069/EDUC2280b3-CPCC.pdf

- Khaleel, Hanan Hasan. (2017). Electronic Evaluation, 1st Ed., Amman, Almasira Press.

- Krusen, Nancy. (2015). The Intersection of Exemplar Professional Accreditation Standards and Quality Matters Rubric Standards for Best Practice in Distance Education. Internet Learning, Volume 4,Issue 2 , Article 7

- Legon, R. (2006). Comparison of the Quality Matters Rubric to Accreditation Standards for Distance Learning. Retrieved from: https://confluence.delhi.edu/download/attachments/74055682/Comparis on+of+the+Quality+Matters+Rubric+-+Summary.pdf

- $\quad$ Loafman, Lucas g Altman, Barbara W.(2014). Going Online: Building Your Business Law Course Using the Quality Matters Rubric. Journal of Legal Studies Education Volume 31, Issue 1, p21-54

- Maryland Online. (2011). Quality Matters Rubric ${ }^{\mathrm{TM}}$ workbook for higher education (2011-2013ed.). Annapolis: Maryland Online.

- Maryland Online. (2018). Non-annotated Standards from the QM K-12 Secondary Rubric, Fourth Edition. Retrieved from: https://www.qualitymatters.org/sites/default/files/PDFs/Standardsfromth eK-12SecondaryRubric.pdf

- Maryland Online.(2017). Non-annotated Standards from the QM K-12 Publisher Rubric, Fourth Edition. Retrieved from: 
https://www.qualitymatters.org/sites/default/files/PDFs/Standardsfromth eK-12PublisherRubric.pdf

- Maryland Online.(2017). Non-annotated Standards from the QM Publisher Rubric, Third Edition. Retrieved from: https://www.qualitymatters.org/sites/default/files/PDFs/QM_Standardsfr omthePublisherRubric_ThirdEdition.pdf

- Maryland Online.(2018). Certifying online learning quality shows you care about learners, educators and metrics. Retrieved from:: https://www.qualitymatters.org/reviews-certifications

- Maryland Online.(2018). Navigating a Journey to Success 2018 QM COMMUNITY IN REVIEW. From: https://www.qualitymatters.org/sites/default/files/PDFs/QM_2018_Com munity-in-Review-Report.pdf

- Miller, Joyce.(2015). EDCI 655: Assessment of Learning and the Learner COURSE SYLLABUS. A\& M university, Texas. Retrieved from:: http://www.tamuc.edu/academics/cvSyllabi/syllabi/201550/50103.pdf

- Mubarez, Manal; \& Fakhri, Ahmad. (2013). E-Learning (Its Concept, Environments, Courses, Evaluation, and Advanced Applications). 3rd Ed., Riyadh: Alzahra Press.

- Mubarez, Manal; \& Fakhri, Ahmad. (2013). E-Learning (Its Concept, Environments, Courses, Evaluation, and Advanced Applications). 3rd Ed., Riyadh: Alzahra Press.

- $\quad$ Mustafa, Akram Fathi. (2015). Developing a model for the motivational design of the inverted course and its impact on learning outcomes and the level of information processing and accepts innovations of supportive technology for people with special needs, the Fourth International Conference on e-learning and distance education, Saudi Arabia, pp. 1-48

- Rashwan, Shadi Mohammed. (2016). Designing a Personal Learning Environment to Develop the Skills of Designing and Producing Electronic 
Evaluation Tools for Computer Teachers in the Preparatory Stage. An Unpublished Master Thesis, Kafr El-Sheikh University, Kafr El-Sheikh Governorate Egypt.

- Research, practice, continuous improvement. Retrieved from: https://www.wpunj.edu/dotAsset/6505debd-5efa-47d8-8c4e1b2298ac592b.pdf

- $\quad$ Roehrs,C, Wang,L, Kendrick, D. (2-13). Preparing Faculty to Use the Quality Matters Model for Course Improvement. MERLOT Journal of Online Learning and Teaching Vol. 9, No. 1.

- Sahtout, Eiman Mohammad. (2014). Designing and Producing E-Learning Resources. Riyadh, Alrushd Bookstore.

- Shahatah, Hassan; \& Alnajjar, Zainab. (2003). Arabic Dictionary of Psychological Terms. 1st Ed., Cairo, Egyptian Lebanese Press.

- $\quad$ Shattuck, K , Zimmerman, W \& Adair, D.(2014). Continuous Improvement of the QM Rubric and Review Processes: Scholarship of Integration and Application. Internet Learning.Volume 3, Issue 1 Spring 2014 Article 5. Retrieved from: https://pdfs.semanticscholar.org/efe0/c4d043b2939df180dca2a89deaa68 afe741e.pdf

- $\quad$ Shattuck, K. (2012). What we're learning from Quality Matters ${ }^{\mathrm{TM}}$-focused research:

- $\quad$ Shattuck, K.(2007). Quality Matters Collaborative program planning at stste level.Onlin Journal of Distance Learning Administration,10(3),1-6.

- $\quad$ Simpson, Jill. (2012). STUDENT PERCEPTIONS OF QUALITY AND SATISFACTION IN ONLINE EDUCATION. Unpublished Ph.D. Dissertation, University of The University of Alabama.

- $\quad$ Sullivan, T., Mackie, C., Massy, W. \& Sinha, E. (Eds.) (2012). Panel on Measuring Higher Education Productivity: Conceptual Framework and Data Needs; Committee on National Statistics; Board on Testing and Assessment; 
Division of Behavioral and Social Sciences and Education; National Research Council. Retrieved from: http://www.nap.edu/catalog.php?record_id=13417

- Swan, Karen; Matthews, Daniel; Bogle, Leonard; Bolesg, Emily, Day, Scott.(2010). Linking Online Course Design and Impentation to Learning Outcomes: A design Experment (2010 QM Research Grant University of Illinois Springfield) Retrieved April 1,2012, From: file:///C:/Users/Toshiba/Downloads/Linking_online_course_design_and_i mpleme.pdf

- $\quad$ Taher, Rachida El-Sayed and Attia, Abdel-Badi (2012). The quality of e-learning is a contemporary view. Cairo: New University House for Publishing.

- The 11th Egyptian Association for Educational Technology Scientific Conference. (2008). E-Learning Technology and Challenges of Educational Development in the Arab world, March 26th -27th.

- The first international conference for measurement and evaluation. (2012) Admission Criteria for Higher Education Institutions, Kingdom of Saudi Arabia, December 2-4

- The Fourteenth Scientific Conference of the Egyptian Association for Education Technology. (2014). E-Learning Technology and E-Training, The Egyptian Association for Education Technology, pp. 364-363.

- The International Conference on Educational Evaluation. (2018). Future skills: Its Development and Evaluation. Riyadh, March, 26th -28th.

- The Second International Conference on E-Learning and Distance Education. (2011). Unique Learning for a New Generation, Riyadh-Al-Faisaliah Hotel, February 21st -24th.

- Vobornik, S. A. (2012). Does Quality Matter? Measuring Whether the Presence of Quality Matters ${ }^{\mathrm{TM}}$ is Predictive of Student Satisfaction in Online Administrative Professional Courses at Chippewa Valley Technical College 
[Master's

Thesis].

Retrieved

from:

http://www2.uwstout.edu/content/lib/thesis/2012/2012voborniks.pdf

- Ward,C.(2012). Aligning the Quality Matters Rubric to the Technological, Pedagogical Content Knowledge Conceptual Framework, In P. Resta (Ed), Proceeding of Society for Information Technation Technology Teacher Education International Conference 2012(4787-4793).

- Youssef, Yusriya; and Salem, Huyam. (2011). An E-Course Design and its Impact on Developing Some Life Skills among Home Economics Students and their Attitudes towards E-Courses. A Paper submitted to the Sixth Arab - Third International Annual Scientific Conference on the Development of Qualitative Higher Education Programs in Egypt and the Arab world in the Light of the Requirements of the Age of Knowledge, April 13th-14th.

- Zainuddin, Mohammad Mahmoud. (2011). E-Learning Competences. 2nd Ed. Riyadh: King Fahd National Library. 